\title{
Withanolides and Related Steroids
}

\author{
Rosana I. Misico, Viviana E. Nicotra, Juan C. Oberti, Gloria Barboza, \\ Roberto R. Gil, and Gerardo Burton
}

\section{Contents}

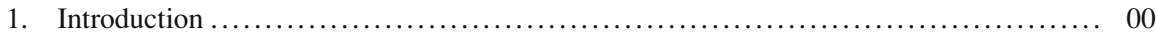

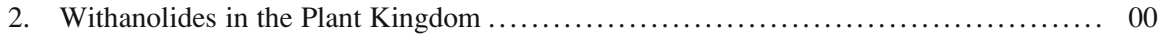

2.1. Solanaceous Genera Containing Withanolides ......................... 00

2.2. Non-Solanaceous Genera Containing Withanolides ....................... 00

3. Classification of Withanolides .......................................... 00

3.1. Withanolides with a $\delta$-Lactone or $\delta$-Lactol Side Chain .................... 00

3.2. Withanolides with a $\gamma$-Lactone Side Chain ............................. 00

4. Withanolides with an Unmodified Skeleton .................................. 00

4.1. The Withania Withanolides ........................................... 00

4.2. Other Withanolides with an Unmodified Skeleton ......................... 00

5. Withanolides with Modified Skeletons .................................... 00

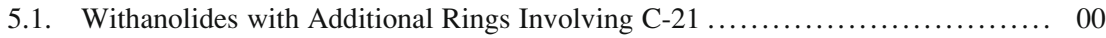

5.2. Physalins and Withaphysalins ....................................... 00

\footnotetext{
R.I. Misico • G. Burton ( $ه)$

Departamento de Química Orgánica and UMYMFOR (CONICET-UBA), Facultad de Ciencias Exactas y Naturales, Universidad de Buenos Aires, Ciudad Universitaria, Pabellón 2, Buenos Aires C1428EGA, Argentina

e-mail:misicori@qo.fcen.uba.ar; burton@qo.fcen.uba.ar

V.E. Nicotra • J.C. Oberti

Departamento de Química Orgánica and IMBIV (CONICET), Facultad de Ciencias Químicas, Universidad Nacional de Córdoba, Ciudad Universitaria, Ciencias Químicas II, Córdoba 5000, Argentina

e-mail: vnicotra@mail.fcq.unc.edu.ar; jco@mail.fcq.unc.edu.ar

G. Barboza

Departamento de Farmacia and IMBIV (CONICET), Facultad de Ciencias Químicas, Universidad Nacional de Córdoba, Ciudad Universitaria, Córdoba 5000, Argentina

e-mail: gbarboza@imbiv.unc.edu.ar

R.R. Gil

Department of Chemistry, Carnegie Mellon University, 4400 Fifth Ave, Pittsburgh, PA 15213, USA

e-mail: rgil@andrew.cmu.edu
} 
5.3. Withanolides Containing an Aromatic Ring and Related Steroids ........... 00

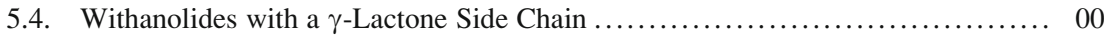

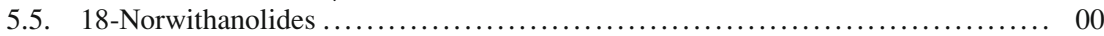

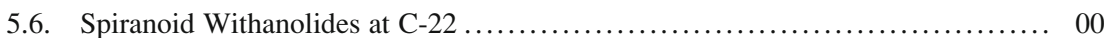

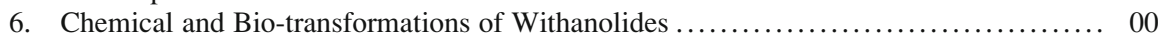

6.1. Chemical Transformations ......................................... 00

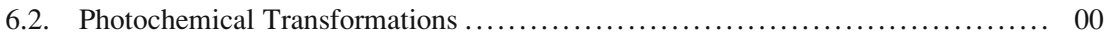

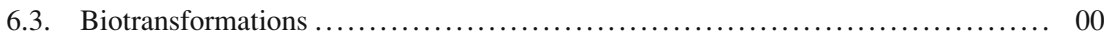

7. Biological Activities of the Withanolides $\ldots \ldots \ldots \ldots \ldots \ldots \ldots \ldots \ldots \ldots \ldots \ldots \ldots \ldots \ldots \ldots$

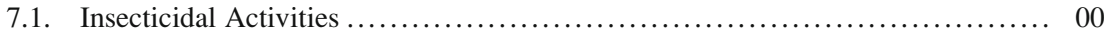

7.2. Phytotoxic Activities ......................................... 00

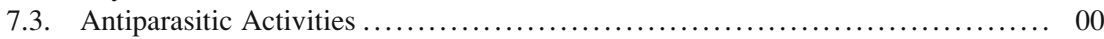

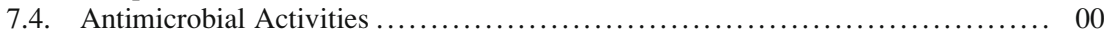

7.5. Anti-inflammatory and Glucocorticoid Related Activities ................... 00

7.6. Cancer-Related Activities .......................................... 00

7.7. CNS-Related Activities ........................................... 00

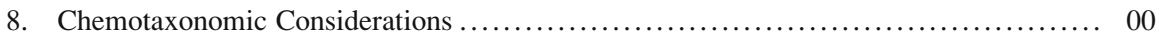

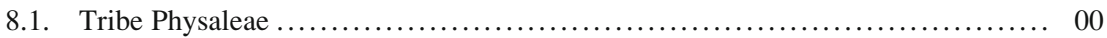

8.2. Tribes Hyoscyameae, Lycieae, and Solaneae $\ldots \ldots \ldots \ldots \ldots \ldots \ldots \ldots \ldots \ldots \ldots \ldots$

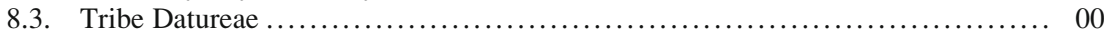

8.4. Genera with Uncertain Positions in the Solanaceae Taxonomic System ........ 00

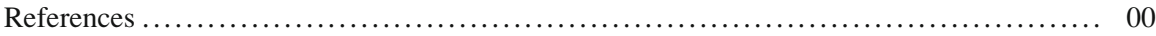

\section{Introduction}

Since the isolation of the first withanolides in the mid 1960s $(1,2)$, ca. 650 members of this family of compounds have been described, with most of these from genera of the Solanaceae. The basic structure of withaferin $\mathrm{A}(\mathbf{1}), \mathrm{a}_{28}$ ergostane with a modified side chain forming a $\delta$-lactone between carbons 22 and 26, was considered for many years the basic template for withanolides (Fig. 1). Nowadays this has given place to a considerable number of related structures that are considered part of the withanolide family. Withanolides have shown to possess many biological activities that include anti-inflammatory, antitumor, cytotoxic, immunomodulating, and cancer chemopreventive as well as antibacterial and antifungal properties. Extracts from Withania somnifera, known by its Sanskrit name "Ashwagandha" or "Indian ginseng", have been used for over 3,000 years in traditional medicine in India (Ayurvedic system). Many of the curative properties of this extract may be associated with the presence of withanolides. Several withanolides also exhibit insecticidal activities, mostly as feedant deterrents, and selective phytotoxicity. A number of review articles have dealt with structural aspects of this group of compounds (3-5) as well as with their biological activities $(6,7)$. The present chapter covers developments and findings in the chemistry and bioactivity of withanolides and related compounds since 1994. 
Fig. 1. Structure of withaferin A (1) and numbering scheme

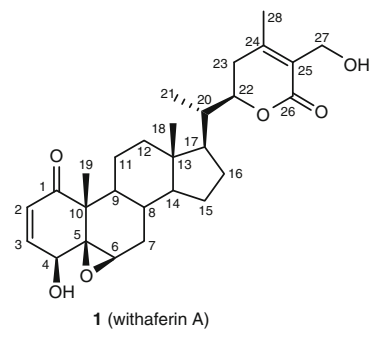

\section{Withanolides in the Plant Kingdom}

\subsection{Solanaceous Genera Containing Withanolides}

The Solanaceae, also known as the nightshade or potato family, is one of the largest flowering plant families in containing nearly 100 genera and $c a$. 2,500 species, with a worldwide distribution in temperate and tropical continents (8-10). However, they are much more diversified in the Andean/Amazonian regions of South America in habitats that vary dramatically. The Solanaceae is also the third most important plant taxon economically and the most valuable in terms of vegetable crops, including the tuber-bearing potato, a number of fruit-bearing vegetables (tomato, eggplant, peppers), ornamental plants (petunias, Nicotiana, Nierembergia), plants with edible leaves (Solanum aethiopicum, S. macrocarpon), and medicinal plants (e.g. Atropa, Capsicum, Datura).

A modern traditional classification of the Solanaceae, predominantly based on morphological evidence with a minor emphasis on chemistry, recognizes six subfamilies (9). However, a recently proposed phylogenetic classification of the Solanaceae provides a different framework to the morphological system, with the inclusion of genera traditionally excluded from the family and with a greater resolution among lineages within the subfamily Solanoideae (10).

Among the nearly 100 genera included in Solanaceae (10), the occurrence of withanolides is restricted to the subfamily Solanoideae. Table 1 summarizes all genera and species known to contain withanolides to date. The four major contributors of withanolide structures are the genera Jaborosa Juss., Datura L., and Physalis L. from the North and South American continents, and Withania Pauq., native to the Old World. Up to the present, $c a .50 \%$ of the species in these genera have been investigated. Jaborosa is an interesting South American genus with a much varied corolla odor, color, and morphology as an adaptation to different pollinators growing from southern Peru to Argentina in very diverse habitats. Datura comprises annual or short-lived perennial herbs, mostly with erect large flowers, common in semiarid habitats in Mexico and the southwest of the United States, but introduced in many countries. Physalis includes mostly American herbs (Central America, Mexico and United States, except for the Euroasian $P$. alkekengi), with solitary pendant yellow or white flowers, and fruiting calyxes that become enlarged and inflated. Finally, Withania is a well-known genus 
Table 1. Genera and species of the Solanaceae containing withanolides

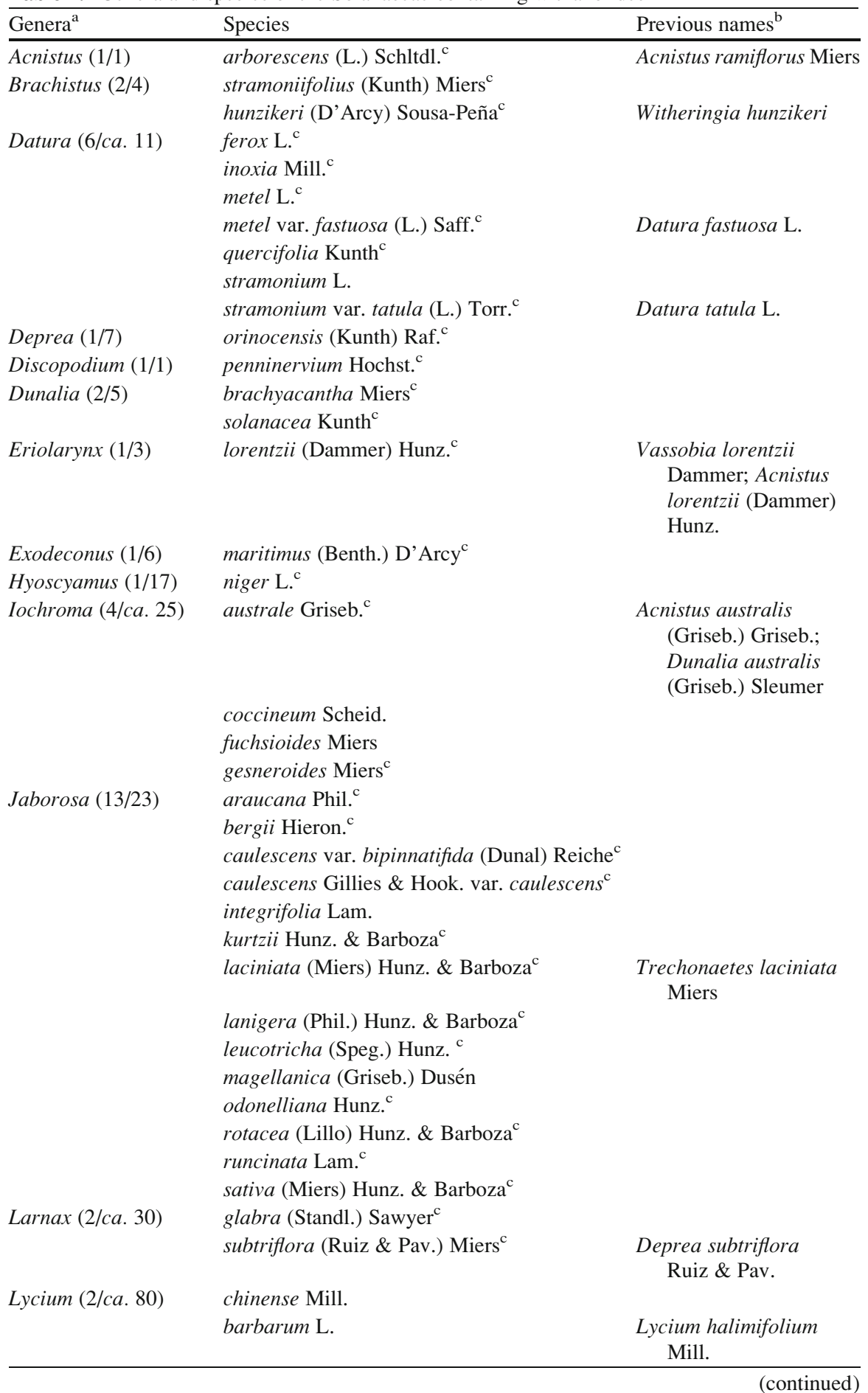


Table 1. (continued)

\begin{tabular}{|c|c|c|}
\hline Genera $^{a}$ & Species & Previous names $^{\mathrm{b}}$ \\
\hline Nicandra $(1 / 2)$ & physalodes (L.) Gaertn. & \\
\hline Margaranthus (1/1) & solanaceous Schltdl. ${ }^{\mathrm{c}}$ & $\begin{array}{r}\text { Physalis solanaceous } \\
\text { (Schltdl.) Axelius }\end{array}$ \\
\hline \multirow[t]{15}{*}{ Physalis (15/ca. 90) } & alkenkegi $\mathrm{L}^{\mathrm{c}}$ & \\
\hline & alkenkegi var. franchetii (Mast.) Makino $^{\mathrm{c}}$ & \\
\hline & angulata $\mathrm{L}^{\mathrm{c}}$ & \\
\hline & 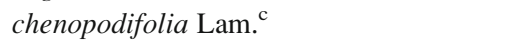 & \\
\hline & cinerascens (Dunal) Hitchc. $^{\mathrm{c}}$ & \\
\hline & coztomatl Dunal $^{\mathrm{c}}$ & \\
\hline & divaricata D. Don ${ }^{\mathrm{c}}$ & \\
\hline & lanceifolia Nees & \\
\hline & minima $\mathrm{L}^{\mathrm{c}}$ & \\
\hline & peruviana $\mathrm{L}^{\mathrm{c}}$ & \\
\hline & 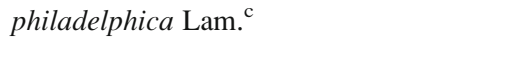 & $\begin{array}{l}\text { Physalis ixocarpa Brot. } \\
\text { ex Hornem. }\end{array}$ \\
\hline & pruinosa $\mathrm{L}$. & \\
\hline & pubescens $\mathrm{L}$. & \\
\hline & virginiana Mill. ${ }^{\mathrm{c}}$ & \\
\hline & viscosa $\mathrm{L}$. & Physalis curassavica $\mathrm{L}$. \\
\hline Salpichroa $(1 / 16)$ & origanifolia (Lam.) Thell. ${ }^{\mathrm{c}}$ & \\
\hline Schraderanthus $(1 / 1)$ & viscosus (Schrad.) Averett ${ }^{\mathrm{c}}$ & $\begin{array}{l}\text { Saracha viscosa Schrad. } \\
\text { Leucophysalis viscosa } \\
\text { (Schrad.) Hunz. }\end{array}$ \\
\hline Solanum $(2 /$ ca. 1,500$)$ & $\begin{array}{l}\text { ciliatum Lam. }^{\mathrm{c}} \\
\text { sisymbrifolium Lam. }^{\mathrm{c}}\end{array}$ & Solanum cilistum Lam. \\
\hline Tubocapsicum $(1 / 2)$ & anomalum (Franch. \& Sav.) Makino ${ }^{c}$ & \\
\hline Vassobia $(1 / 2)$ & breviflora (Sendtn.) Hunz. ${ }^{\mathrm{c}}$ & $\begin{array}{l}\text { Acnistus breviflorus } \\
\text { Sendtn. }\end{array}$ \\
\hline \multirow[t]{5}{*}{ Withania $(6 / 20)$} & $\begin{array}{l}\text { adpressa } \text { Cors. }^{\mathrm{c}} \\
\text { aristata (Aiton) Pauq. }\end{array}$ & \\
\hline & coagulans (Stocks) Dunal ${ }^{\mathrm{c}}$ & Withania coagulance \\
\hline & frutescens (L.) Pauq. & \\
\hline & obtusifolia V. Tackh. & \\
\hline & somnifera (L.) Dunal ${ }^{\mathrm{c}}$ & \\
\hline Witheringia $(2 / 12)$ & $\begin{array}{l}\text { coccoloboides (Dammer) Hunz. } \\
\text { solanacea L'Hér. }{ }^{c}\end{array}$ & \\
\hline
\end{tabular}

${ }^{\mathrm{a}}$ In parenthesis are the number of species with withanolides/number of total species. ${ }^{\mathrm{b}}$ Previous names cited in literature. ${ }^{\mathrm{c}}$ Species included in this chapter

of perennial herbs or shrubs with flowers that are perfect or functionally imperfect, occurring in Europe and Asia.

Table 1 also includes four monotypic genera, Acnistus Schott (Southern Mexico to Eastern Brazil and Paraguay), Margaranthus Schltdl. (Southern United States to the Antilles), Schraderanthus Averett (Mexico to Guatemala), and Discopodium Hochst. (tropical Africa). In the remaining genera containing withanolides, only isolated species have been characterized phytochemically. 


\subsection{Non-Solanaceous Genera Containing Withanolides}

Withanolides have been detected in six species belonging to different families (Table 2), including the rhizomes of species of Tacca J.R. Forst. \& G. Forst. (family Dioscoreaceae, formerly the family Taccaceae), in the aerial parts of Senna siamea (family Leguminosae), in the bark of Eucalyptus globulus (family Myrtaceae), and in species of Ajuga L. (family Lamiaceae).

\section{Classification of Withanolides}

The withanolides are polyoxygenated steroids with a $\mathrm{C}_{28}$ ergostane skeleton. A common feature is the presence of oxygen atoms at C-1, C-22, and C-26 although a few exceptions with a non-functionalized $\mathrm{C} 22$ are included. They may be classified into two major groups depending on the arrangement of the side chain, those with a $\delta$-lactone or $\delta$-lactol comprising C-22 and C-26 and those with a $\gamma$-lactone usually involving $\mathrm{C}-23$ and $\mathrm{C}-26$.

\subsection{Withanolides with a $\delta$-Lactone or $\delta$-Lactol Side Chain}

Most of the known withanolides belong to this group, which may be further divided into 13 subgroups: withanolides with the parent skeleton of withaferin A (1), withaphysalins, physalins, acnistins, withajardins, withametelins, sativolides, subtriflora- $\delta$-lactones, spiranoid- $\delta$-lactones, norbornane-type withanolides, ring-D aromatic withanolides, ring-A aromatic withanolides, and taccalonolide- $\delta$-lactones (Fig. 2). The $\delta$-lactone formed between a carboxyl group at C-26 and a hydroxy at

Table 2. Genera containing withanolides from outside the Solanaceae

\begin{tabular}{|c|c|c|}
\hline Family and genera & Species & Name cited ${ }^{\mathrm{a}}$ \\
\hline Monocotyledoneae & chantrieri Andréb $^{b}$ & \\
\hline \multicolumn{3}{|l|}{ Fam. Dioscoreaceae } \\
\hline \multirow[t]{3}{*}{ Tacca } & paxiana $\mathrm{H}$. Limpr. ${ }^{\mathrm{b}}$ & \multirow{10}{*}{$\begin{array}{l}\text { Tacca subflaellata } \\
\text { Cassia siamea } \\
\text { Lam. }\end{array}$} \\
\hline & plantaginea (Hance) Drenth ${ }^{\mathrm{b}}$ & \\
\hline & subflabellata P.P. Ling \& C.T. Ting ${ }^{\mathrm{b}}$ & \\
\hline Dicotyledoneae & siamea (Lam.) Irwin \& Barneby & \\
\hline Fam. Leguminosae & & \\
\hline Senna & & \\
\hline Fam. Myrtaceae & globulus Labill. $^{\mathrm{b}}$ & \\
\hline Eucalyptus & & \\
\hline Fam. Lamiaceae & bracteosa Wall. ex Benth. ${ }^{\mathrm{b}}$ & \\
\hline Ajuga & parviflora Benth. $^{\mathrm{b}}$ & \\
\hline
\end{tabular}

${ }^{\mathrm{a}}$ Names cited in literature. ${ }^{\mathrm{b}}$ Species included in this chapter 
Withanolides and Related Steroids<smiles>[R]C1=CCCCC2CCC3C(CC[C@]4(C)C3CC[C@@H]4[C@H](C)[C@H]3CC(C)C(C)C(=P)O3)[C@]12C</smiles>

parent skeleton

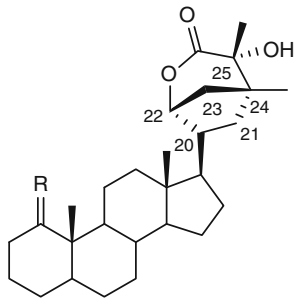

acnistins

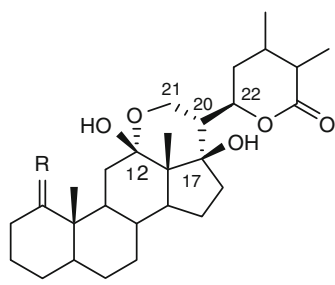

sativolides

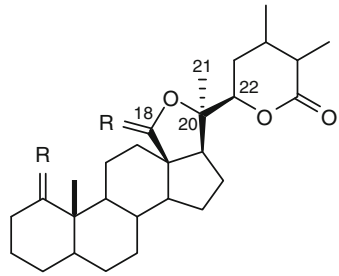

withaphysalins

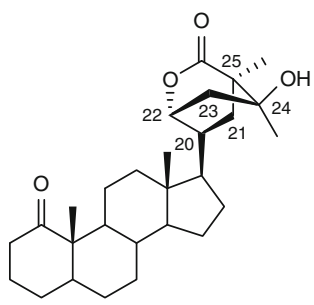

withajardins

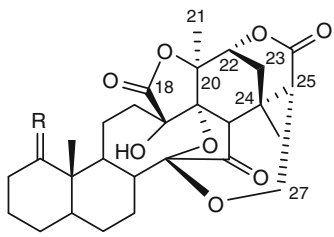

physalins

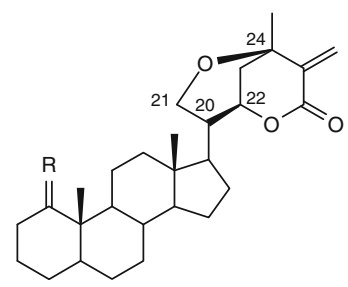

withametelins

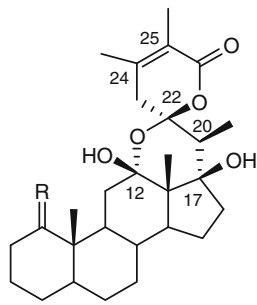

spiranoid- $\delta$-lactones

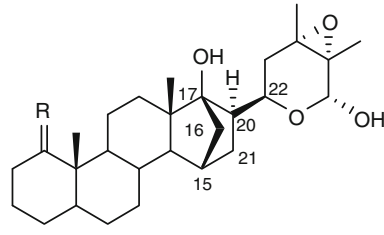

norbornane-type withanolides

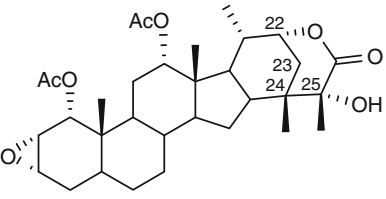

taccalonolide- $\delta$-lactones

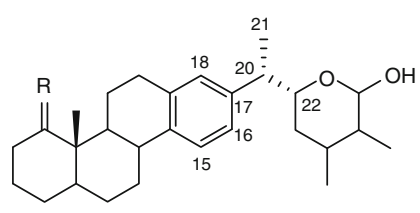

ring-D aromatic withanolides

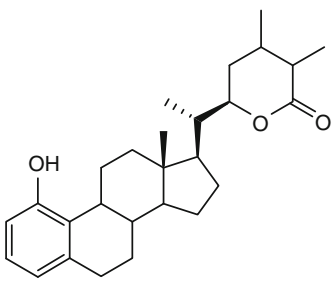

ring-A aromatic withanolides

$\mathrm{R}=\mathrm{O}$ or $\mathrm{H}, \mathrm{OH}$

Fig. 2. General structures of withanolides with a $\delta$-lactone or $\delta$-lactol side chain. Numbering of relevant positions has been added for clarity in some structures 
C-22 is the most common arrangement; other types include lactone formation with a hydrated carbonyl at C-22 and $\delta$-lactols between an aldehyde at C-26 and a hydroxy at C-22. All known withanolides have the same stereochemistry at C-22, which corresponds to $(22 R)$ except when substituents at C-23 or C-22 change the relative priorities of groups around the asymmetric center.

Withanolides with an unmodified skeleton are the most abundant and are regarded as possible precursors of most of the other compounds in this group. A further subdivision of the withanolides is usually made according to the orientation of the side chain; those with the "normal" $17 \beta$-oriented side chain as well as those with the less usual $17 \alpha$-oriented side chain are known. In the latter case a $17 \beta$-hydroxy (either free or involved in a cyclic ether) is generally present although several exceptions are known.

\subsection{Withanolides with a $\gamma$-Lactone Side Chain}

The presence of an oxygenated function at $\mathrm{C}-23$ allows the formation of a $\gamma$-lactone with a carboxyl group at C-26; these withanolides may be divided in five subgroups, spiranoid withanolides, trechonolides, subtriflora- $\gamma$-lactones, ixocarpalactones, and taccalonolide- $\gamma$-lactones. A sixth subgroup with a $\gamma$-lactone side chain involving C-26 and C-28 corresponds to the perulactones (Fig. 3).

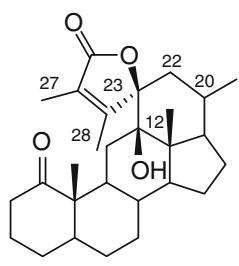

spiranoid- $\gamma$-lactones

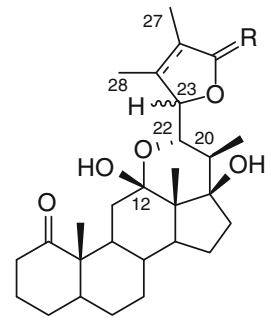

trechonolides

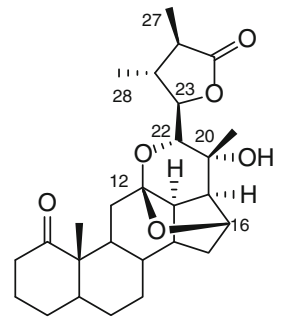

subtriflora- $\gamma$-lactones

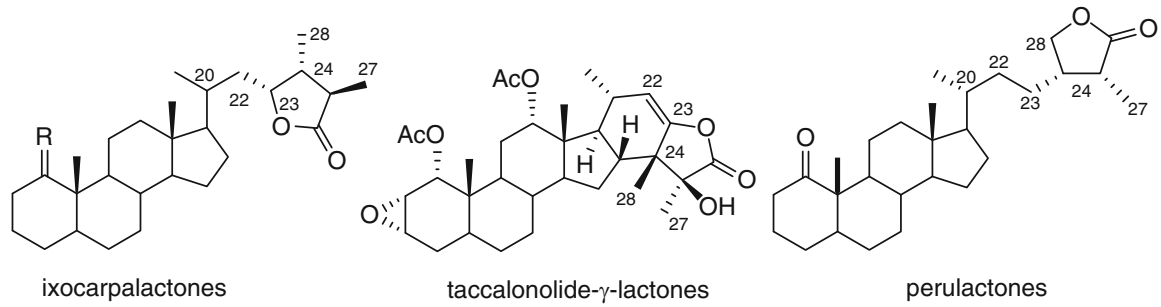

$\mathrm{R}=\mathrm{O}$ or $\mathrm{H}, \mathrm{OH}$

Fig. 3. General structures of withanolides with a $\gamma$-lactone side chain. Numbering of relevant positions has been added for clarity 


\section{Withanolides with an Unmodified Skeleton}

Despite the large number of withanolides with the parent skeleton of withaferin A (1) that are already known, many new entities have been described with minor variations. These correspond mostly to different combinations of hydroxylated substituents and the occurrence of glycosidated derivatives. Among the many structures that fall within this group, the Withania withanolides comprise a major subgroup and are presented separately. Then, other representative substitutions on the parent skeleton will be described.

\subsection{The Withania Withanolides}

The Withania genus, although studied extensively in the past, has continued to provide new withanolide structures. Leaves, roots, and fruits of $W$. somnifera and $W$. coagulans have been investigated, with a total of 45 and 29 new structures reported, respectively. New withanolides have also been isolated from $W$. adpressa and $W$. aristata. Unfortunately, with several groups working simultaneously on the same plant, some structures have been reported as new more than once. As mentioned above, all of them conform to the classical withanolide skeleton with few unusual features.

\subsection{1. $\quad 5 \beta, 6 \beta$-Epoxywithanolides and Related Compounds}

The basic structure of withaferin A (1) may be found in several new structures isolated from $W$. somnifera, and simple variations are the $17 \alpha$-hydroxy derivative 2 (11) and the $\Delta^{16}$ analogues 3 (12) and witharistatin (4) (13), with the latter isolated from $W$. aristata. The same basic structure may be found in $\mathbf{5}$ where the 2,3-double bond has been hydrated (14) and in 6 in which the double bond is reduced (15). The latter compound also has an unusual fragment etherifying the $4 \beta$-hydroxy group. One of the most common variations in the withaferin A substitution pattern is the hydrolytic cleavage of the 5,6-epoxide according to the Fürst-Plattner rule (16), to give the trans-diaxial $5 \alpha, 6 \beta$-diol as in coagulin $\mathrm{H}(7)$ and coagulin $\mathrm{S}(\mathbf{8})$ isolated from $W$. coagulans $(17,18)$. A less common cleavage is that occurring in a transdiequatorial manner, as found in $\mathbf{9}$ and $\mathbf{1 0}$ (14), later reported as new by Kuroyanagi et al. (19), and in 4-deoxywithaperuvin (11) (20). Compound 12 represents an unusual variant of the above, with a $3 \alpha, 6 \alpha$-epoxy bridge $(21)$, which could derive from the cyclization of $\mathbf{1 0}$ also present in the same extract. While Michael-type addition of alcohols to the $\Delta^{2}$-1-keto system of withanolides is well known, intramolecular addition is rare. Nevertheless, the same arrangement has been found previously in withaperuvins D (22) and F (23), although the authors did not directly compare the spectroscopic data of these substances. 
Compounds 13 and $\mathbf{1 4}$ are two glycosides closely related to withaferin $\mathrm{A}(\mathbf{1})$. In the case of $\mathbf{1 3}$ the configuration of the hydroxy group at C-16 was not determined (15).

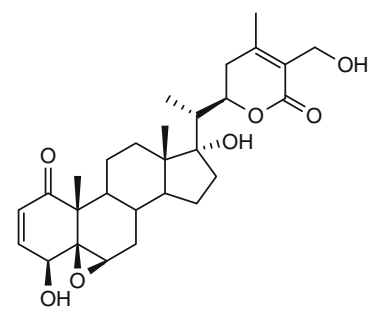

$2(17 \alpha$-hydroxywithaferin A)
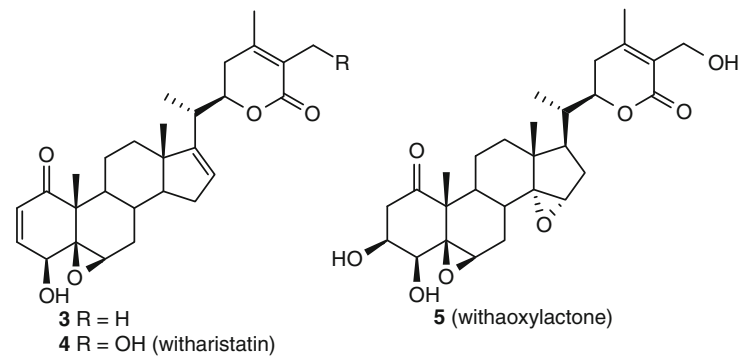

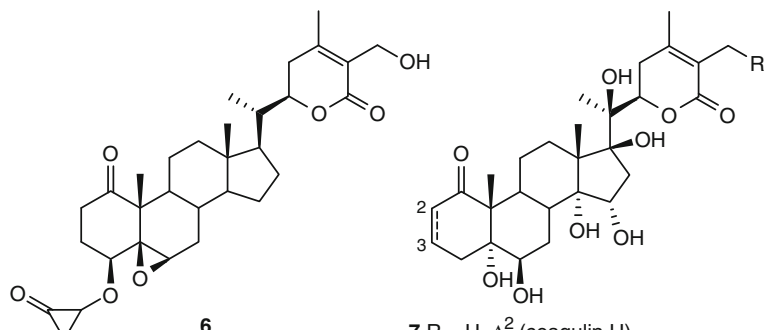

$7 \mathrm{R}=\mathrm{H}, \Delta^{2}$ (coagulin $\mathrm{H}$ )

$8 \mathrm{R}=\mathrm{OH}, 2$,3-dihydro (coagulin $\mathrm{S}$ )<smiles>CC1=C(CO)C(=O)O[C@H]([C@H]2CCC3C4C[C@H](O)[C@]5(O)C(O)CCC(=O)C5(C)C4CC[C@@]32C)C1</smiles>

9 (somnifericin)<smiles>CC1=C(CO)C(=O)O[C@H]([C@H]2CCC3C4CC(O)[C@]5(O)C(=O)C=C[C@H](O)C5(C)C4CC[C@@]32C)C1</smiles>

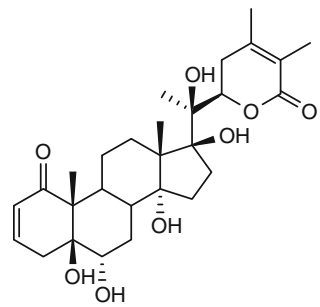

11 (4-deoxywithaperuvin)

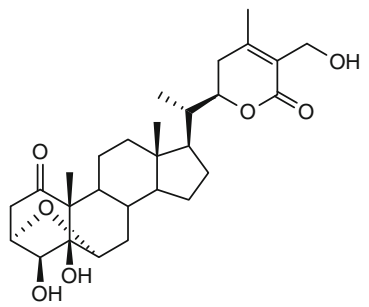

10 (2,3-dehydrosomnifericin)

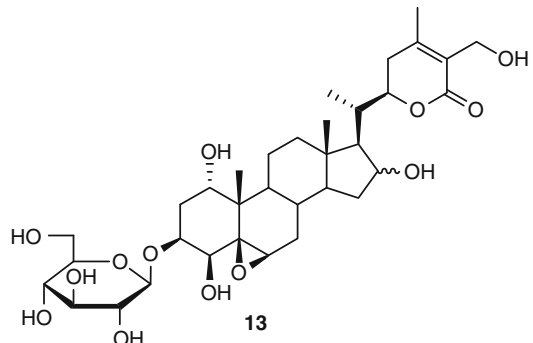

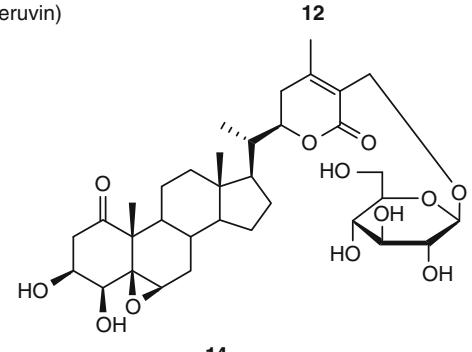

14

\subsection{2. $5 \alpha$-Hydroxy-6$\alpha, 7 \alpha$-Epoxywithanolides and Related Compounds}

The $5 \alpha$-hydroxy- $6 \alpha, 7 \alpha$-epoxy substitution pattern is also a common arrangement found in $W$. somnifera withanolides. Simple variations arising from the 
combination of hydroxy substituents at both typical positions (C-14, C-17, C-20) and some less common ones such as $\mathrm{C}-16$ or $\mathrm{C}-23$ are observed in withasomniferols A (15) and B (16) (24), 14 $\alpha, 17 \alpha$-dihydroxywithanolide R (17) (20), isowithanone (18) (25), and the $16 \beta$-acetate 19 (26). Withasomniferol B (16) is a stereoisomer of the known ixocarpanolide, although the configurations at positions 24 and 25 were not specified. Hydration of the 2,3-double bond was found in compounds $\mathbf{2 0}(11), \mathbf{2 1}$, and $\mathbf{2 2}$ (12), and the latter was isolated as the 3sulfate, an unusual feature in withanolides (see Sect. 4.2.5.). Other variations found were the reduced $1 \alpha$-alcohol $\mathbf{2 3}(25)$ and the related glycosides withanoside II (24), withanoside I (25), and withanoside III (26) (27), with the $1 \alpha, 3 \beta$ dihydroxy arrangement being fairly common among withanolides (see next section). Also, the chlorinated withanolide Z (27) (28), arising from trans-diaxial cleavage of the 6,7-epoxide and the $\Delta^{7}$-withanolide 28 (24) are known. Compound 29 contains an unusual $5 \alpha, 7 \alpha$-epoxy bridge that would result from rearrangement of the $5 \alpha$-hydroxy- $6 \alpha, 7 \alpha$-epoxide (26).

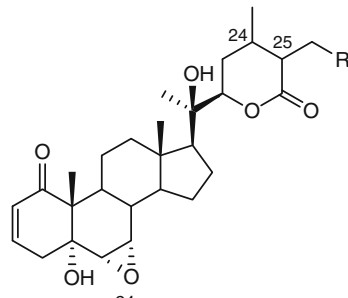

$15 \mathrm{R}=\mathrm{OH}, \Delta^{24}$ (withasomniferol A) $16 \mathrm{R}=\mathrm{H}$ (withasomniferol $\mathrm{B}$ )<smiles>CC(=O)O[C@H]1CC2C3C(=O)C4(O)CC=CC(=O)[C@@]4(C)C3CC[C@]2(C)/C1=C(/C)[C@@H]1CC(C)=C(C)C(=O)O1</smiles>

19

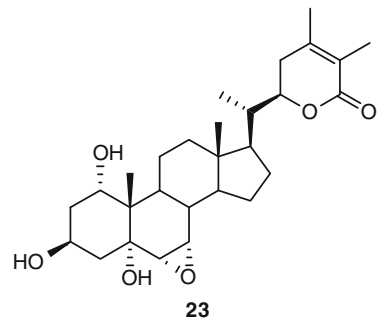

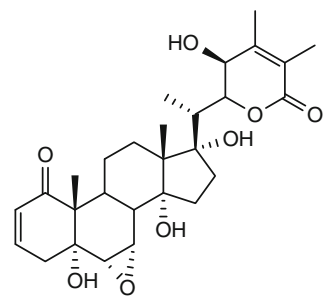

17 (14 $\alpha, 17 \alpha$-dihydroxywithanolide $\mathrm{R})$

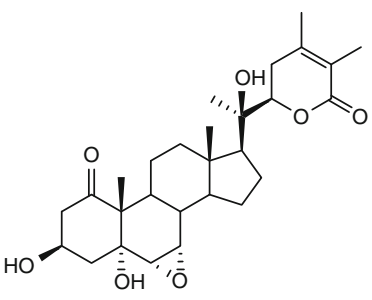

20

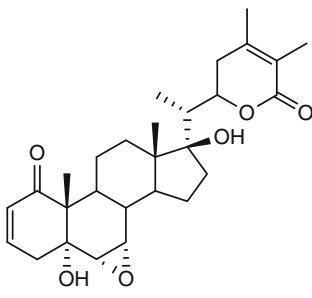

18 (iso-withanone)

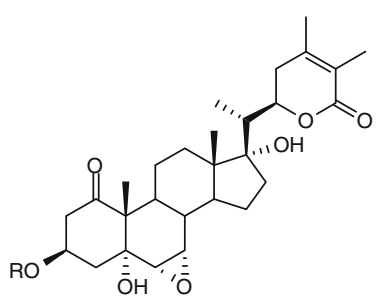

$21 \mathrm{R}=\mathrm{H}$ $22 \mathrm{R}=\mathrm{SO}_{3} \mathrm{H}$

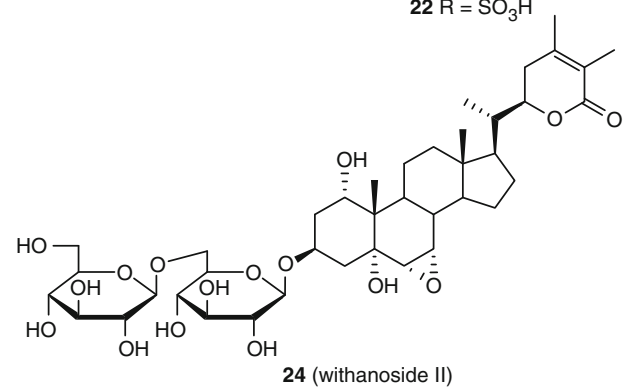



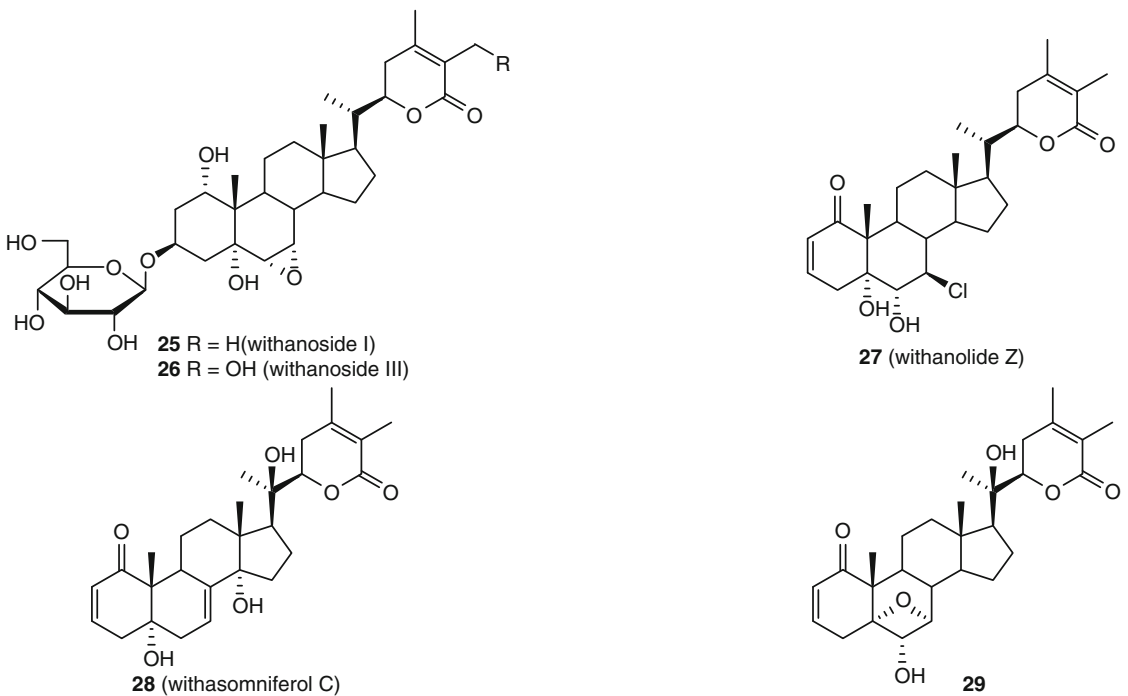

\subsection{3. $1 \alpha, 3 \beta$-Dihydroxy- $\Delta^{5}$-Withanolides and Related Compounds}

As mentioned above, the $1 \alpha, 3 \beta$-dihydroxy arrangement is a well-known structural variation among the withanolides and several examples have been shown in combination with $5 \beta, 6 \beta$ - or $6 \alpha, 7 \alpha$-epoxides. Eleven $3 \beta$-O-glycosides isolated from $W$. somnifera contained the $1 \alpha, 3 \beta$-dihydroxy arrangement combined with a 5,6-double bond in ring B. These include compound 30, later reported as withanoside V (19, 27), withanosides IV (31), VI (32) and VII (33) (27), and 24,25-dihydrowithanoside VI (34) containing a disacharide at position 3 (29). The configurations at positions 24 and 25 of the latter compound were not elucidated. Also within this group are three withanolides with an additional sugar moiety at C-27 (21), withanosides VIII (35), IX (36), and X (37) (this structure was reported again as new, one year later (15)), an analogue of withanoside VI with a monosacharide at C-3 named withanoside XI (38) (21), and an analogue of withanoside IV with a trisacharide moiety at C-3 (39) (15). Coagulin Q (40) isolated from $W$. coagulans (30), has the same aglycone as withanoside VI (32), but with a monosacharide unit at $\mathrm{C}-3$. In all cases the carbohydrate units are $\beta$-D-glucose. 

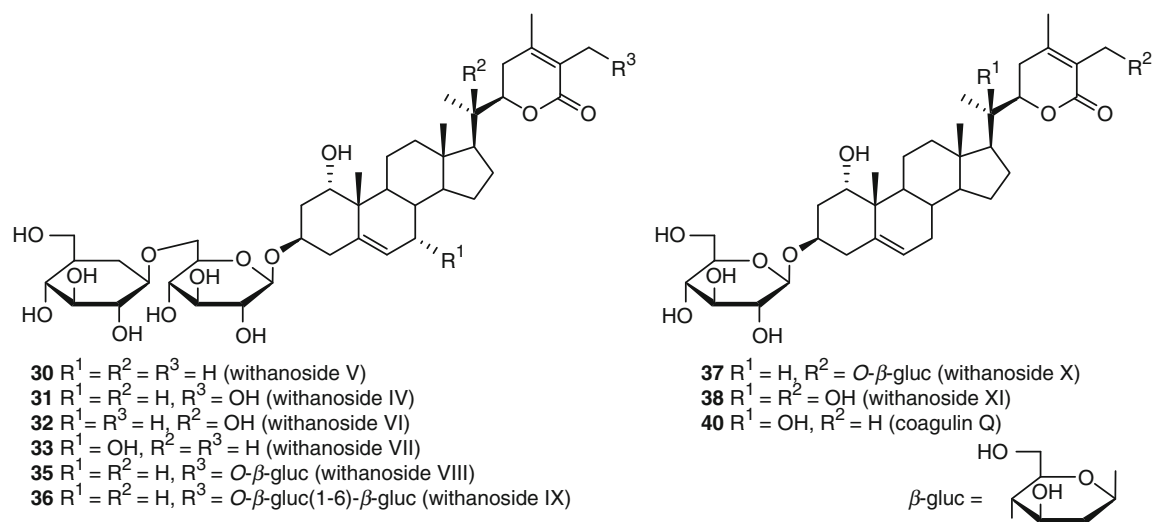

$37 \mathrm{R}^{1}=\mathrm{H}_{3} \mathrm{R}^{2}=\mathrm{O}-\beta$-gluc (withanoside $\mathrm{X}$ ) $38 \mathrm{R}^{1}=\mathrm{R}^{2}=\mathrm{OH}$ (withanoside $\mathrm{XI}$ ) $40 \mathrm{R}^{1}=\mathrm{OH}, \mathrm{R}^{2}=\mathrm{H}$ (coagulin $\mathrm{Q}$ )
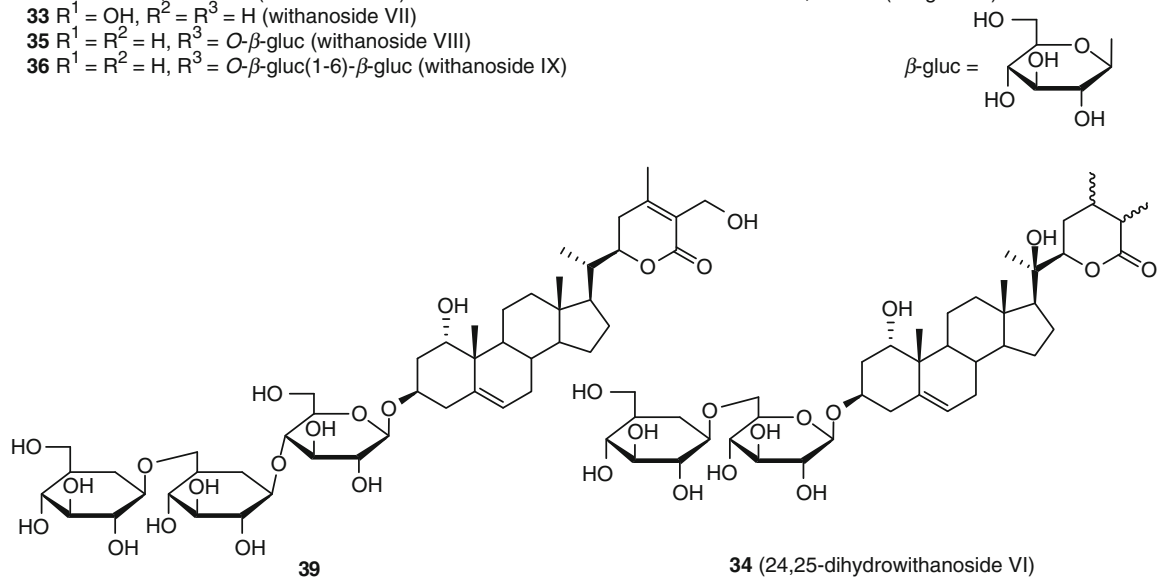

\subsubsection{Other $\Delta^{5}$-Withanolides}

Withanolides containing a 5,6-double bond in combination with either a $\Delta^{2}$ - or $\Delta^{3}$-1-ketone or a $3 \beta$-hydroxy-1-ketone are quite common and are the biosynthetic precursors of the $5 \beta, 6 \beta$-epoxywithanolides. Several new withanolides with these arrangements have been isolated from Withania species, mostly from $W$. coagulans. Compound 41 was isolated originally from $W$. adpressa (31) and later reported as new from $W$. coagulans (32). Compound $\mathbf{4 2}$ had been synthesized by Lavie and coworkers (33) but was isolated for the first time as a natural product by Atta-ur-Rahman et al. from W. coagulans (34). Ten withanolides with closely related structures were also isolated from this plant, withacoagulin (43) (34), withacoagulins A-F (44-49) (35), the $14 \beta, 15 \beta$-epoxide 50, the $14 \alpha$-alcohol 51 (36), and the 17 -epimer of withacoagulin $\mathrm{D}$, coagulansin $\mathrm{A}(\mathbf{5 2})$ (37). The $3 \beta$-hydroxy- $\Delta^{5}$ arrangement is present in coagulansin $\mathrm{B}(\mathbf{5 3})(37)$ and in the three $3 \beta$ - $O$-glycosides, coagulin L (54) (17), coagulin O (55) (38), and coagulin P (56) (30). 


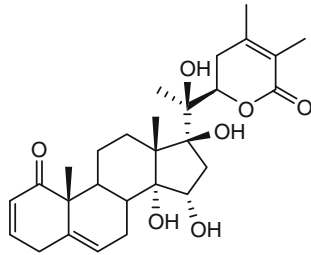

41

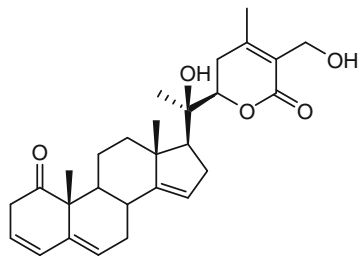

45 (withacoagulin B)

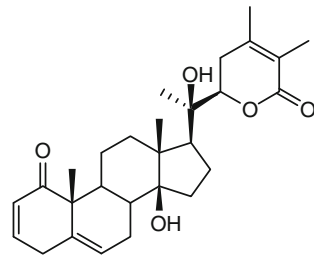

48 (withacoagulin E)

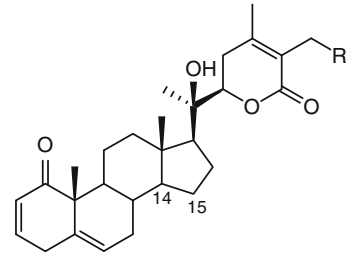

$42 \mathrm{R}=\mathrm{H}$

$43 \mathrm{R}=\mathrm{OH}, \Delta^{14}$ (withacoagulin)

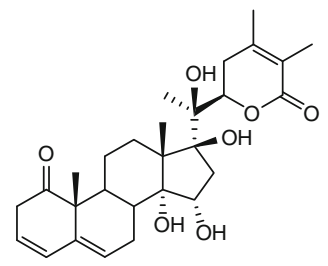

46 (withacoagulin C)

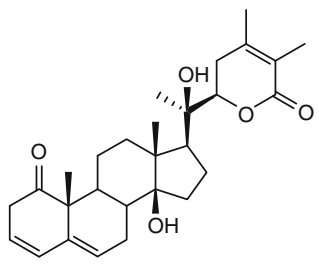

49 (withacoagulin F)

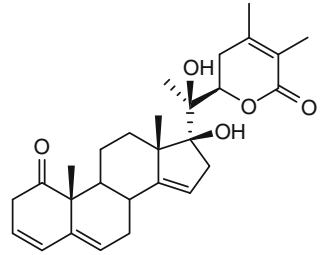

44 (withacoagulin A)<smiles>CC1=C(CO)C(=O)O[C@H]([C@](C)(O)[C@]2(O)CC[C@]3(O)C4CC=C5CC=CC(=O)[C@]5(C)C4CC[C@@]32C)C1</smiles>

47 (withacoagulin D)

50 (14,15 $\beta$-epoxywithanolide I)

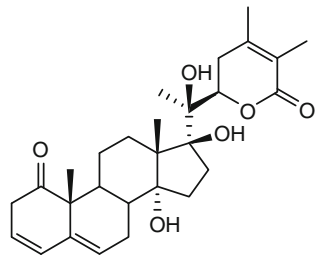

51 (17 $\beta$-hydroxywithanolide K)

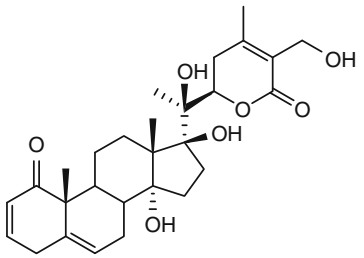

52 (coagulansin A)

Glucosomniferanolide (57), isolated from $W$. somnifera, contains a glucose unit at the tertiary hydroxy group at C-20 (39). This compound was described as having a $(22 S)$ configuration, opposite to that found in all withanolides with a $\delta$-lactone side chain. However, spectroscopic observations supporting this assumption only indicate that H-22 is equatorial instead of axial (broad signal with $W_{1 / 2}=5 \mathrm{~Hz}$ ), an orientation that can result from a simple conformational inversion of the lactone ring half chair, probably due to the presence of the bulky substituent at C-20. Thus, this structure should be revised. 
<smiles>C[C@H]1CC([C@](C)(O)[C@H]2CC[C@@]3(O)C4CC=C5C[C@@H](O)CC(=O)[C@]5(C)C4CC[C@]23C)OC(=O)[C@H]1C</smiles>

53 (coagulansin B)

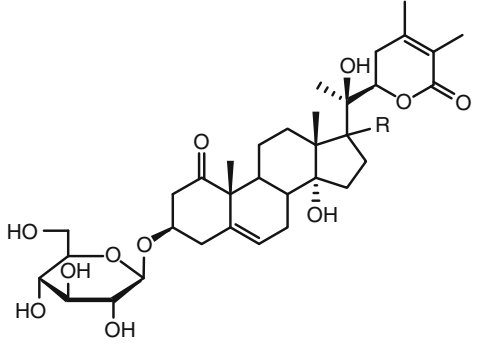

$54 \mathrm{R}=\beta-\mathrm{OH}$ (coagulin $\mathrm{L})$ $55 \mathrm{R}=\alpha-\mathrm{H}$ (coagulin $\mathrm{O}$ )

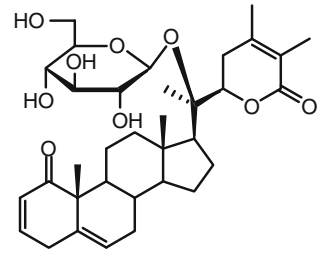

57 (glucosomniferanolide)

Several $14 \alpha, 20$-epoxywithanolides closely related to the known coagulin (58) (40), were isolated from $W$. coagulans. These included coagulins B-E (59-62) (41), coagulins $F$ and $G(\mathbf{6 3}, \mathbf{6 4})(42)$, coagulin $R(\mathbf{6 5})(30)$, the diol coagulin $M(66)$ and the glycoside coagulin $\mathrm{N}(\mathbf{6 7})(38)$, coagulin $\mathrm{J}(\mathbf{6 8})$, the diol coagulin I (69) and the glycoside coagulin K (70) (17), and compound 71 (34). Malik and coworkers had previously reported the isolation of $\mathbf{7 1}$ and the 3-O-glycoside of coagulin $\mathrm{R}$ from Physalis peruviana $(43,44)$ and of ajugin, identical to coagulin R from Ajuga parviflora (see Sect. 4.2.) (45).

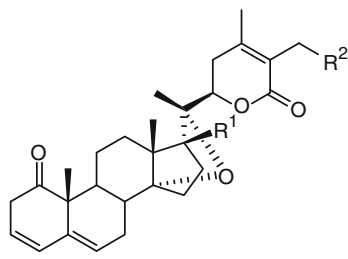

$58 \mathrm{R}^{1}=\mathrm{OH}, \mathrm{R}^{2}=\mathrm{OH}$ (coagulin) $62 R^{1}=R^{2}=H$ (coagulin E) $63 \mathrm{R}^{1}=\mathrm{H}, \mathrm{R}^{2}=\mathrm{OH}$ (coagulin $\mathrm{F}$ ) $71 \mathrm{R}^{1}=\mathrm{OH}, \mathrm{R}^{2}=\mathrm{H}$

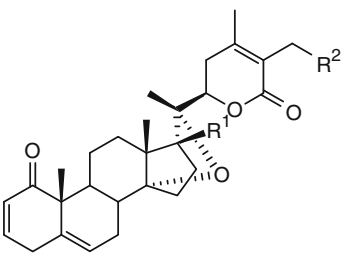

$59 \mathrm{R}^{1}=\mathrm{H}, \mathrm{R}^{2}=\mathrm{OH}$ (coagulin $\mathrm{B}$ ) $60 \mathrm{R}^{1}=\mathrm{OH} \mathrm{R}^{2}=\mathrm{H}$ (coagulin $\mathrm{C}$ ) $61 R^{1}=R^{2}=H$ (coagulin $D$ ) $64 R^{1}=R^{2}=O H$ (coagulin $G$ )

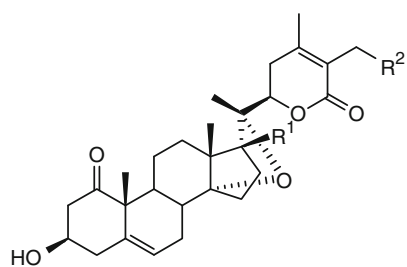

$65 \mathrm{R}^{1}=\mathrm{OH} \mathrm{R} \mathrm{R}^{2}=\mathrm{H}$ (coagulin $\mathrm{R}$ ) $68 \mathrm{R}^{1}=\mathrm{H} \mathrm{R}^{2}=\mathrm{OH}$ (coagulin $\mathrm{J}$ ) 


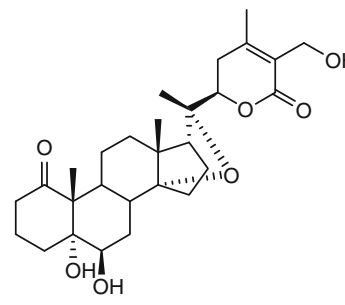

66 (coagulin M)
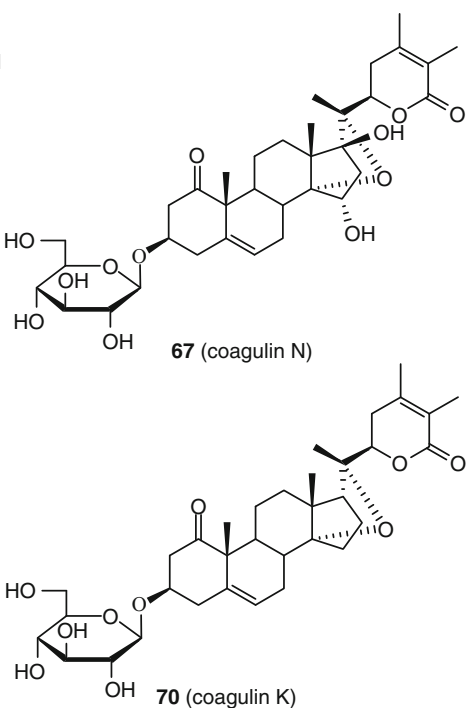

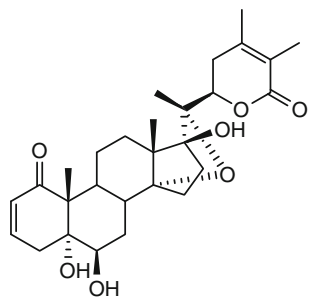

69 (coagulin I)

\subsubsection{Other Substitution Patterns}

Some less common substitution patterns isolated from $W$. somnifera include a $\Delta^{1,4}$-3-keto withanolide (72) (12), a series of four $8 \beta$-hydroxywithanolides (73-76), a $7 \beta$-hydroxywithanolide with a $\Delta^{2,4}-1$-keto arrangement in ring $\mathrm{A}(77)$ (46), and two dimeric withanolides bound by a thioether linkage (78) (47) or a sulfoxide (79) (48). Other less common features found in these compounds are the presence of an $11 \beta$-hydroxy $(\mathbf{7 4 , 7 6})$ or an 18 -hydroxy group $(\mathbf{7 5}, \mathbf{7 7})(46)$. The $3 \beta$-O-sulfate of 2,3-dihydrowithaferin A (80) was isolated from aeroponically grown $W$. somnifera plants (49).

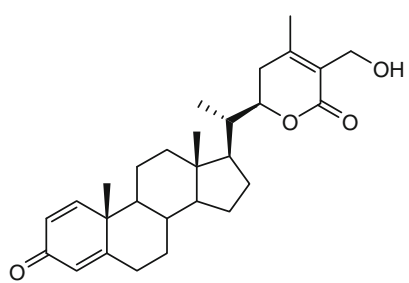

72

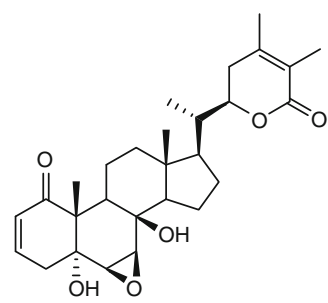

73 (withasomnilide)

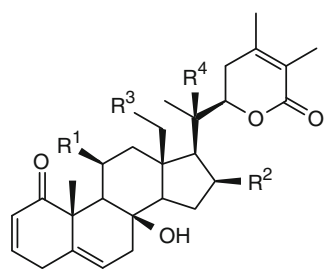

$74 \mathrm{R}^{1}=\mathrm{R}^{2}=\mathrm{OH}, \mathrm{R}^{3}=\mathrm{R}^{4}=\mathrm{H}$ (withasomniferanolide) $75 \mathrm{R}^{1}=\mathrm{R}^{2}=\mathrm{H}, \mathrm{R}^{3}=\mathrm{R}^{4}=\mathrm{OH}$ (somniferawithanolide) 


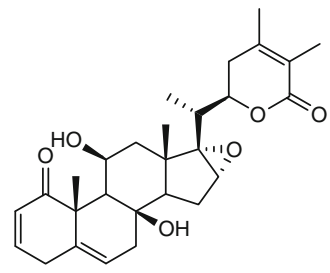

76 (somniferanolide)

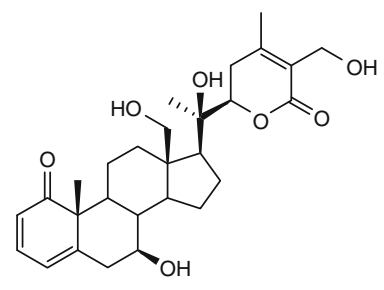

77 (somniwithanolide)

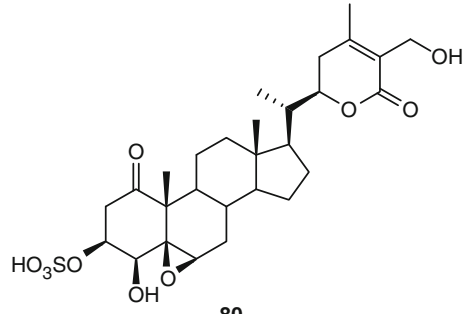

80

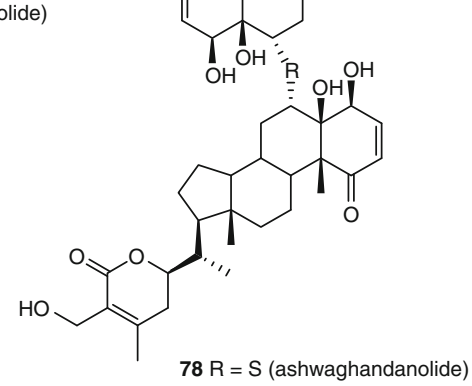

$79 \mathrm{R}=\mathrm{S}=\mathrm{O}$

\subsection{Other Withanolides with an Unmodified Skeleton}

As mentioned above, a considerable number of withanolides with the parent skeleton of withaferin A (1) have been isolated. With few exceptions, in new withanolides the substitution patterns of rings A and B correspond to those described in the previous section for the Withania withanolides. Structural variations consist mainly of combinations of oxygenated functions (hydroxy or carbonyl groups) at different positions of the steroid nucleus (most commonly at positions 12, 14, 16, 17, and 18) and the side chain (mostly at C-20, C-21, and C-27). These functionalities may also be involved in cyclic entities as lactones, lactols, or cyclic ethers. These withanolides are presented in Sect. 5., with the exception of $14 \alpha, 20$ epoxywithanolides that are included in Sect. 4.2.1.

\subsubsection{C-14, C-17, and C-20 Hydroxylated Withanolides and Related Compounds}

Hydroxylation at C-14, C-17 and C-20 is common in many withanolides. Usually the 14-hydroxy group has the $\alpha$-orientation (see Sect. 4.1.), although there is a growing number of $14 \beta$-hydroxywithanolides. As already mentioned, hydroxy substitution at C-17 occurs with either the $\alpha$ - or $\beta$-orientation, of which the former is more common. New structures with different combinations of hydroxy groups at the above-mentioned positions have been reported, occasionally combined with hydroxy groups at positions 15,16 , and 18 . The genus Physalis is particularly rich in 14-hydroxywithanolides, with these probably being the biosynthetic precursors 
of polyoxyfunctional structures such as the physalins, present in many Physalis

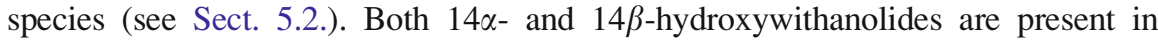
Physalis plants. A series of $14 \alpha, 17 \beta, 20$-trihydroxywithanolides was isolated from P. peruviana (81-85) (50). Phyperunolides B (81) and C (82) have the unusual feature of a free hydroxy group at C-28; another 28-hydroxywithanolide, 86, was reported by Dinan et al. from the same plant (51). Hydroxylation at C-28 is a prerequisite in the formation of perulactones (Fig. 3), common components of $P$. peruviana. The 3-ethoxy withanolide $\mathbf{8 5}$ is probably an artifact formed during isolation. Also from P. peruviana, Ahmad and coworkers isolated the closely related 87 (52), the glycosides 88-91 (53), and a glycoside of coagulin R (92) (44). As already mentioned (Sect. 4.1.4.), another withanolide with a $14 \alpha, 20$-ether bridge (71), was also isolated from this plant (43). From $P$. cinerascens collected in Mexico, Maldonado et al. isolated 24,25-dihydrowithanolide S (93) with a saturated lactone side chain, together with the known withanolide S (54).

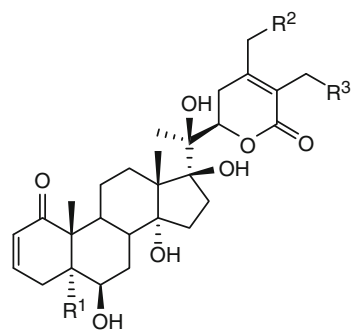

$81 \mathrm{R}^{1}=\mathrm{R}^{2}=\mathrm{OH}, \mathrm{R}^{3}=\mathrm{H}$ (phyperunolide $\mathrm{B}$ ) $82 \mathrm{R}^{1}=\mathrm{Cl}, \mathrm{R}^{2}=\mathrm{OH}, \mathrm{R}^{3}=\mathrm{H}$ (phyperunolide $\mathrm{C}$ ) $83 R^{1}=R^{3}=O H, R^{2}=H$ (phyperunolide $D$ )

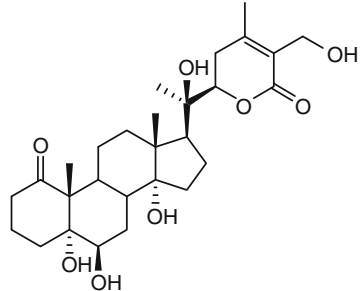

87

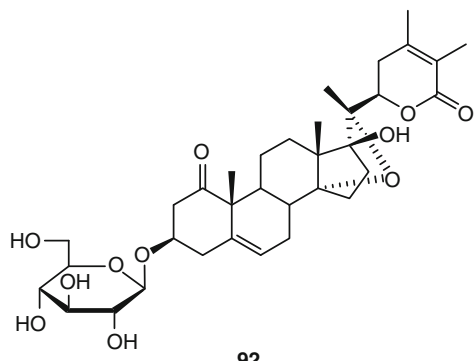

92

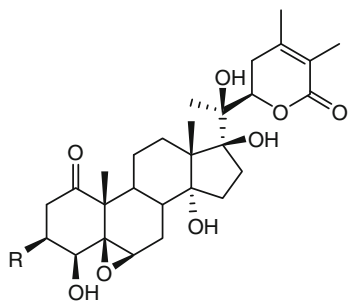

$84 \mathrm{R}=\mathrm{OH}$ (phyperunolide $\mathrm{E}$ ) $85 \mathrm{R}=\mathrm{OCH}_{2} \mathrm{CH}_{3}$ (phyperunolide $\mathrm{F}$ )

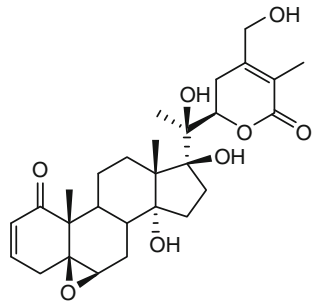

86 (28-hydroxywithanolide E)

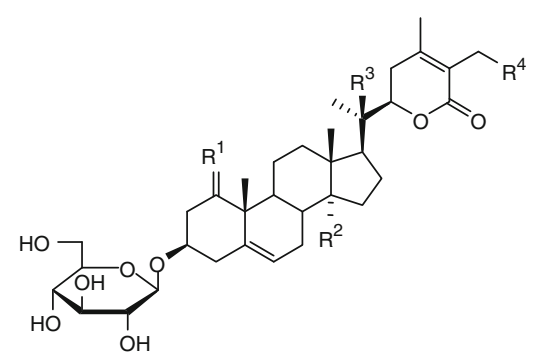

$88 \mathrm{R}^{1}=\mathrm{H}, \alpha-\mathrm{OAc}, \mathrm{R}^{2}=\mathrm{R}^{3}=\mathrm{OH}, \mathrm{R}^{4}=\mathrm{H}$ $89 \mathrm{R}^{1}=\mathrm{H}, \alpha-\mathrm{OAc}, \mathrm{R}^{2}=\mathrm{R}^{3}=\mathrm{H}, \mathrm{R}^{4}=\mathrm{OH}$ $90 \mathrm{R}^{1}=\mathrm{O}, \mathrm{R}^{2}=\mathrm{H}_{3} \mathrm{R}^{3}=\mathrm{R}^{4}=\mathrm{OH}$ $91 \mathrm{R}^{1}=\mathrm{O}, \mathrm{R}^{2}=\mathrm{R}^{3}=\mathrm{R}^{4}=\mathrm{OH}$

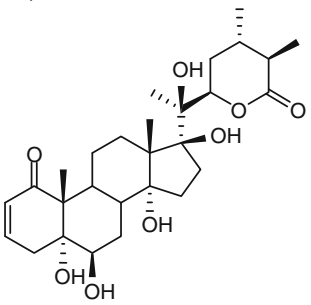

93 (24,25-dihydrowithanolide S) 
An investigation of $P$. angulata growing in Taiwan gave the 15-oxygenated withangulatins B-D (94-96) and the 16-hydroxylated withangulatins $\mathrm{G}$ (97) and $\mathrm{H}(\mathbf{9 8})$ together with withangulatin $\mathrm{E}(\mathbf{9 9})$ and a $\Delta^{16} 14 \alpha$-hydroxywithanolide, withangulatin F (100) (55). Several other $\Delta^{16} 14 \alpha$-hydroxy withanolides have been reported from Physalis species. These include phyperunolide A (101) isolated from $P$. peruviana (50) and four 15-acetyloxy withanolides isolated from $P$. angulata, withangulatin I (102) (56), physagulin M (103) with the unusual feature of a free hydroxy group at C-23 (57), physagulin O (104), and compound 105 (58). The latter withanolide was incorrectly named physagulin $\mathrm{L}$, as this name had already been assigned (see below). Physagulin N (106), the methanol addition product of physagulin $\mathrm{A}$, was probably formed during its isolation (57). $\Delta^{16}$ Withanolides with oxygen substituents at $\mathrm{C}-14$ and $\mathrm{C}-15$ have the appropriate functionalities for cleavage of the 13,14-bond, and the occurrence of such withanolides in physalin-rich plants strongly suggests that they are either precursors or shunt products in the biosynthesis of physalins (59). A $\Delta^{14}$-withanolide, 107, was also reported from P. minima collected in Pakistan (60).

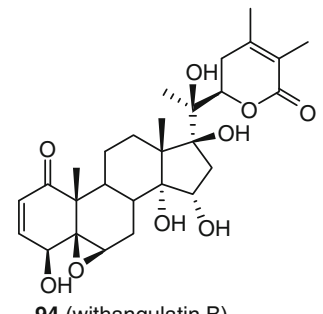

94 (withangulatin B)

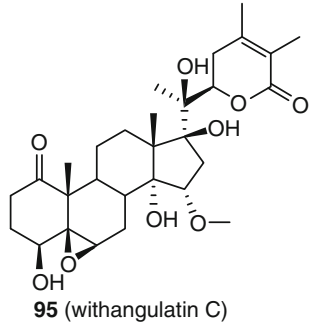

95 (withangulatin C)
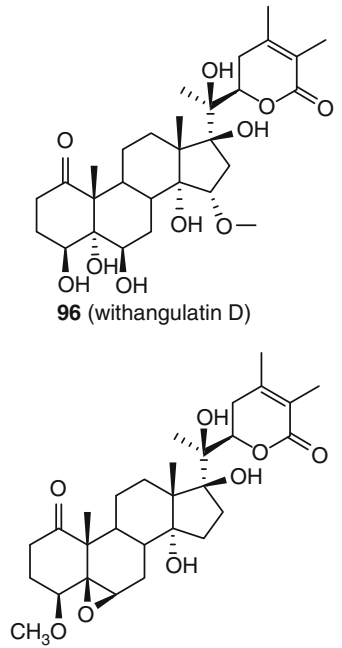

99 (withangulatin E)

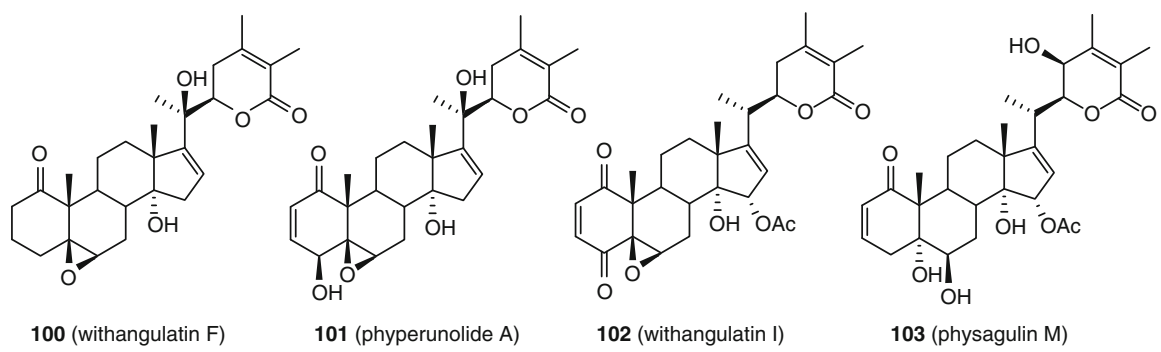



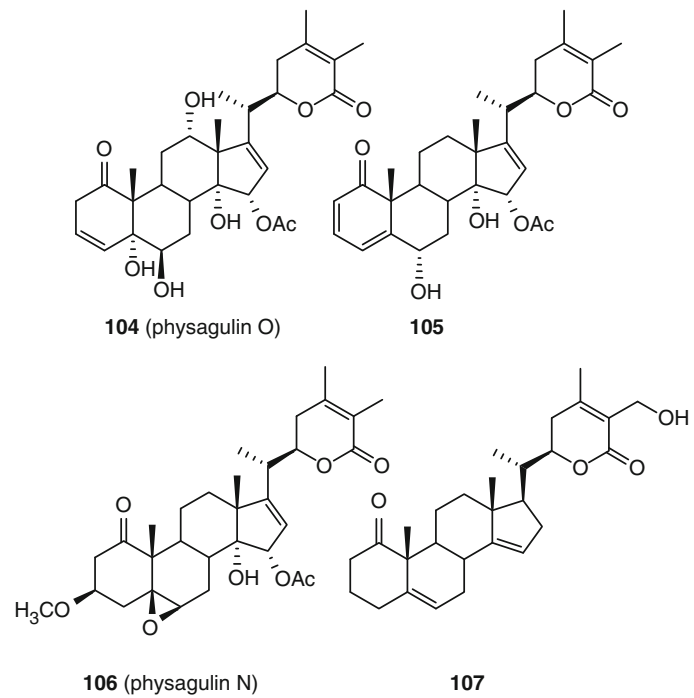

Ajuga (Lamiaceae) is one of the few genera outside the Solanaceae that contains withanolides, most of which are closely related to the coagulins (Sect. 4.1.). From A. parviflora, Malik and coworkers have reported seven $14 \alpha$-hydroxywithanolides, compound 108 (isolated together with coagulin J) (61), ajugins A (109), B (110) (62), C (111), D (112) (63), E (113), and F (114) (64), a $\Delta^{14}$ withanolide (115), and a $14 \alpha, 20$-epoxywithanolide (116) (65). As already mentioned, ajugin, identical to coagulin $\mathrm{R}(\mathbf{6 5})$, was first isolated from this plant (45).

Several 14 $\beta$-hydroxywithanolides have been isolated from Physalis species, and all of them also have an $\alpha$-oxygenated function (hydroxy or acetate) at position 15. These include physagulins $\mathrm{H}-\mathrm{K}$ (117-120) (66), physagulin L (121) (57), and compounds 122 and 123 (58) from $P$. angulata. The latter two compounds were
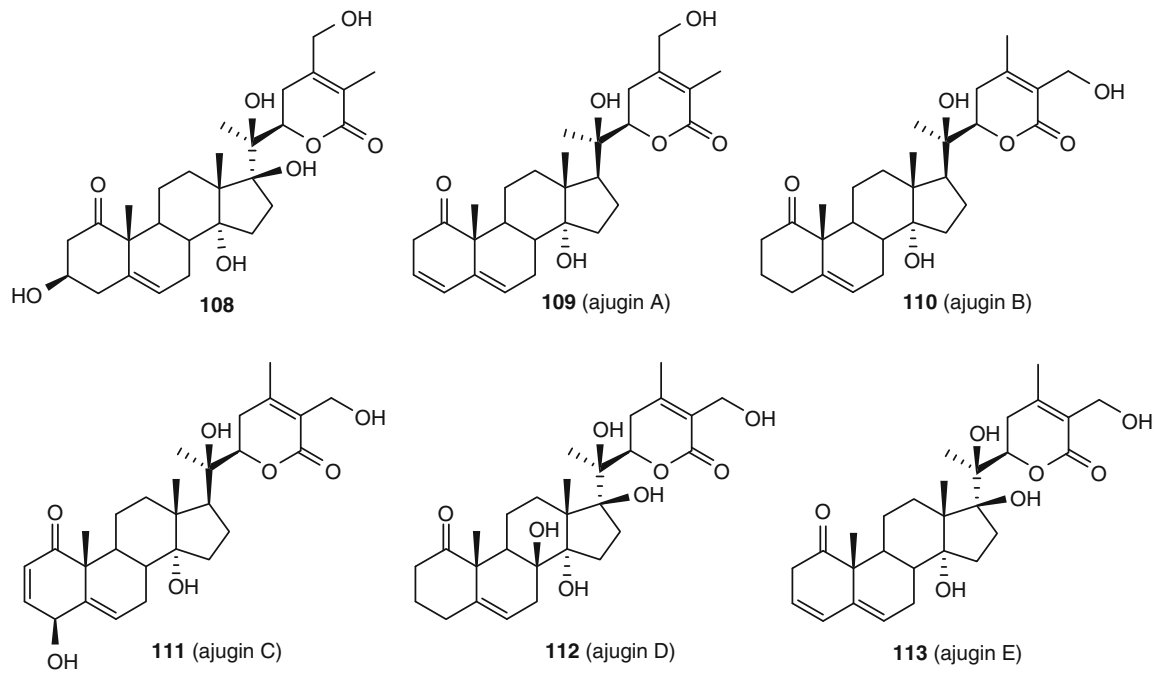
<smiles>CC1=C(CO)C(=O)O[C@H]([C@H](C)[C@]2(O)CC[C@]3(O)C4CC=C5CCCC(=O)C5(C)C4CC[C@@]32C)C1</smiles>

114 (ajugin F)<smiles>CC1=C(C)C(=O)O[C@H]([C@](C)(O)[C@]2(O)CC=C3C4CC=C5CC(O)CC(=O)[C@]5(C)C4CC[C@]32C)C1</smiles>

115

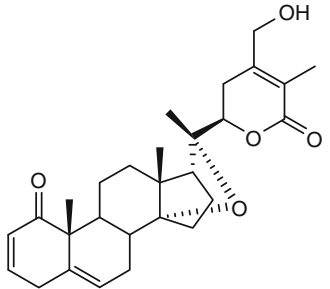

116

incorrectly named physagulins $\mathrm{M}$ and $\mathrm{N}$, as these names had already been assigned (see above). The chlorohydrin $\mathbf{1 2 4}$ was reported from $P$. alkekengi var. franchetii (67) and the deacetylated analogue of physapubenolide (125) from $P$. peruviana (52). Outside the Physalis genus, new 14 $\beta$-hydroxywithanolides have been isolated from Jaborosa leucotricha (jaborosalactone 8 (126)) (68) and J. bergii (jaborosalactol 23 (127)) (69).

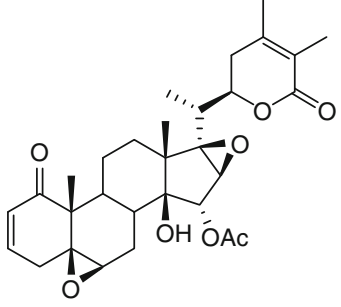

117 (physagulin $\mathrm{H}$ )

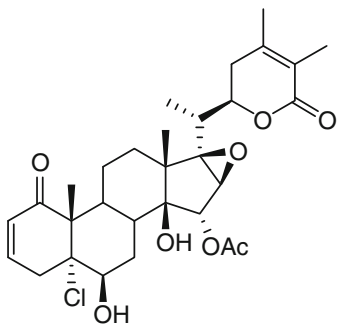

118 (physagulin I)<smiles>[R][C@@]1([C@H](C)[C@H]2CC(C)=C(C)C(=O)O2)C[C@H](OC(C)=O)[C@@]2(C)CCC3C(C[C@H](O)[C@]4(O)CC=CC(=O)[C@@]34C)[C@@]12O</smiles>

$119 \mathrm{R}=\alpha-\mathrm{H}$ (physagulin $\mathrm{J})$ $120 \mathrm{R}=\beta-\mathrm{OH}$ (physagulin $\mathrm{K}$ )

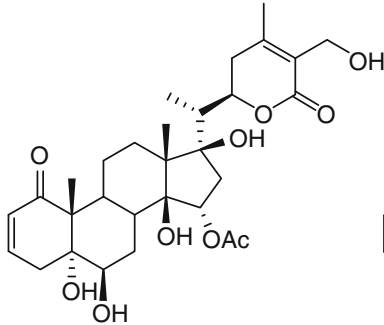

121 (physagulin L)

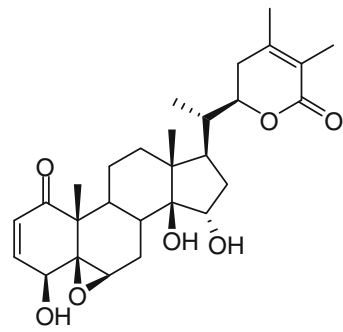

125 (deacetylphysapubenolide)

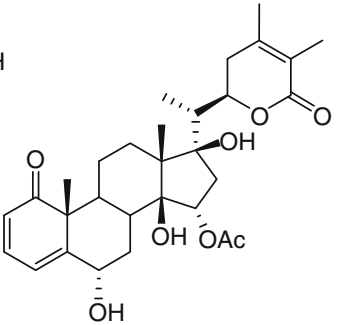

122

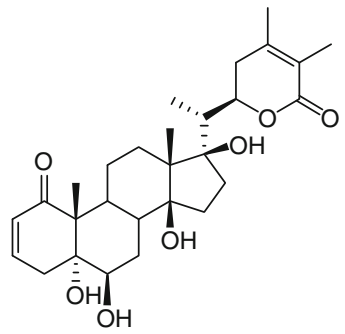

126 (jaborosalactone 8)<smiles>CC1=C(C)C(=O)O[C@@H]([C@H]2CC(O)C3(O)C4C[C@H](O)[C@H]5CC=CC(=O)[C@@]5(C)C4CC[C@]23C)C1</smiles>

$123 \mathrm{R}^{1}=\mathrm{OH}, \mathrm{R}^{2}=\mathrm{H}$ $124 \mathrm{R}^{1}=\mathrm{Cl}, \mathrm{R}^{2}=\mathrm{Ac}$

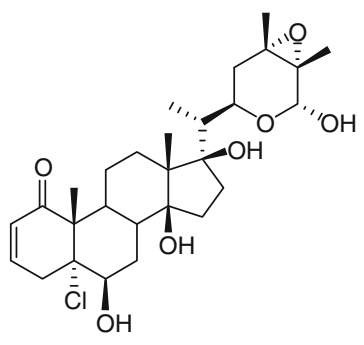

127 (jaborosalactone 23) 


\subsubsection{C-18 Hydroxylated Withanolides}

Withanolides with a functionalized C-18 at various oxidation levels (alcohol, aldehyde, and lactone carbonyl) have been isolated from plants of the genera Withania (see Sect. 4.1.5.), Acnistus, Dunalia, Eriolarynx, Iochroma, and Physalis (4, 5). Hydroxylation at C-18 is usually combined with hydroxy groups occurring at positions 14, 17, or 20. Thus, 18-hydroxywithanolide D (128) was isolated from Eriolarynx lorentzii (synonym Vassobia lorentzii) (70), and the related 18-hydroxywithanolide 129 and the corresponding 18-aldehyde 130 were isolated from Dunalia brachyacantha (71) (both plants collected in Argentina), while the 18-acetoxywithanolide $\mathbf{1 3 1}$ was reported from Iochroma gesneroides together with several 3-methoxylated derivatives formed during the extraction procedure (72). As part of a systematic study of Mexican Physalis species, five 18-acetoxywithanolides, the physachenolides A-E (132-136) were isolated from the leaves, flowers, and stems of Physalis chenopodifolia (73). Physachenolide B (133) has a 28-hydroxy group while physachenolide E (136) is a $\Delta^{14}$-withanolide. The aerial parts of Physalis coztomatl, also collected in Mexico,

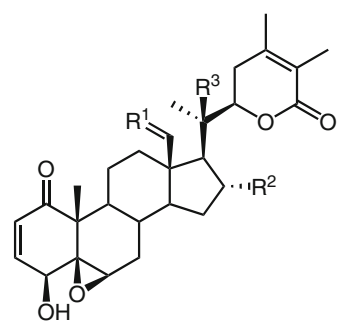

$128 \mathrm{R}^{1}=\mathrm{H}, \mathrm{OH}, \mathrm{R}^{2}=\mathrm{H}, \mathrm{R}^{3}=\mathrm{OH}$

(18-hydroxywithanolide $\mathrm{D}$ )

$129 \mathrm{R}^{1}=\mathrm{H}, \mathrm{OH}, \mathrm{R}^{2}=\mathrm{R}^{3}=\mathrm{H}$

$130 \mathrm{R}^{1}=\mathrm{O}, \mathrm{R}^{2}=\mathrm{OH}$

$131 \mathrm{R}^{1}=\mathrm{H}, \mathrm{OAc}, \mathrm{R}^{2}=\mathrm{OAc}, \mathrm{R}^{3}=\mathrm{H}$

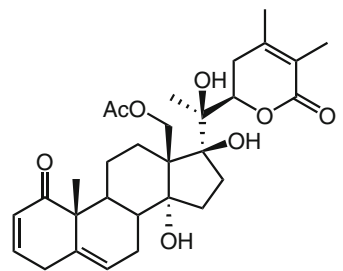

135 (physachenolide D)

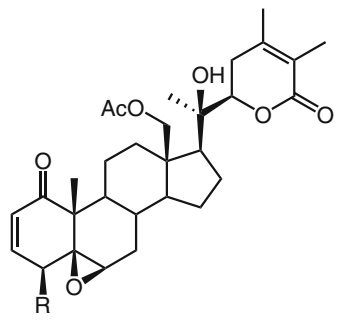

$139 \mathrm{R}=\mathrm{H}$ (physacoztolide $\mathrm{C}$ )

$142 \mathrm{R}=\mathrm{OH}$ (18-acetoxywithanolide $\mathrm{D})$

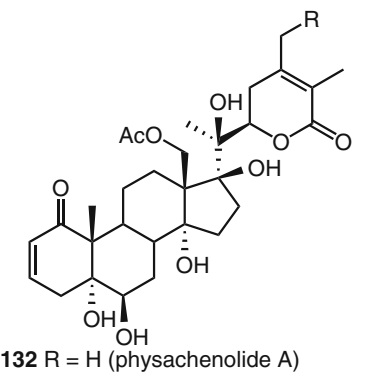

$133 \mathrm{R}=\mathrm{OH}$ (physachenolide $\mathrm{B}$ )

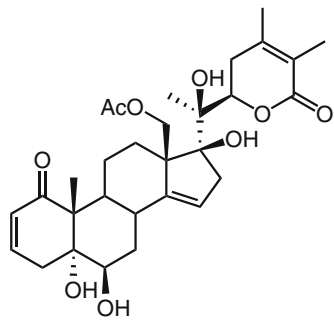

136 (physachenolide E)

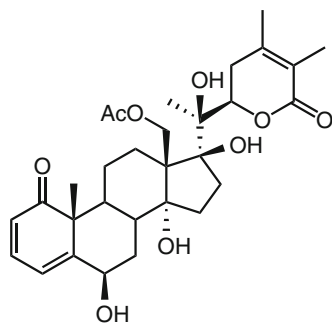

140 (physacoztolide D)

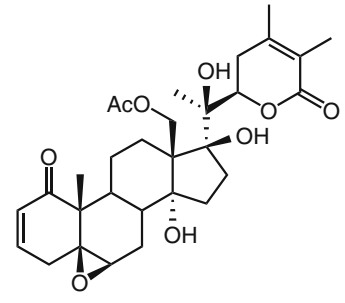

134 (physachenolide C)

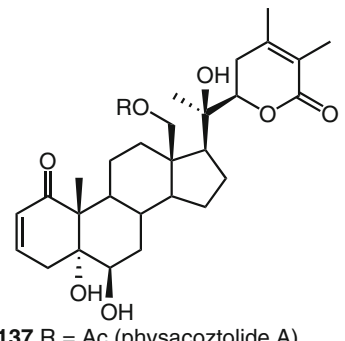
$138 \mathrm{R}=\mathrm{H}$ (physacoztolide $\mathrm{B}$ )<smiles>CC(=O)OC[C@]12CCC3C(CC=C4CC=CC(=O)[C@@]43C)[C@@]1(O)CC[C@@H]2[C@](C)(O)C1CC(C)=C(C)C(=O)O1</smiles>

141 (physacoztolide E) 
rendered five new withanolides functionalized at $\mathrm{C}-18$, the physacoztolides A-E (137-141), together with physachenolide C (134), 18-acetoxywithanolide D (142), and 18-hydroxywithanolide D (128) (74).

\subsubsection{C-12 and C-21 Oxygenated Withanolides}

Withanolides with a free hydroxy or keto group at C-12 are mostly restricted to the Datura genus. In the genus Jaborosa, 12-ketowithanolides are most probably involved as precursors in the formation of additional rings with the side chain, giving rise to several modified skeletons (see Sect. 5.9.). However, only two withanolides with unmodified skeletons containing a free ketone at $\mathrm{C}-12$ have been reported from these plants, (-)-jaboromagellonine (143) from $J$. magellanica (75) and jaborosalactone 44 (144) from J. kurtzii (76). Four new 12-oxygenated withanolides were isolated from plants of Datura ferox collected in Argentina, together with other known daturalactones. 15 $\beta$-Hydroxynicandrin B (145) was found to have the common $5 \alpha$-hydroxy- $6 \alpha, 7 \alpha$-epoxy substitution pattern in ring B (see Sect. 4.1.2.) (77), while daturalactones 5-7 (146-148) exhibit related arrangements resulting from hydrolytic cleavage of the epoxide or rearrangement of the epoxyalcohol (78). The $12 \beta$-epimer of 145, baimantuololine A (149) (79) and the closely related glycosides baimantuoluosides A-C (150-152) (80), were isolated from the dry flowers of Datura metel (used in Chinese medicine). The $1 \beta$-alcohol $\mathbf{1 5 3}$ from Datura quercifolia collected in India is closely related to the compounds mentioned above (81). 12-Oxygenated withanolides have also been reported from the stem bark of the Ethiopian shrub Discopodium penninervium (154) (82), from Iochroma gesneroides (155) (72), and from Acnistus arborescens (156) (83), with the latter two compounds bearing a $12 \beta$-acetoxy group.

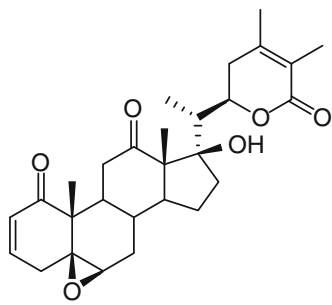

143 ((-)jaboromagellonine)

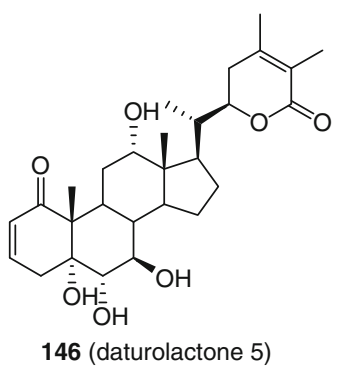

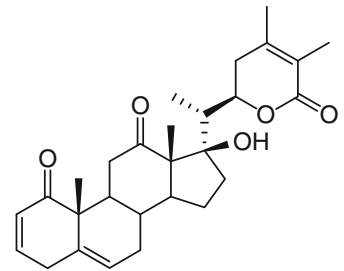

144 (jaborosalactone 44)

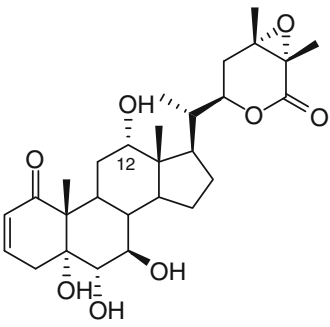

147 (daturolactone 6)

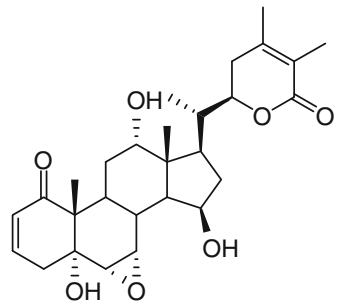

145 (15 $\beta$-hydroxynicandrin B)<smiles>CC1=C(C)C(=O)O[C@@H]([C@H](C)[C@H]2CCC3C4C(CC(=O)[C@]32C)[C@@]2(C)C(=O)C=CC[C@]2(O)[C@H](O)[C@H]4O)C1</smiles>

148 (daturolactone 7) 


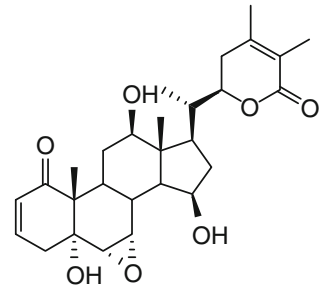

149 (baimantuoluoline A)

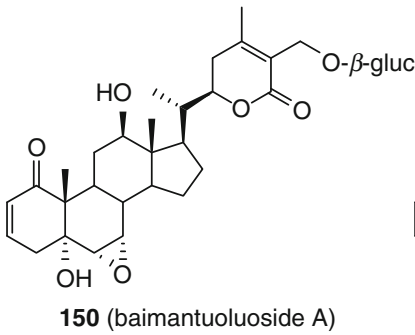

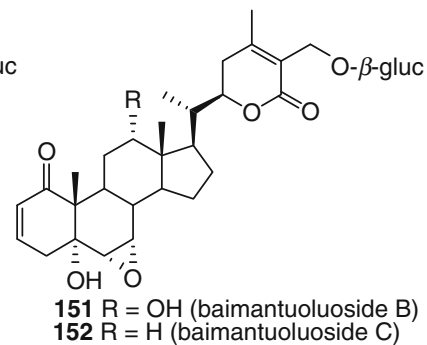

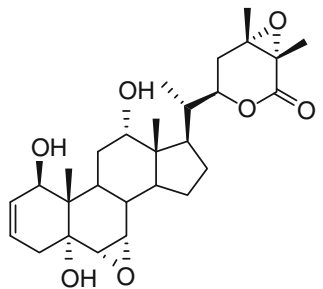

153<smiles>CC1=C(C)C(=O)[C@@H](C2CCC3C4CC=C5CC=CC(=O)C5(C4)C3CC2O)OC1=O</smiles>

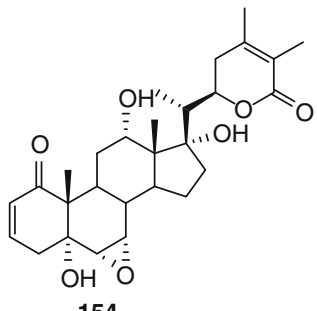

154

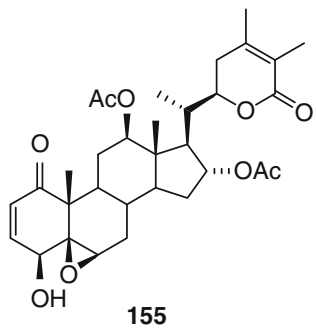

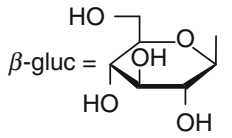

From Dunalia brachyacantha collected in Bolivia, Bravo et al. isolated the glycosides dunawithanine $\mathrm{G}$ (157) and dunawithanine H (158) (84), closely related to the known dunawithanine F (159) (85).

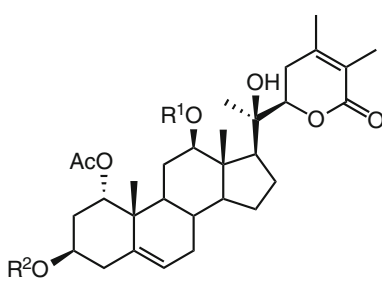

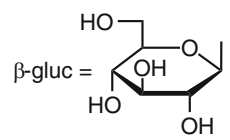

$157 R^{1}=A c, R^{2}=$

(dunawithanine $\mathrm{G}$ )

$158 R^{1}=H, R^{2}=$

(dunawithanine $\mathrm{H}$ )

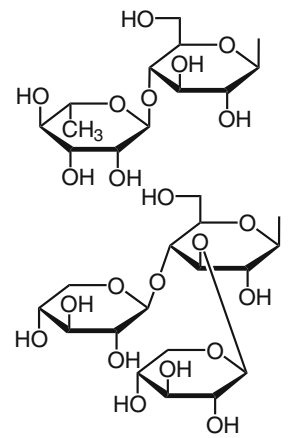

$159 R^{1}=H, R^{2}=\beta$-gluc(1-3)-[ $\beta$-gluc(1-4)]- $\beta$-gluc(dunawithanine $\mathrm{F}$ ) 
Outside the Solanaceae, most withanolides from Tacca species bear a $12 \alpha$ acetoxy group. Tacca species originate in the tropical and subtropical regions, mostly in Asia and Africa. They contain highly oxygenated withanolides, usually with modified skeletons (see Sect. 5.4.4.) characterized by a $1 \alpha$-acetoxy group and a $2 \alpha, 3 \alpha$-epoxide in ring $\mathrm{A}$, although several have been reported with the unmodified parent skeleton. From the rhizomes of Tacca chantrieri, Yokosuka et al. isolated two glycosides, chantriolides A (160) and B (161), with a glucose unit at C-27 (86). From Tacca plantaginea, Liu et al. isolated plantagiolides A-E (162-166) (87). Tacca species are also rich in glycosidated sterols not included in this review; the withanolide $\mathbf{1 6 7}$ with a steroid nucleus that resembles a sterol was also isolated from the rhizomes of $T$. chantrieri (88).
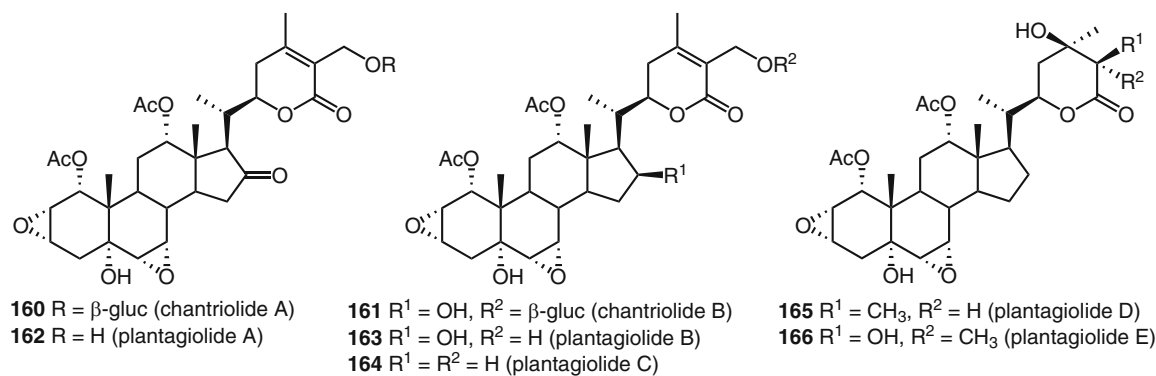

$163 \mathrm{R}^{1}=\mathrm{OH}, \mathrm{R}^{2}=\mathrm{H}$ (plantagiolide $\mathrm{B}$ )

$165 \mathrm{R}^{1}=\mathrm{CH}_{3}, \mathrm{R}^{2}=\mathrm{H}$ (plantagiolide $\mathrm{D}$ ) $166 \mathrm{R}^{1}=\mathrm{OH}, \mathrm{R}^{2}=\mathrm{CH}_{3}$ (plantagiolide $\mathrm{E}$ )

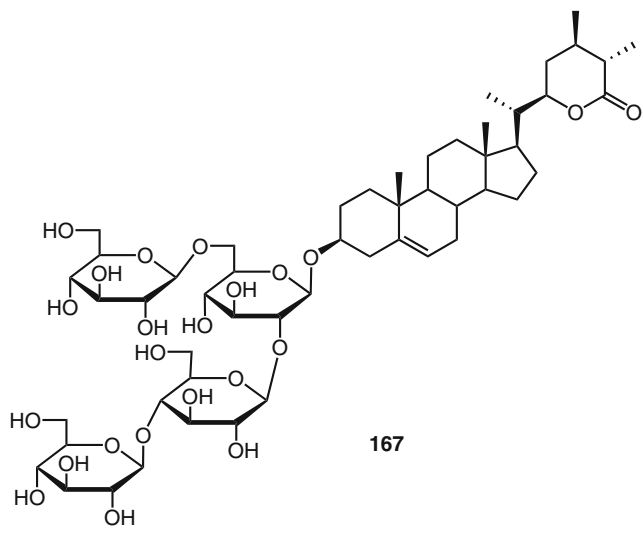

Although 21-oxygenated withanolides are present in Datura, Jaborosa, and Tacca species, 21-hydroxywithanolides with an unmodified skeleton have only been reported in the genus Datura, in many cases combined with a $12 \beta$-hydroxy group. Withafastuosin D (168) is the major withanolide of D. metel var. fastuosa (synonym D. fastuosa), and was isolated from the leaves together with withafastuosin E (169) (89); withafastuosin F (170) was isolated from the flowers of the plant (90). Withametelin $\mathrm{H}$ (171) isolated from the leaves of $D$. metel has the unusual feature of a methoxy group at C-27 (91). From flowers of D. metel, Pan et al. isolated the 27-glycoside withametelin P (172) (92) and Yang et al. 
isolated baimantuoluolines $\mathrm{C}, \mathrm{B}$, and $\mathrm{F}$ (173-175), with the former also having a 27-methoxy group $(79,93)$. It should be noted that the name "withametelin" is usually reserved for withanolides possessing an oxygen bridge between C-21 and C-24 (see Sect. 5.1.1.), and 21-hydroxywithanolides are the most probable biosynthetic precursors of these compounds. Another five 21-hydroxywithanolides, withatatulin (176) (94) and withatulins B-E (177-180), were isolated by Ray and coworkers from D. stramonium var. tatula (synonym D. tatula), which grows in the sub-Himalayan tracts of India and is often cultivated as an ornamental plant $(95,96)$.
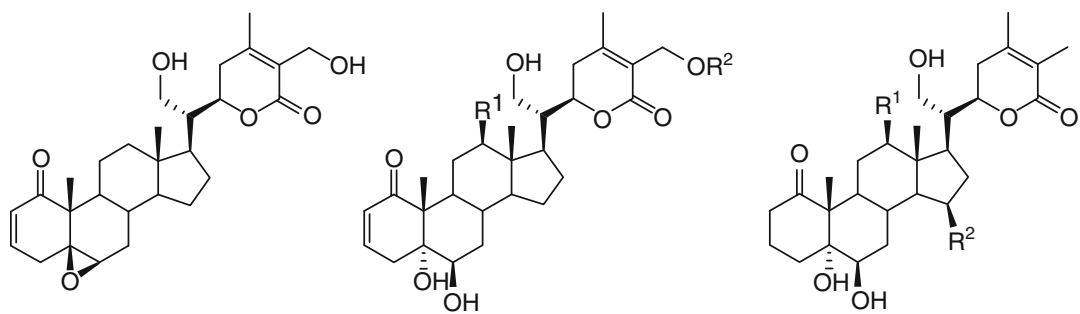

168 (withafastuosin D)

$169 \mathrm{R}^{1}=\mathrm{H}, \mathrm{R}^{2}=\mathrm{H}$ (withafastuosin $\mathrm{E}$ ) $174 \mathrm{R}^{1}=\mathrm{H}, \mathrm{R}^{2}=\mathrm{OH}$ (baimantuoluoline B) $170 \mathrm{R}^{1}=\mathrm{OH}, \mathrm{R}^{2}=\mathrm{H}$ (withafastuosin $\mathrm{F}$ ) $175 \mathrm{R}^{1}=\mathrm{OH}, \mathrm{R}^{2}=\mathrm{H}$ (baimantuoluoline $\mathrm{F}$ ) $171 \mathrm{R}^{1}=\mathrm{H}, \mathrm{R}^{2}=\mathrm{CH}_{3}$ (withametelin $\mathrm{H}$ ) $172 \mathrm{R}^{1}=\mathrm{H}, \mathrm{R}^{2}=\beta$-gluc (withametelin $\mathrm{P}$ ) $173 \mathrm{R}^{1}=\mathrm{OH}, \mathrm{R}^{2}=\mathrm{CH}_{3}$ (baimantuoluoline $\mathrm{C}$ )

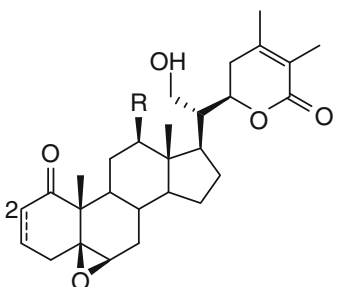

$176 \mathrm{R}=\mathrm{H}$ (withatatulin) $177 \mathrm{R}=\mathrm{OH}, \Delta^{2}$ (withatatulin $\mathrm{B}$ ) $180 \mathrm{R}=\mathrm{H}, \Delta^{2}$ (withatatulin $\mathrm{E}$ )<smiles>CC1=CC[C@@H]([C@H](CO)[C@H]2CCC3C4C[C@H](O)C5=CC=CC(=O)[C@]5(C)C4C[C@H](O)[C@@]32C)OC1=O</smiles>

178 (withatatulin C)<smiles>CC1=C(C)C(=O)O[C@@H]([C@H](CO)[C@H]2CCC3C4C[C@H](O)[C@]5(O)CC=CC(=O)[C@]5(C)C4C[C@H](O)[C@@]32C)C1</smiles>

179 (withatatulin D)

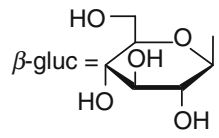

\subsubsection{Other Hydroxylated Withanolides}

Besides those already mentioned above, several other 16-oxygenated withanolides have been reported. Exodeconolides A-C (181-183) were isolated from Exodeconus maritimus collected in Peru (97), the 16-acetates 184 and $\mathbf{1 8 5}$ were reported from Acnistus arborescens collected in Brazil (98), $16 \alpha$-acetoxyhyoscyamilactol (186) from the seeds of Hyoscyamus niger used in 
Chinese medicine (99), $\mathbf{1 8 7}$ from Dunalia brachyacantha collected in Argentina (71), 188-190 from the leaves of Discopodium penninervium (100), and virginols A (191) and C (192) from Physalis virginiana (101). Virginol B (193) was also reported from $P$. virginiana (101) and $\mathbf{1 9 4}$ was isolated from the roots of D. penninervium (102). The known withaphysacarpin (195) and its 3-methoxy derivative, 196, with a $16 \beta$-hydroxy group, were isolated from the fruits of Physalis philadelphica and the configuration of the lactone methyl groups was established as shown, for both compounds (103). LC-MS analysis of an ethyl acetate extract of the plant suggested that $\mathbf{1 9 6}$ may occur naturally although in minor amounts, being generated to a larger extent as a result of the extraction procedure. From leaves and stems of $P$. philadelphica, Kinghorn and coworkers isolated philadelphicalactones A and B $(\mathbf{1 9 7}, \mathbf{1 9 8})$ and compound 199, all of them with a saturated $\delta$-lactone side chain $(104,105)$.<smiles>[R7]C1CC2C3C(=O)C4(O)CC=CC(=O)[C@@]4(C)C3CCC2(C)C1=C(C)[C@H]1CC(C)=C(C)C(=O)O1</smiles>

$181 \mathrm{R}^{1}=\mathrm{OH}, \mathrm{R}^{2}=\mathrm{H}$ (exodeconolide $\left.\mathrm{A}\right)$ $182 \mathrm{R}^{1}=\mathrm{H} ; \mathrm{R}^{2}=\mathrm{OH}$ (exodeconolide $\left.\mathrm{B}\right)$

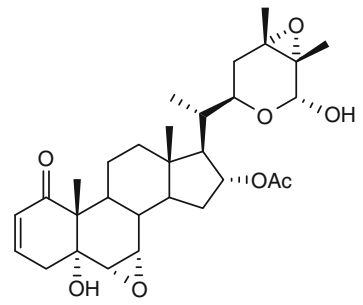

186 (16 $\alpha$-acetoxyhyoscyamilactol)

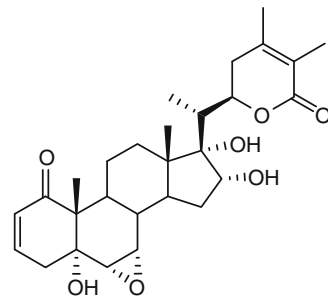

183 (exodeconolide C)

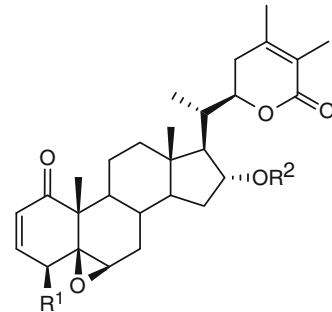

$187 \mathrm{R}^{1}=\mathrm{OH}, \mathrm{R}^{2}=\mathrm{H}$ $188 R^{1}=H, R^{2}=A C$

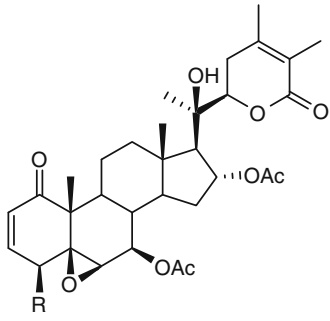

$184 \mathrm{R}=\mathrm{OH}$ $185 \mathrm{R}=\mathrm{H}$<smiles></smiles>

$189 \mathrm{R}=\mathrm{AC}$ $190 \mathrm{R}=\mathrm{H}$

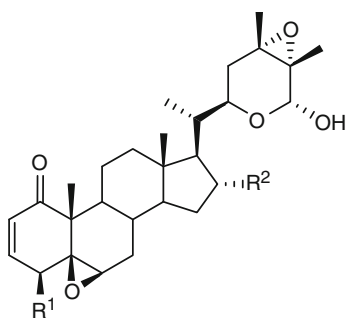

$191 \mathrm{R}^{1}=\mathrm{OH}, \mathrm{R}^{2}=\mathrm{OAc}$ (virginol A) $192 R^{1}=H, R^{2}=$ OAc (virginol C) $193 \mathrm{R}^{1}=\mathrm{OH}, \mathrm{R}^{2}=\mathrm{H}$ (virginol $\left.\mathrm{B}\right)$<smiles>CC1=C(C)C(=O)O[C@H]([C@H](C)[C@]2(O)CCC3C4C(CC[C@@]34C)[C@@]3(C)C(=O)C=CC[C@]3(O)C[C@H]2O)C1</smiles> 


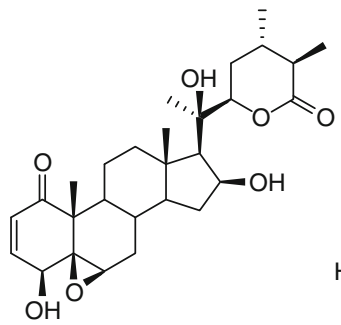

195 (withaphysacarpin)

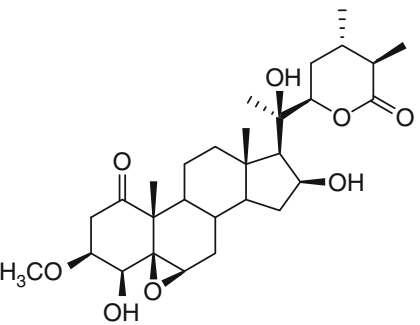

196

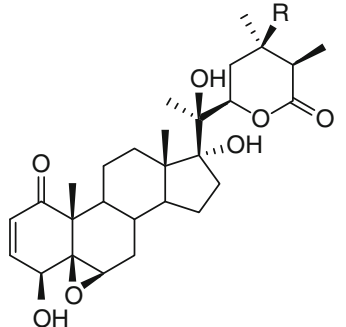

$197 \mathrm{R}=\mathrm{H}$ (philadelphicalactone $\mathrm{A})$ $198 \mathrm{R}=\mathrm{OH}$ (philadelphicalactone $\mathrm{B})$<smiles>CC1C(=O)OC([C@](C)(O)[C@H]2CCC3C4C(O)C=C5C(O)C=CC(=O)[C@@]5(C)C4CC[C@@]32C)C[C@@H]1C</smiles><smiles>CC1=CCC[C@@]2(O)CC(=O)C3C4CC[C@H]([C@H](C)C5C[C@H](C)[C@@](C)(O)[C@@H](O)O5)[C@]4(C)CCC3[C@]12O</smiles>

A 24,25-diol related to Nic-3 was reported from Larnax glabra (106), but, however, comparison of the NMR data indicates that this compound (larnaxolida $A$ ) is actually Nic-3 (200) (3). An epimer at C-5 was also reported (larnaxolida B), but the spectroscopic data do not correspond to the proposed structure.

Tubocapsanolides A (201), D (202), and F (203) and the 20-hydroxy and the 23hydroxy derivatives of tubocapsanolide A 204 and 205 were isolated from Tubocapsicum anomalum (107). From Ajuga bracteosa collected in the north of Pakistan, Malik and coworkers isolated two 28-hydroxywithanolides, bracteosins A (206) and B (207), with C-19 in the latter compound oxidized to a carboxylic acid, and bracteosin $\mathrm{C}$ (208) (108). As in previous cases, these compounds probably derive from the corresponding $\Delta^{2}$-1-ketones, upon reaction with methanol during their isolation.

From the aerial parts of Datura metel collected in China, Ma et al. isolated three new 27-glycosides, daturametelins H, I, and J (209-211), together with the known daturataturin A (212) and the aglycone 213 (109). The closely related 7-acetate 214 was isolated from Iochroma gesneroides (72).

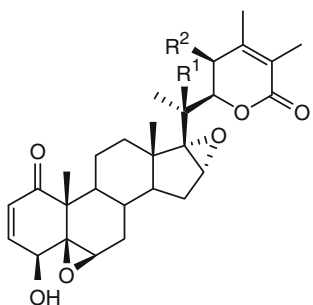

$201 R^{1}=R^{2}=H$ (tubocapsanolide $\left.A\right)$

$204 \mathrm{R}^{1}=\mathrm{OH}, \mathrm{R}^{2}=\mathrm{H}$

$205 \mathrm{R}^{1}=\mathrm{H}, \mathrm{R}^{2}=\mathrm{OH}$

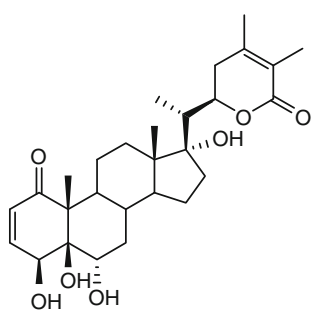

202 (tubocapsanolide D)

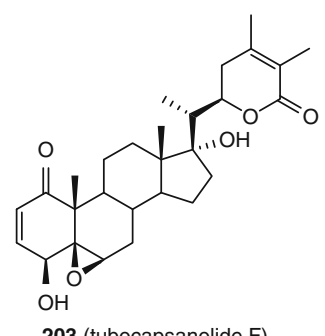

203 (tubocapsanolide F) 


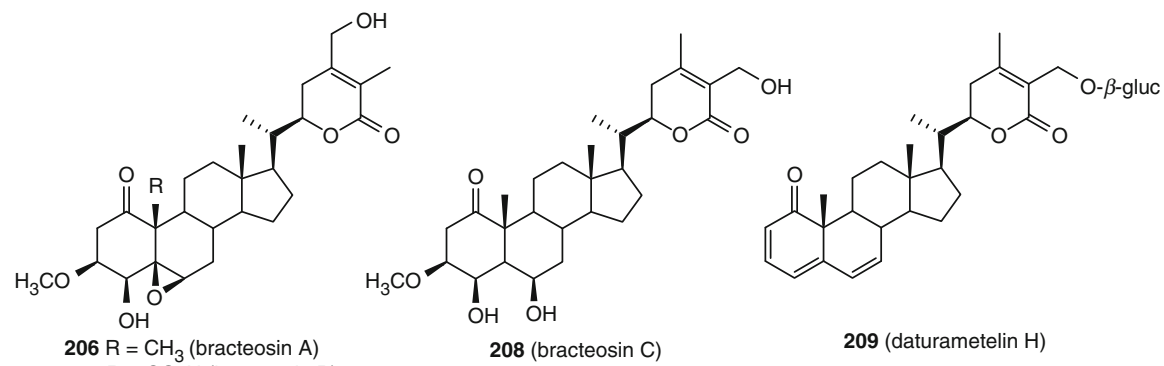

$207 \mathrm{R}=\mathrm{CO}_{2} \mathrm{H}$ (bracteosin $\left.\mathrm{B}\right)$

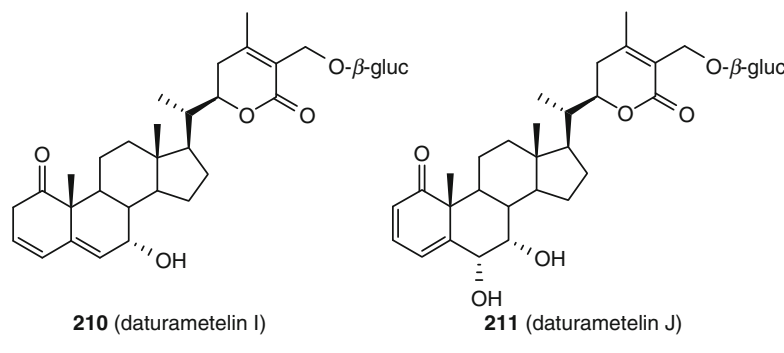<smiles>[R7]CC1=C(C)C[C@@H]([C@H]2CC[C@H]3[C@H]4[C@H](CC[C@@]23C)[C@]2(C)C(=O)C=CCC2=C[C@@H]4O)OC1=O</smiles><smiles>CC(=O)O[C@H]1C=C2[C@@H](O)C=CC(=O)[C@]2(C)C2CC[C@]3(C)C(CC[C@H]3[C@H](C)C3CC(C)=C(CO)C(=O)O3)C21</smiles>

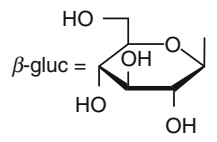

\subsubsection{Cilistols and Related Withanolides}

Nohara and coworkers investigated Solanum ciliatum (synonym Solanum cilistum) and isolated a series of withanolides with a $\delta$-lactol side chain, which included several $\Delta^{5}-3 \beta$-O-sulfates and 6-substituted 3,5-cyclowithanolides. Variations at the side chain comprise a 24,25-epoxide or the corresponding 24,25-diol from hydrolytic cleavage, 26- $O$-glycosides, or reaction products of the epoxide or the hemiketal with methanol. Cilistols a, b, d, q, g, and f (215-220) contain a $\Delta^{2,5}-1$-ketone in rings $\mathrm{A} / \mathrm{B}$, and the latter two compounds (with the cleaved epoxide) exist as equilibrium mixtures of the epimeric $\mathrm{C}-26$ hemiketals (110). The C-26 glycosides, cilistols t, I, and j (221-223) present a $\Delta^{5}-1 \alpha, 3 \beta$-diol arrangement in rings $\mathrm{A} / \mathrm{B}$ and cilistols $\mathrm{y}$ (224) and $\mathrm{w}$ (225) have the unusual feature of a $3 \beta$-O-sulfate group (111). The 3,5-cyclosteroid moiety found in cilistols u, p, pm, and p1 (226-229) (112) has no precedent among natural products but is easily formed from $\Delta^{5}$-steroids with a good leaving group at C-3 
(e.g. a sulfate); this rearrangement occurs even under very mild conditions (traces of methanol or water in the extraction or purification solvents may be enough), thus the assumption that these compounds are natural products should be taken with caution. The ergostane glycoside, cilistol v (230), or a closely related sterol, is probably the biosynthetic precursor of cilistols in this plant (111). Cilistepoxide (231) and cilistediol (232) are two closely related withanolides isolated from Solanum sisymbriifolium collected in Brazil (113).

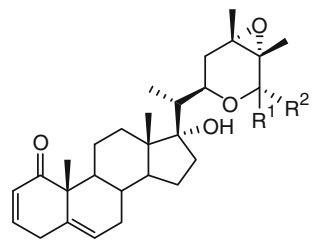

$215 \mathrm{R}^{1}=\mathrm{H}, \mathrm{R}^{2}=\mathrm{OH}$ (cilistol a) $216 \mathrm{R}^{1}=\mathrm{OCH}_{3}, \mathrm{R}^{2}=\mathrm{H}$ (cilistol b)

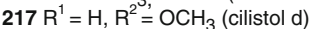
$218 \mathrm{R}^{1}=\mathrm{H}, \mathrm{R}^{2}=\mathrm{O}-\beta$-gluc (cilistol q)

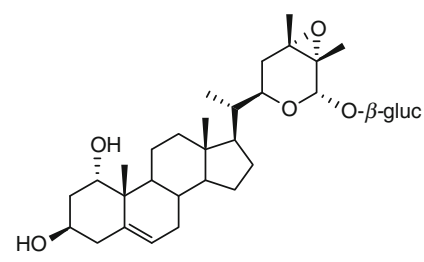

221 (cilistol t)

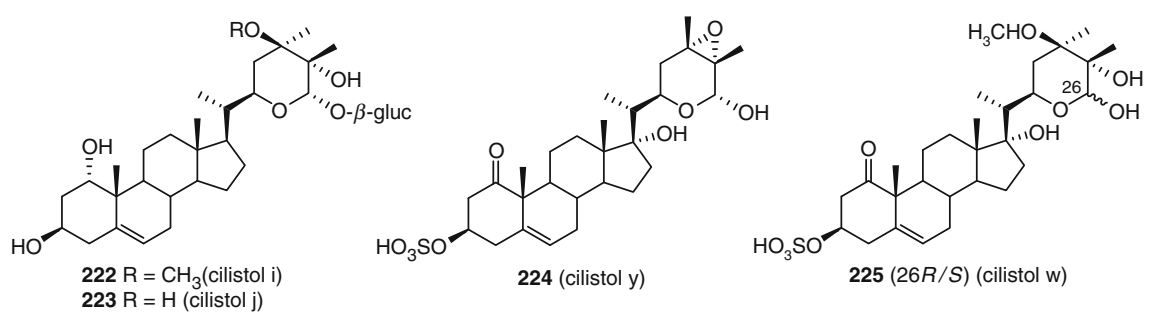

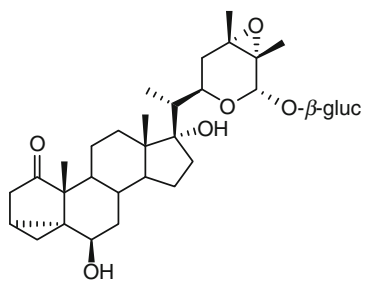

226 (cilistol u)

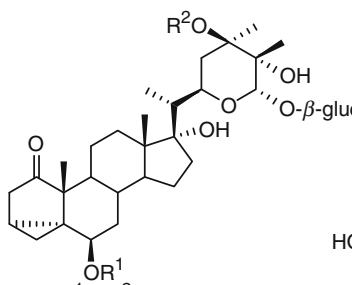

$227 R^{1}=R^{2}=H$ (cilistol p) $228 \mathrm{R}^{1}=\mathrm{CH}_{3}, \mathrm{R}^{2}=\mathrm{H}$ (cilistol pm) $229 \mathrm{R}^{1}=\mathrm{R}^{2} \stackrel{3}{=} \mathrm{CH}_{3}$ (cilistol p1)

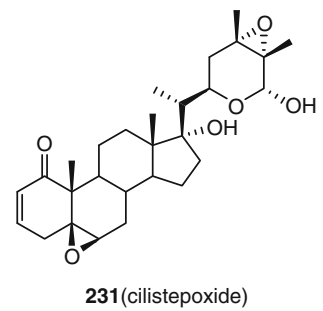

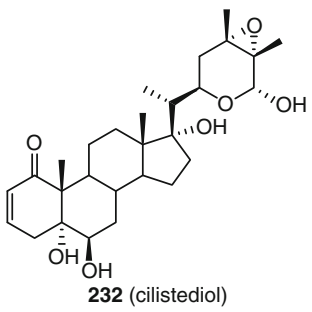

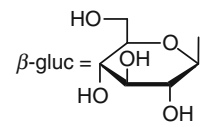




\section{Withanolides with Modified Skeletons}

A large number of withanolides with structures that depart from the classical withaferin A (1) parent structure are known nowadays. Modifications usually found are additional rings formed by direct $\mathrm{C}-\mathrm{C}$ bonds, cyclic ethers and hemiketals, or lactones that may involve carbons from the steroid nucleus or from the side chain. Other modifications include formation of seco-steroids (as in physalins), a rearranged steroid nucleus, aromatic rings, and lack of an angular methyl as among the most important. One particularly interesting example is that present in a $\mathrm{C}_{29}$ withanolide from the bark of Eucalyptus globulus (233) that has an ethyl substituent at C-25 instead of the usual methyl group (114).

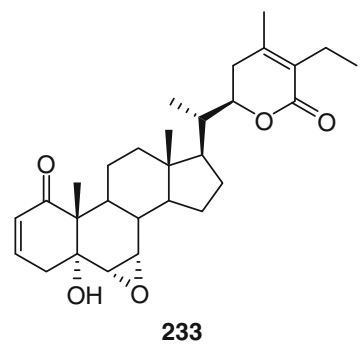

\subsection{Withanolides with Additional Rings Involving C-21}

Carbon-21 may participate in additional rings by forming either direct $\mathrm{C}-\mathrm{C}$ bonds or ether bridges with other carbons in the side chain or in the steroid nucleus. Several new withanolide types with these arrangements have been reported.

\subsubsection{Withametelins and Sativolides}

Withametelin (234) exhibits an oxygen bridge between C-21 and C-24 resulting in a bicyclic side chain; it was isolated by Ray and coworkers from the dried leaves of Datura metel (3). Several withanolides with this functionality were subsequently isolated; some have also been named as withafastuosins, daturametelins, and baimantuoluolines on different occasions. The flowers of D. metel, used for centuries in traditional Chinese medicine, have been shown to contain several withametelins. Pan et al. isolated the $12 \beta$-hydroxylated derivatives withametelins I-M (235-239), together with withametelins $\mathrm{N}$ (240) and O (241), and the secowithametelins 242 and 243 (92). Also from the dry flowers, Yang et al. isolated baimantuoluolines D (244) and E (245) (93). The closely related structures withametelinone (246), withametelinol (247), withametelinols A (248) and B (249), witharifeen (250), and daturalicin (251) were isolated by Siddiqui et al. 
from the aerial parts of Datura inoxia collected in Pakistan (115-117). Daturacin (252) was reported also from $D$. inoxia as the first withanolide with a (22S) configuration based on a negative Cotton effect at $249.4 \mathrm{~nm}$ (118). The proposed configuration inversion at C-22 and C-24 compared to other withametelins (92), would require $\mathrm{H}-20$ to occupy an axial instead of equatorial position. However, the almost perfect coincidence of the ${ }^{1} \mathrm{H}$ and ${ }^{13} \mathrm{C}$ NMR data of the side chain with those of other "normal" withametelins and the assignment of the configuration at C-5 based exclusively on $\mathrm{CD}$ data, suggest that this structure should be extensively revised.

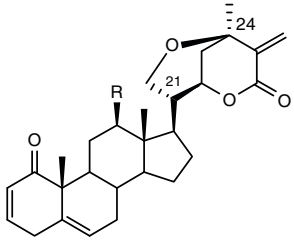

$234 \mathrm{R}=\mathrm{H}$ (withametelin) $238 \mathrm{R}=\mathrm{OH}$ (withametelin $\mathrm{L}$ )

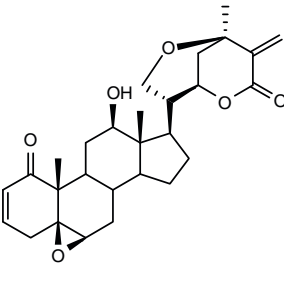

235 (withametelin I)

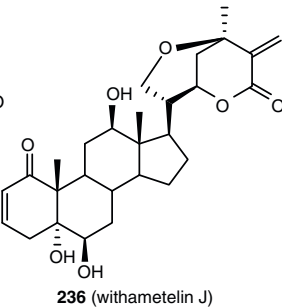

236 (withametelin J)

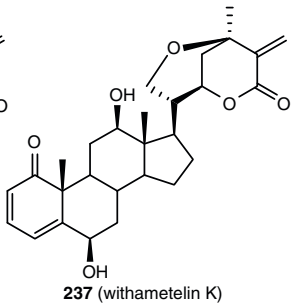

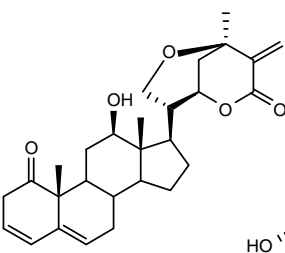

239 (withametelin M)

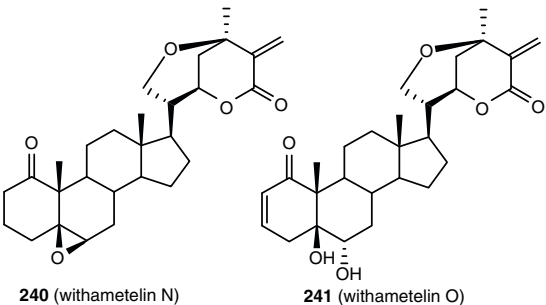

241 (withametelin O)

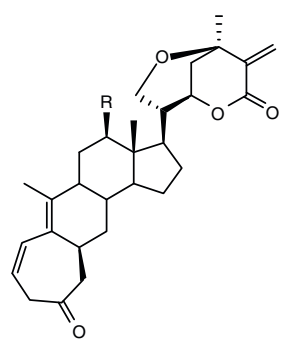

$242 \mathrm{R}=\mathrm{H}$

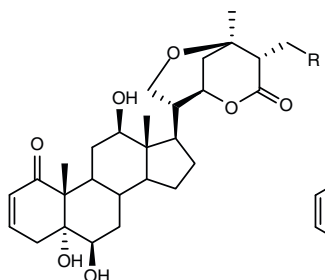

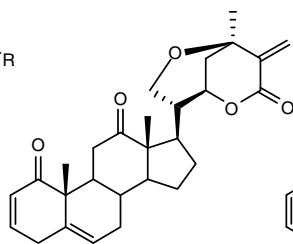

246 (withametelinone)

$244 \mathrm{R}=\mathrm{OCH}_{3}$ (baimantuoluoline $\mathrm{D}$ )

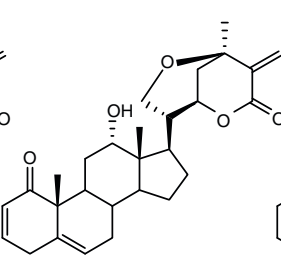

247 (withametelinol)

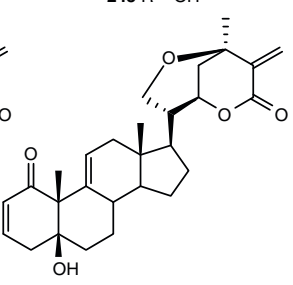

248 (withametelinol A)

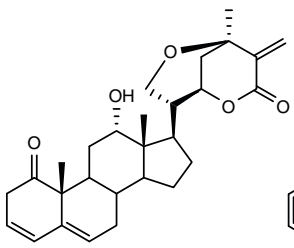

249 (withametelinol B)

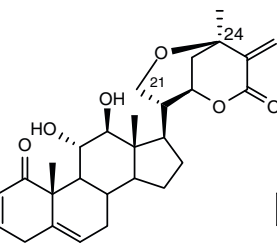

250 (witharifeen)

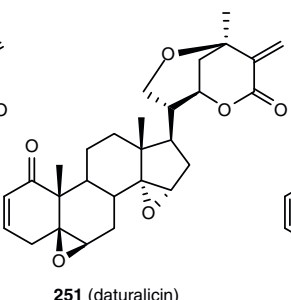

251 (daturalicin)

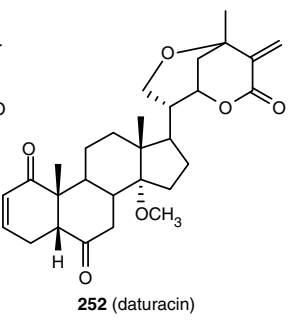


At variance with the above, sativolides have an oxygen bridge between $\mathrm{C}-21$ and $\mathrm{C}-12$ in the steroid nucleus. The additional six-membered hemiketal (or ketal) ring, results from what must have been originally a C-12 ketone and a C-21 hydroxy group. Jaborosalactones R (253), S (254), and T (255), were isolated from Jaborosa sativa (synonym Trechonaetes sativa) collected in Argentina (119). C-12Hemiketals are highly reactive towards simple alcohols (see Sect. 5.4.2.), thus the methyl ketal 255 is probably formed during isolation. Nicotra et al. reported the isomeric clorohydrin, jaborosalactone 37 (256), from Jaborosa rotacea (120). Interestingly, the $\Delta^{2}$-withanolide $\mathbf{2 5 7}$ was present in Jaborosa caulescens var. caulescens (isolated together with the 12-O-methyl derivative) while its 2,3dihydro derivative $\mathbf{2 5 8}$ was present in J. caulescens var. bipinnatifida (121).

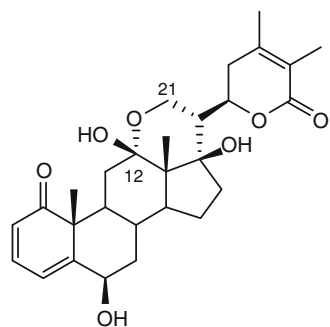

253 (jaborosalactone R)

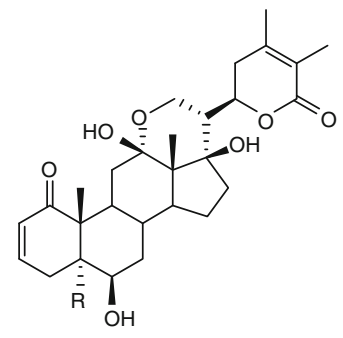

$254 \mathrm{R}=\mathrm{OH}$ (jaborosalactone $\mathrm{S}$ ) $256 \mathrm{R}=\mathrm{Cl}$ (jaborosalactone 37)

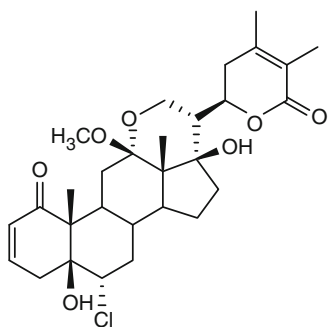

255 (jaborosalactone T)

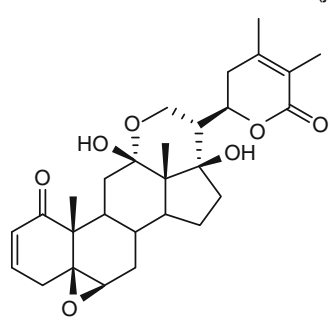

257 (jaborosalactone 38)

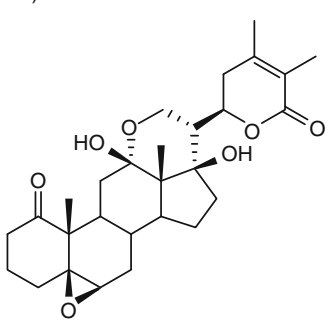

258 (jaborosalactone 39)

\subsubsection{Acnistins}

The acnistins also exhibit a bicyclic side chain involving $\mathrm{C}-21$ and the lactone ring but, at variance with withametelins, $\mathrm{C}-21$ is directly bonded to $\mathrm{C}-24$ via a $\mathrm{C}-\mathrm{C}$ bond instead of an ether bond $(3,4)$. It has been proposed that the 21,24 bond is probably formed via a $\mathrm{SN}_{2}$ type reaction in withanolides having a good leaving group at C-21. The first examples of this family, acnistins A (259) and E (260), were isolated by Usubillaga et al. from plants of Acnistus arborescens (synonym Acnistus ramiflorus) collected in Venezuela, with their stereochemical and spectroscopic assignments later revised by Luis et al. $(122,123)$. Withanolides with this bicyclic side chain have been reported also from Tubocapsicum anomalum (3). Luis and coworkers isolated acnistins A and E, together with the new acnistins B (261), 
C (262), D (263), F (264), G (265), and H (266), from the leaves of Dunalia solanacea collected in Medellin (Colombia) (124-126).

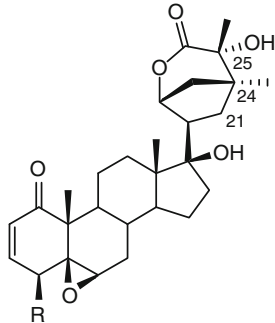

$259 \mathrm{R}=\mathrm{H}$ (acnistin A) $260 \mathrm{R}=\mathrm{OH}$ (acnistin $\mathrm{E})$

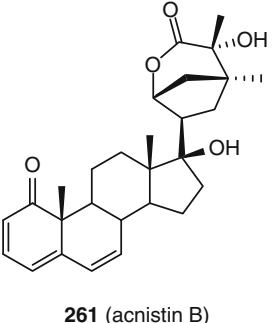

261 (acnistin B)
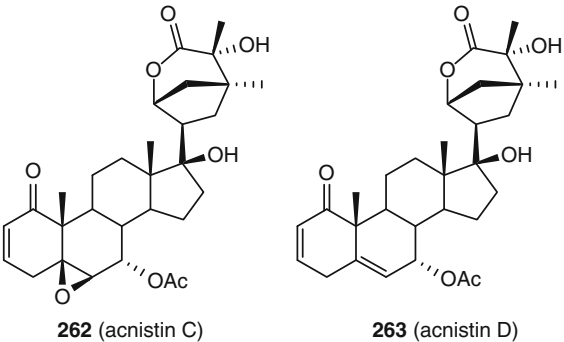
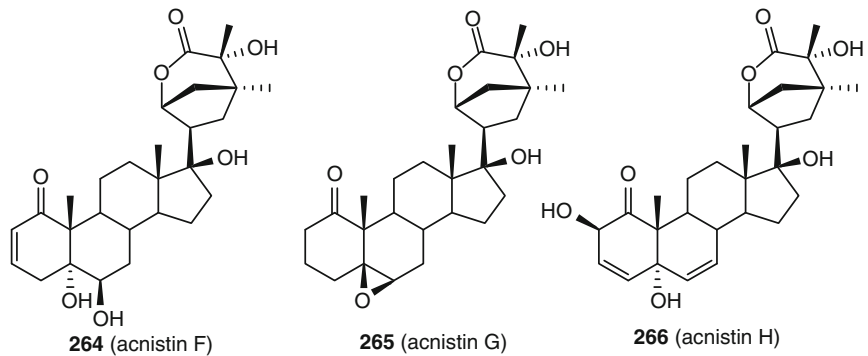

An epimer of acnistin A, 17-epiacnistin A (267) was isolated from Discopodium penninervium collected in Ethiopia (127). Recently, using bioassay-directed fractionation, six new 17-epiacnistins were isolated from Tubocapsicum anomalum collected in Taiwan (107). Anomanolides A (268) and B (269) were identified as the 17-epimer of acnistin $\mathrm{E}$ and the ring $\mathrm{B}$ diol resulting from diequatorial cleavage of the epoxide. Anomanolides C-F (270-273) had an additional 16 $\alpha$-hydroxy substituent. From fruits of $T$. anomalum collected in Japan, Kiyota et al. isolated three acnistin glycosides, isotubocaposides A-C (274-276) with a $1 \alpha, 3 \beta$-dihydroxy substitution pattern in ring A (128). The distinctive feature of these acnistins was an inverted configuration at C-25 as determined by X-ray crystallography.

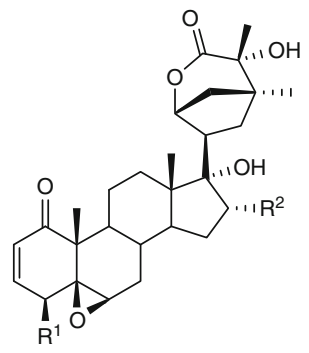

$267 \mathrm{R}^{1}=\mathrm{R}^{2}=\mathrm{H}($ 17-epiacnistin A) $268 \mathrm{R}^{1}=\mathrm{OH}, \mathrm{R}^{2}=\mathrm{H}$ (anomanolide $\left.\mathrm{A}\right)$ $270 \mathrm{R}^{1}=\mathrm{R}^{2}=\mathrm{OH}$ (anomanolide $\mathrm{C}$ )

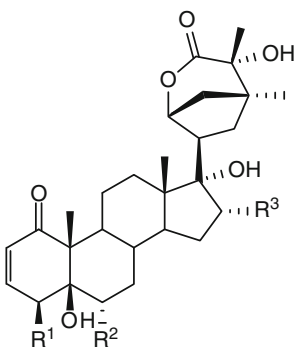

$269 \mathrm{R}^{1}=\mathrm{R}^{2}=\mathrm{OH}, \mathrm{R}^{3}=\mathrm{H}$ (anomanolide $\left.\mathrm{B}\right)$ $271 \mathrm{R}^{1}=\mathrm{R}^{3}=\mathrm{OH}, \mathrm{R}^{2}=\mathrm{Cl}$ (anomanolide $\left.\mathrm{D}\right)$ $272 \mathrm{R}^{1}=\mathrm{H}, \mathrm{R}^{2}=\mathrm{R}^{3}=\mathrm{OH}$ (anomanolide $\mathrm{E}$ ) $273 \mathrm{R}^{1}=\mathrm{R}^{3}=\mathrm{OH}, \mathrm{R}^{2}=\mathrm{H}$ (anomanolide $\mathrm{F}$ ) 

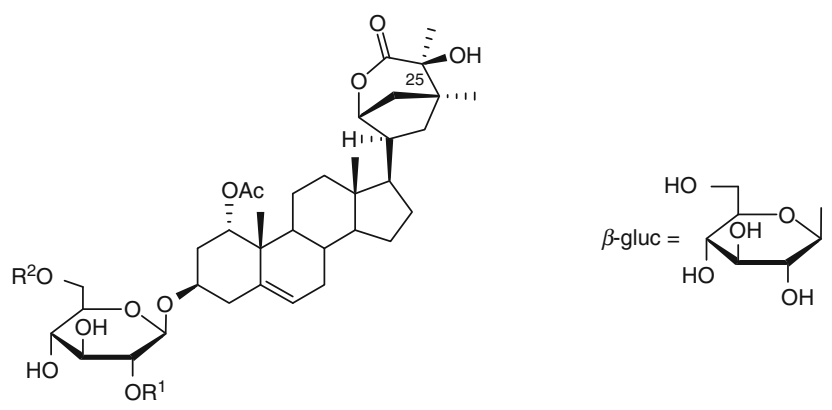

$274 \mathrm{R}^{1}=\mathrm{R}^{2}=\beta$-gluc (isotubocaposide $\mathrm{A}$ )

$275 \mathrm{R}^{1}=\mathrm{H}, \mathrm{R}^{2}=\beta$-gluc (isotubocaposide $\mathrm{B}$ )

$276 \mathrm{R}^{1}=\beta$-gluc, $\mathrm{R}^{2}=\mathrm{H}$ (isotubocaposide $\mathrm{C}$ )

\subsubsection{Withajardins}

In the withajardins, $\mathrm{C}-21$ is directly bonded to $\mathrm{C}-25$ resulting in a bicyclic lactone side chain with a six-membered homocycle. Withajardins A-E (277-281) were isolated from plants of Deprea orinocensis collected in Colombia $(129,130)$. A 16,17-dihydroxylated withajardin, tubonolide A (282), was isolated from the stems and leaves of T. anomalum (107) and the glycosides tuboanosides A and B (283 and 284) from the fruits of this same plant (131). The latter three compounds have an inverted configuration at C-24 compared to the other withajardins, and this was confirmed by X-ray diffraction in the case of tuboanosides A and B (Fig. 4). (It should be noted that in the original publication, the configuration at $\mathrm{C}-20$ in the structure drawing of these compounds is incorrect; the structure shown here was taken from the X-ray data deposited at the Cambridge Crystallographic Data Centre, CCDC). A common precursor has been proposed in the biogenetic routes to acnistins, withajardins, and withametelins; the simultaneous finding of acnistins and withajardins in T. anomalum supports this proposal.

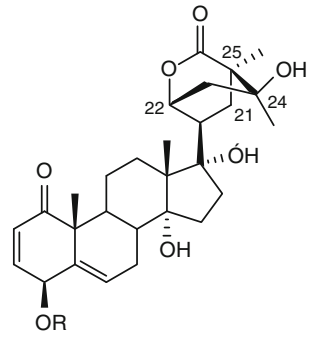

$277 \mathrm{R}=\mathrm{H}$ (withajardin $\mathrm{A}$ ) $280 \mathrm{R}=\mathrm{Ac}($ withajardin $\mathrm{D})$

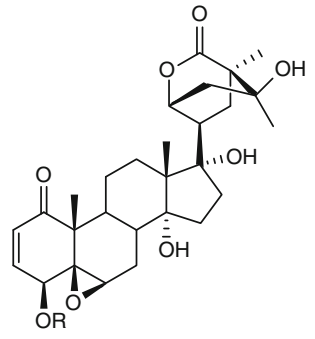

$278 \mathrm{R}=\mathrm{H}$ (withajardin $\mathrm{B}$ ) $279 R=A c$ (withajardin C)

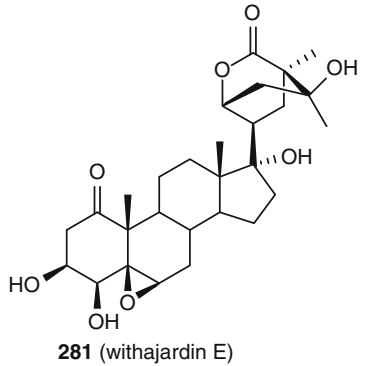

281 (withajardin E) 

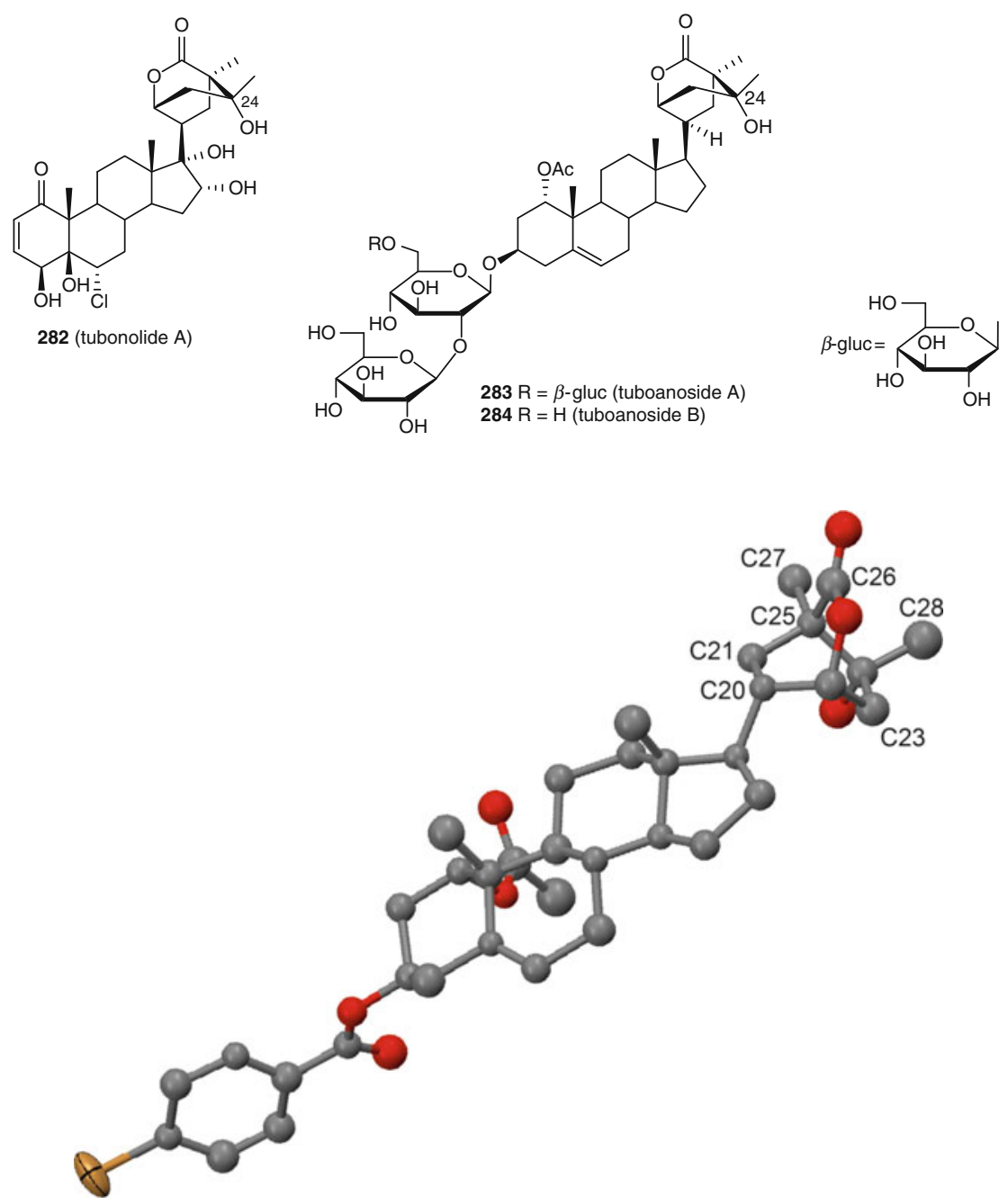

Fig. 4. X-ray crystal structure of the $p$-bromobenzoate of tuboanosigenin (CCDC 680092), aglycone of tuboanosides A (283) and B (284) (131). Structure drawing generated with Mercury 2.3

\subsubsection{5,21-Cyclowithanolides (Norbornane Type)}

Nicotra et al. reinvestigated Jaborosa bergii and isolated five new withanolides with a carbon-carbon bond between $\mathrm{C}-15$ and $\mathrm{C}-21$, resulting in a novel norbornane-type structure in ring D (69). Jaborosalactols 18 (285) and 22 (286) have a $14 \alpha$-hydroxy group while jaborosalactols 19-21 (287-289) contain a 8,14 double bond. $14 \alpha$-Hydroxywithanolides are known to dehydrate easily giving a mixture of $\Delta^{8,14}$ and $\Delta^{14}$ unsaturated derivatives (132), and the finding 
that jaborosalactone 22 (286) spontaneously gave 289 strongly suggests that, in this case, the $\Delta^{8,14}$ unsaturated compounds are artifacts formed during isolation. The bridgehead nature of C-15 would prevent the formation of $\Delta^{14}$ derivatives (69).

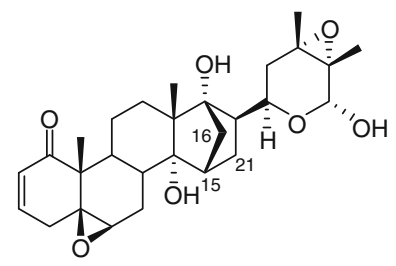

285 (jaborosalactol 18)

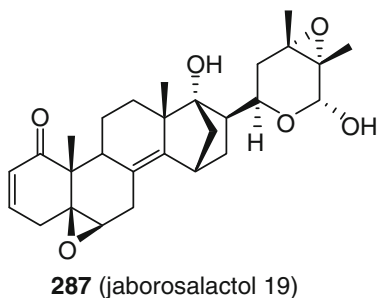

287 (jaborosalactol 19)

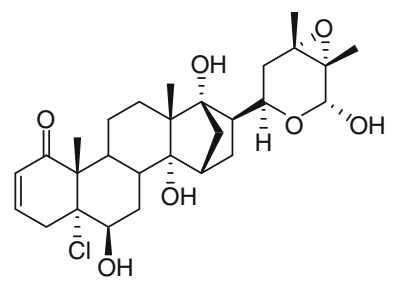

286 (jaborosalactol 22)<smiles>[R6][R8]([H])([H])[H]</smiles>

\subsection{Physalins and Withaphysalins}

The physalins are a group of 13,14-seco-16,24-cycloergostane constituents of certain Physalis species $(3,133)$. In recent years, some known physalins have been found in Brachistus stramoniifolius (physalins B, F, and H) (134), B. hunzikeri (sub nom. Witheringia hunzikeri) (physalin B) (135), Margaranthus solanaceous (sub nom. Physalis solanaceous) (physalins A, B, D, and F) (136), Schraderanthus viscosus (sub nom. Saracha viscosa) (physalins D, F, and H) (137), and Witheringia solanacea (physalins B, D, and F) (138). A total of 22 new physalins have been reported from Physalis species and several structures described previously have been revised. Withaphysalins, with an oxidized $\mathrm{C}-18$ involved in a lactone or lactol ring with C-20 (see Fig. 2), are believed to be the biosynthetic precursors of physalins.

\subsubsection{Normal Physalins}

Fifteen new withanolides with the normal physalin skeleton were isolated from Physalis species, differing in the substitution pattern of rings A and B. From the 
calyces of $P$. alkekengi var. franchetii, Qiu et al. isolated three 3-hydroxy1-ketophysalins (139), the new physalins Y (290) and Z (291) with a $3 \alpha$-oriented hydroxy group, and compound 292 that had NMR data coincident with isophysalin $\mathrm{G}$ previously isolated from the same plant by Sunayama et al., but was not fully characterized (140). NOE correlations of 292 established the $\beta$-orientation for the 3-hydroxy group of isophysalin G. The 3-methoxy analogues 293 and 294 had been isolated previously by the same authors (141). Physalin S (295) isolated from the same plant, had a $6 \beta$-hydroxy-3,5-cyclo arrangement, a common acid rearrangement product of 3-hydroxy- $\Delta^{5}$ steroids (see Sect. 4.2.5.) (142).

Two other physalins from $P$. alkekengi var. franchetii corresponded to the $5 \alpha, 6 \beta$-diol, physalin T (296) (as already mentioned derived from hydrolytic opening of a 5,6-epoxide) (143), and the less common 2,5-endoperoxy- $\Delta^{3}$ arrangement of physalin Q (297) (144). Choudhary et al. isolated the four physalins 298, 299 (60), 300, and 301 (145) from P. minima, the latter three containing a $11 \beta$-hydroxy group. A reduced derivative at $\mathrm{C}-1$, physalin $\mathrm{V}$ (302), was also isolated from P. angulata (146).

Several 3-alkoxy derivatives besides those mentioned above have been reported, but most probably all of these are artifacts formed by reaction of a $\Delta^{2}$-1-ketone with ethanol or methanol during isolation. Thus, the 3-ethoxy derivative $\mathbf{3 0 3}$ isolated from $P$. alkekengi, was found only in trace amounts in the original extract when analyzed by HPLC (67). The 3-methoxy derivative 304 (physalin U) was initially isolated from $P$. minima (60) and later from $P$. angulata (146), while the 3-methoxy derivative 305 was isolated from $P$. angulata (55). The latter compound was named physalin $\mathrm{W}$ although this name had already been assigned to another physalin (see below).

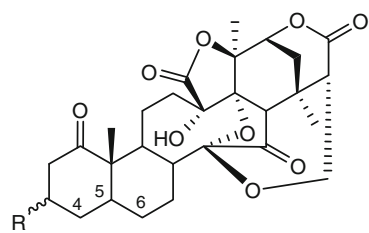

$290 \mathrm{R}=\alpha-\mathrm{OH}, \Delta^{5}$ (physalin $\mathrm{Y}$ ) $291 \mathrm{R}=\alpha-\mathrm{OH}, \Delta^{4,6}$ (physalin Z) $292 \mathrm{R}=\beta-\mathrm{OH}, \Delta^{4,6}$ (isophysalin G) $293 \mathrm{R}=\alpha-\mathrm{OCH}_{3}, \Delta^{4,6}$ $294 \mathrm{R}=\beta-\mathrm{OCH}_{3}, \Delta, 4$

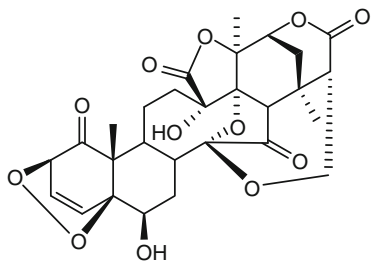

297 physalin Q

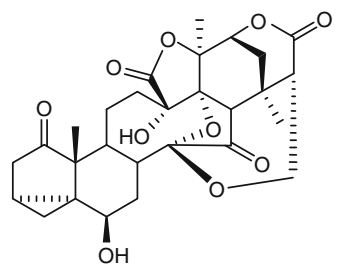

295 (physalin S)

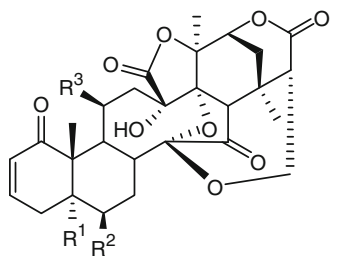

$298 R^{1}=O H, R^{2}=R^{3}=H$ $299 \mathrm{R}^{1}=\mathrm{R}^{2}=\mathrm{R}^{3}=\mathrm{OH}$ $300 \mathrm{R}^{1}=\mathrm{OCH}_{3}, \mathrm{R}^{2}=\mathrm{H}, \mathrm{R}^{3}=\mathrm{OH}$
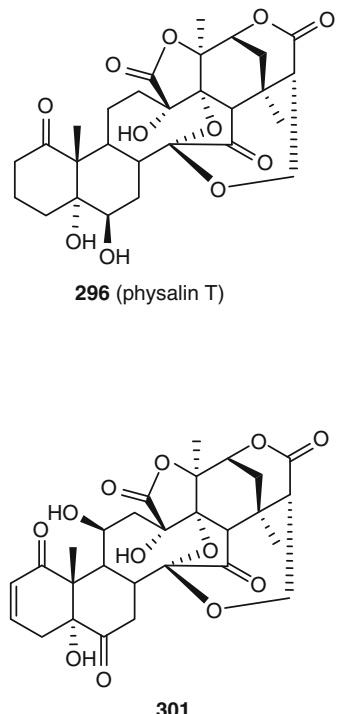

301 


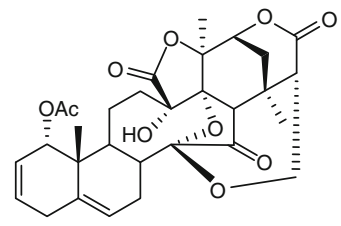

302 (physalin V)

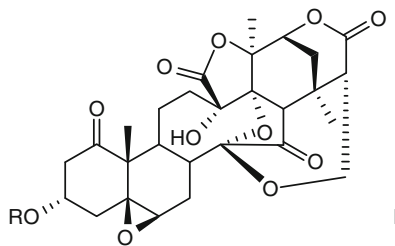

$303 \mathrm{R}=\mathrm{CH}_{2} \mathrm{CH}_{3}$

$304 \mathrm{R}=\mathrm{CH}_{3}$ (physalin $\mathrm{U}$ )

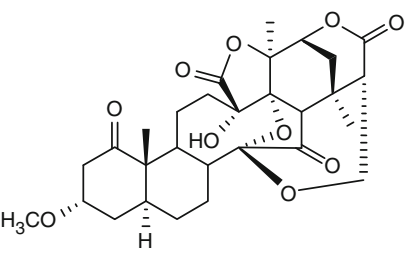

305

\subsubsection{Neophysalins and Cyclophysalins}

Neophysalins have a rearranged skeleton in which C-14 is directly bound to C-16 and the $\mathrm{C}-15$ carbonyl forms a lactone with the oxygen atom at $\mathrm{C}-17$. Four new neophysalins and a 11,16-cyclophysalin were isolated from P. alkekengi var. franchetii. Physalins W (306) and X (307) were initially isolated by Chen et al. (147) and their structures revised by Qiu and coworkers (139). The latter authors also reported the isolation of the 3-methoxy analogues physalin I (308) and physalin II (309). Physalin R (310) is a normal physalin with an additional bond between C-11 and C-16 (142). The authors showed that this cyclophysalin skeleton could be obtained from normal physalins upon irradiation with an halogen-tungsten lamp under argon.

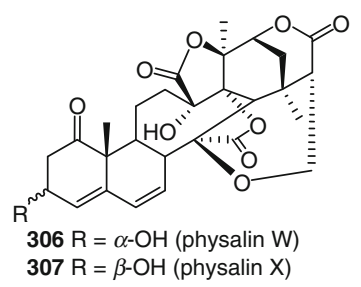

$307 \mathrm{R}=\beta-\mathrm{OH}$ (physalin $\mathrm{X}$ )
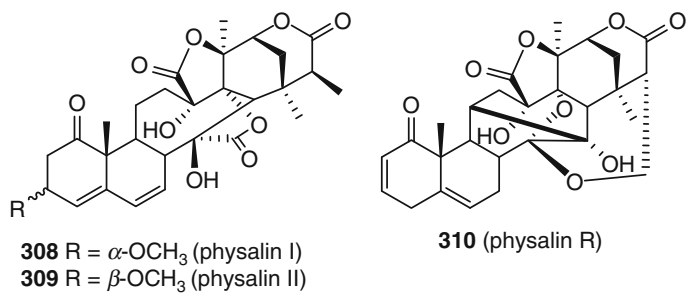

\subsubsection{Revised Physalin Structures}

The structures of several physalins have been revised. Spectroscopic studies and chemical correlations revealed that the reported structure of physalin $\mathrm{K}$ containing a $4 \alpha, 5 \alpha$-epoxy- $6 \alpha$-hydroxy-2-en-1-one arrangement in rings $\mathrm{A} / \mathrm{B}$ was incorrect, the revised structure corresponds to a $2 \alpha, 5 \alpha$-epidioxy- $6 \beta$-hydroxy-3-en-1-one (311), an isomer of physalin Q (297) (144).

Makino et al. have revised the structure of physalin $\mathrm{H}$, originally reported as having a $\Delta^{5}-7 \beta$-hydroxy arrangement in ring $\mathrm{B}$. The correct structure corresponded to the clorohydrin 312 (148). The authors also demonstrated that physalin E originally reported as a $5 \alpha, 7 \alpha$-dihydroxy-2-en-1-one is identical to the 5,6-diol 
physalin D (313). The acetate of physalin $\mathrm{E}$ also corresponds to the 6-acetate of physalin D. Chen et al. revised the structure of physalin G (314), and the NMR resonances were assigned using 2D NMR and the configuration at C-6 established as $(R)$ based on NOE data and the coupling constants of $\mathrm{H}-6$ with $\mathrm{H}-7 \alpha$ and $\mathrm{H}-7 \beta$ (149).

Sen and Pathak reported a constituent of P. minima as "physalin L" but the proposed structure 315 (150) was different from that reported previously for this compound and was also inconsistent with the spectroscopic data given as shown by Kawai et al., who synthesized compound 315 (151). The true structure of the compound isolated by Sen and Pathak has not been established although its ${ }^{1} \mathrm{H}$ NMR spectrum was comparable to the 2,3-dihydro derivative of 315 .

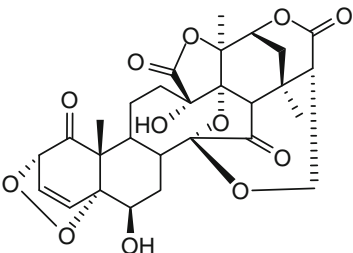

311 (physalin K)

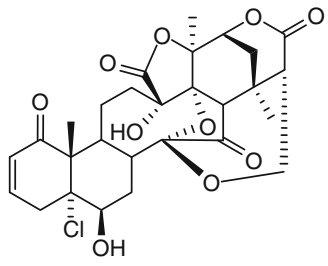

312 (physalin $\mathrm{H}$ )

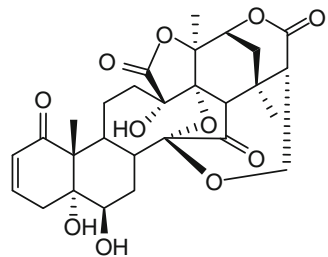

313 (physalin D and E)
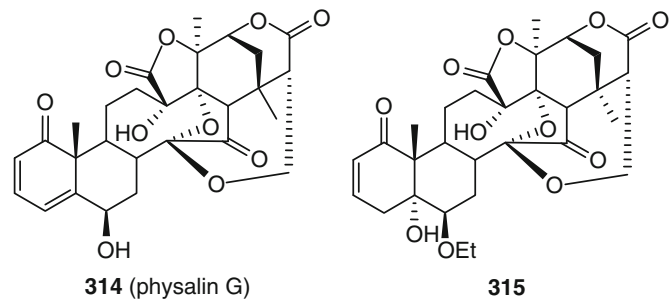

\subsubsection{Withaphysalins and Related Withanolides}

Withaphysalins comprise a group presenting an oxygen bridge between C-18 and C-20; depending on the oxidation state of $\mathrm{C}-18$, a lactol or lactone ring may result (see Fig. 2). Hemiketals at C-18 are highly reactive towards simple alcohols and usually the methyl ketals are formed when methanol is used for extraction or purification. When the free hemiketals are isolated, they exist as an equilibrium mixture of both epimers at C-18; epimeric methyl ketals on the other hand may be separated.

Withaphysalins F-L (316-322) were isolated from Eriolarynx lorentzii (sub nom. Vassobia lorentzii) collected in Argentina (70). Compounds 318 and 319 
are the corresponding methyl ketals of withaphysalin G (317) and most probably artifacts. The hemiketal corresponding to withaphysalins $\mathrm{K}$ and $\mathrm{L}$ was not isolated. Veras et al. isolated withaphysalins M (323), N (324), O (325), 2,3-dihydrowithaphysalin $\mathrm{F}$ (326), and withaphysalin $\mathrm{F}$ (316) from Acnistus arborescens collected in northeastern Brazil $(152,153)$. The ethyl ketal $\mathbf{3 2 5}$ is most probably an artifact from reaction of $\mathbf{3 1 6}$ with ethanol used for extraction. The 4-acetate of withaphysalin F (327) and the saturated lactone derivative 328 were isolated from Dunalia brachyacantha $(71)$.

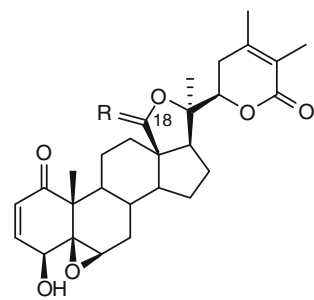

$316 \mathrm{R}=\mathrm{H}, \mathrm{OH},(18 \mathrm{R} / \mathrm{S})$ (withaphysalin $\mathrm{F}$ ) $323 \mathrm{R}=\mathrm{O}$ (withaphysalin $\mathrm{M}$ ) $325 \mathrm{R}=\mathrm{H}$,OEt (withaphysalin O)

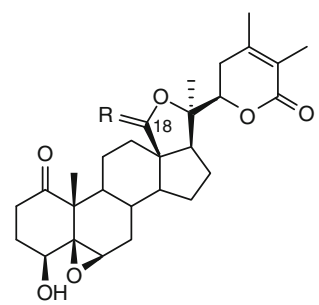

$324 \mathrm{R}=\mathrm{O}$ (withaphysalin $\mathrm{N}$ ) $326 \mathrm{R}=\mathrm{H}, \mathrm{OH},(18 R / S)$

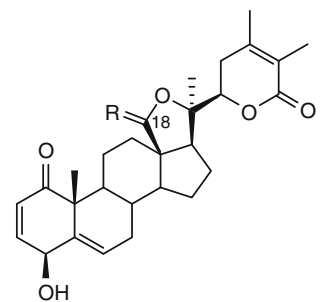

$317 \mathrm{R}=\mathrm{H}, \mathrm{OH},(18 R / S)$ (withaphysalin $\mathrm{G}$ ) $318 \mathrm{R}=\mathrm{H}, \mathrm{OCH}_{3},(18 R)$ (withaphysalin $\mathrm{H}$ ) $319 \mathrm{R}=\mathrm{H}, \mathrm{OCH}_{3},(18 \mathrm{~S}$ ) (withaphysalin I) $320 \mathrm{R}=\mathrm{O}$ (withaphysalin $\mathrm{J}$ )

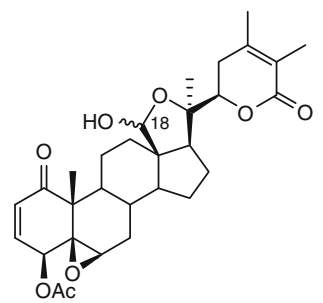

$327(18 R / S)$

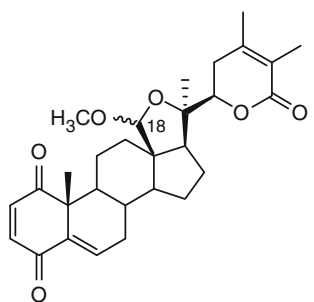

321 (18R) (withaphysalin $\mathrm{K}$ ) 322 (18S) (withaphysalin L)

From Physalis minima, Ma et al. reported seven new withaphysalins (154). Withaphysalins Q-S (329-331) and the 5-O-methyl derivative 332 were isolated as the methyl ketals at C-18; as hemiketals are highly reactive and methanol was extensively used during isolation and purification, it is possible that the actual natural products are the free hemiketals. The 3-methoxy group in $\mathbf{3 2 9}$ probably derives from the $\Delta^{2}$-1-ketone and the 5-methoxy group in $\mathbf{3 3 2}$ could result from addition of methanol to a $5 \beta, 6 \beta$-epoxide, thus both compounds might be artifacts derived from the known withaphysalin B (333). Withaphysalin P (334) and the acetylated derivatives of the known withaphysalin $C, \mathbf{3 3 5}$ and 336, appear to be biosynthetic intermediates in the conversion of withaphysalins to physalins. The authors also mention the isolation of the known $5 \alpha, 6 \alpha$-epoxywithaphysalin $\mathrm{A}$ (337), but this compound has been described only as a synthetic product (155). $5 \alpha, 6 \alpha$-Withanolides are rare and this would be the first report of $\mathbf{3 3 7}$ as a natural product. 


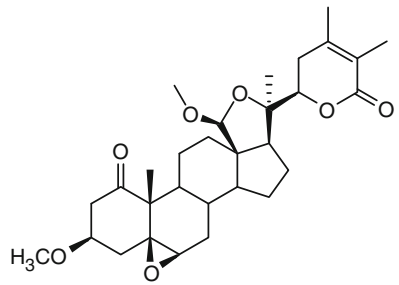

329 (withaphysalin Q)

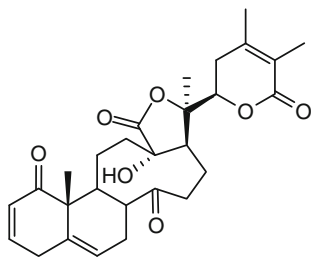

334 (withaphysalin P)

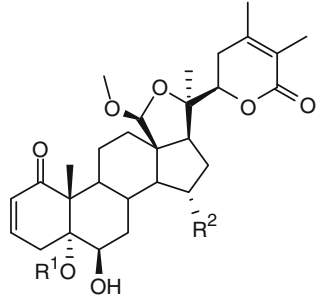

$330 \mathrm{R}^{1}=\mathrm{H}, \mathrm{R}^{2}=\mathrm{H}$ (withaphysalin $\mathrm{R}$ ) $331 \mathrm{R}^{1}=\mathrm{H}, \mathrm{R}^{2}=\mathrm{OH}$ (withaphysalin $\mathrm{S}$ ) $332 \mathrm{R}^{1}=\mathrm{CH}_{3}, \mathrm{R}^{2}=\mathrm{H}$

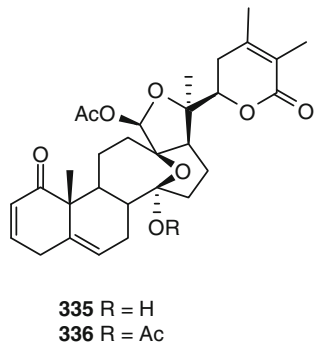

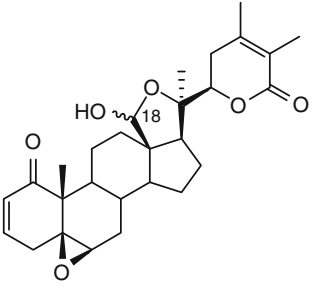

$333(18 R / S)$ (withaphysalin B)

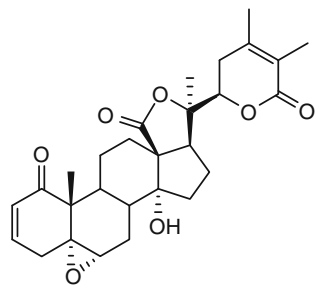

337 ( $5 \alpha, 6 \alpha$-epoxywithaphysalin A)

\subsection{Withanolides Containing an Aromatic Ring and Related Steroids}

Two distinct groups of withanolides containing aromatic rings in the steroid nucleus have been found. One of them corresponds to an abeo-ergostane skeleton with an expanded 6-member ring D that incorporates C-18 (see Fig. 2) (3). The other group presents an aromatic A ring with loss of the angular methyl at C-10. In the discussion that follows, closely related withanolides from a biosynthesis standpoint are also included.

\subsubsection{Aromatic Ring-D Withanolides and Related Steroids}

A small group of withanolides and related steroids with a six-membered aromatic ring $\mathrm{D}$, the nicandrenoids, were isolated in the early 1970s from the Peruvian "shoofly" plant Nicandra physalodes (e.g. Nic-1, 338) (59). These compounds remained a curiosity within the withanolides for almost 20 years, until Veleiro et al. isolated salpichrolide A (339) from Salpichroa origanifolia (156). Compound 339 was also the first withanolide having a 5,6-epoxide with $\alpha$-configuration, a feature that proved to be characteristic of several salpichrolides. Further studies on this plant showed that the withanolides present and the relative amounts were strongly dependent on the time of the year in which plants were collected and 
also on their geographical origin. The major components in S. origanifolia plants collected in Buenos Aires and Córdoba provinces (Argentina), were salpichrolides A (339) and G (340), with salpichrolides B (341) and C (342) being isolated as minor components $(157,158)$.

At variance with other withanolide families, salpichrolides present limited modifications in the substitution pattern of rings $\mathrm{A}$ and $\mathrm{B}$. On the other hand, a higher variability was observed for the side chain. Salpichrolides H (343) and I (344) were isolated from plants collected in Buenos Aires in the winter (158), and salpichrolides J (345), K (346), and M (347) from plants collected in Salta province (Argentina) in the summer (159). Salpichrolides H (343) and M (347) correspond to the two possible products resulting from hydrolytic (trans) cleavage of the sidechain epoxide. Salpichrolides J (345) and K (346) are the first examples of withanolides with a side chain in which the oxidation levels at C-22 and C-26 are reversed; salpichrolide K (346) slowly cyclized to salpichrolide J (345) in solution. Figure 5 shows a possible biosynthesis pathway for these compounds.

Plants collected in Buenos Aires in winter also contained two ergostane derivatives, salpichrolides $\mathrm{E}$ (348) and $\mathrm{F}(\mathbf{3 4 9})$, probably resulting from degradation of the lactone side chain of salpichrolides A and C (160). The configuration at C-22 was assumed to be the same as that in the salpichrolides with an intact side chain (i.e. $(22 R)$ ), but the orientation of the C-24 methyl could not be determined. It is noteworthy that similar degradation products are present in $N$. physalodes, the other plant known to contain withanolides with an aromatic ring D (59).<smiles>CC(C)c1ccc2c(c1)CCC1C2C2C=CC(=O)C1(O)CC=CC2=O</smiles>

338 (Nic-1)<smiles>CC1(C)C(O)OCCC2OC21</smiles>

$$
339
$$

$339 \mathrm{R}^{1}=\mathrm{O}, \mathrm{R}^{2}=\mathrm{H}$ (salpichrolide A) $340 \mathrm{R}^{1}=\mathrm{O}, \mathrm{R}^{2}=\mathrm{OH}$ (salpichrolide $\mathrm{G}$ ) $341 \mathrm{R}^{1}=\alpha-\mathrm{OH}, \beta-\mathrm{H}, \mathrm{R}^{2}=\mathrm{H}$ (salpichrolide $\mathrm{B}$ )<smiles>C[C@H](c1ccc2c(c1)CCC1C2C[C@@H]2O[C@@]23CC=CC(=O)[C@]13C)[C@H]1C[C@@](C)(O)[C@@](C)(O)[C@H](O)O1</smiles>

343 (salpichrolide H)

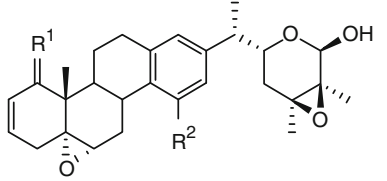<smiles>CC1=C[C@H](c2ccc3c(c2)CCC2C3CC[C@@]3(O)CC=CC(=O)C23C)O[C@@H](O)[C@@]1(C)O</smiles>

344 (salpichrolide I)

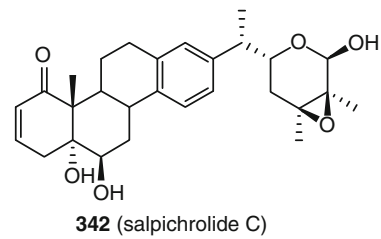<smiles>C[C@]1(O)CO[C@@]2(C)C[C@]1(C)O2</smiles>

345 (salpichrolide J)

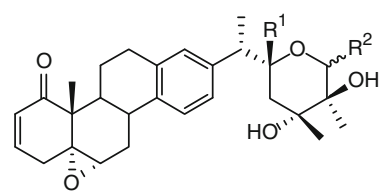

$346 \mathrm{R}^{1}=\mathrm{OH} \mathrm{R}^{2}=\mathrm{H}$ (salpichrolide $\mathrm{K}$ ) $347 \mathrm{R}^{1}=\mathrm{H} \mathrm{R}^{2}=\mathrm{OH}$ (salpichrolide $\mathrm{M}$ )<smiles>CC(=O)C(C)C[C@H](C)OC=O</smiles>

348 (salpichrolide E)<smiles>CC(=O)[C@H](C)C[C@@H](COC=O)[C@@H](C)c1ccc2c(c1)CCC1C2CC(O)[C@@]2(O)CC=CC(=O)C12</smiles>

349 (salpichrolide F) 


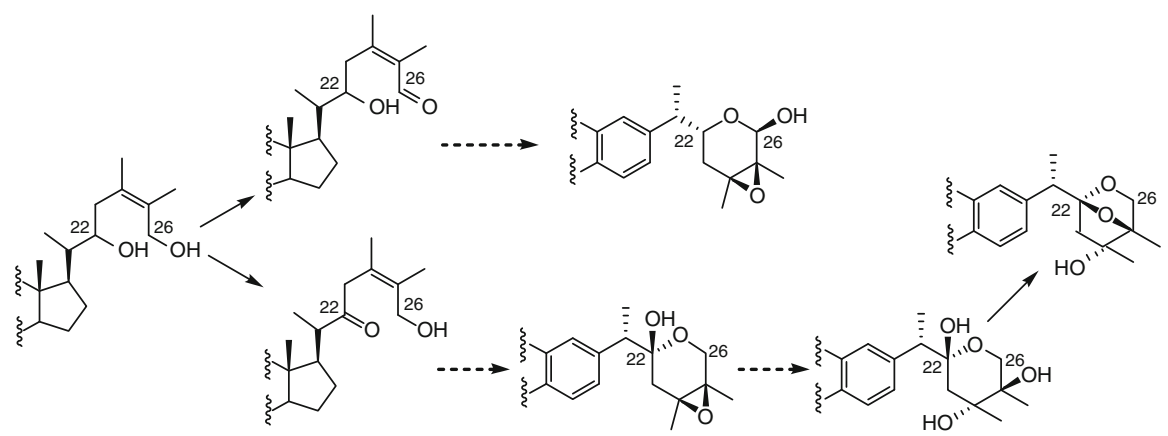

Fig. 5. Proposed biosynthetic pathway for the formation of the side chain in normal salpichrolides and in salpichrolides $\mathrm{J}$ (345) and K (346)

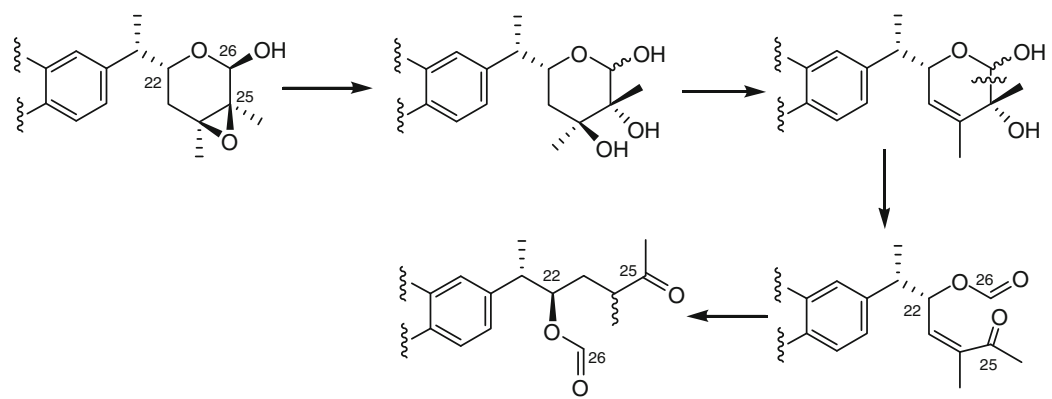

Fig. 6. Proposed degradative pathway for the formation of the side chain in salpichrolides E (348) and F (349). Starting from salpichrolide A (339) the first two intermediates correspond to compounds 343 and 344

Salpichrolides H (343) and I (344) could be intermediates in the degradation pathway leading from salpichrolide A (339) to salpichrolide E (348). Oxidative cleavage of the C-25-C-26 bond would give rise to the formyloxy group (C-26) and the methyl ketone (Fig. 6).

Besides the withanolides with an aromatic D ring, salpichrolides D (350), (157) L (351), and N (352) (159), with a normal (5-membered) D ring were isolated from S. origanifolia. All of these have a characteristic $5 \alpha, 6 \alpha$-epoxide moiety, unique to S. origanifolia. A possible pathway for ring D aromatization proposed by Whiting involves the oxidation of C-18 followed by a 1,2-shift of C-17 to form a new sixmembered ring via a cyclopropyl fused intermediate (161). Salpichrolide L (351) may be the precursor of the putative 14,16-diene intermediate; cleavage of the C-13-C-17 bond would lead to salpichrolide A and related compounds (Fig. 7, route $a$ ). An alternative cleavage of the cyclopropyl intermediate through the C-13-C-18 bond would result in migration of the angular methyl to give salpichrolide N (352) (Fig. 7, route $b$ ). 


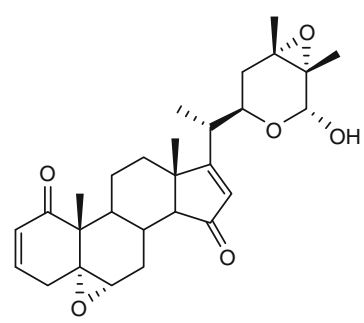

350 (salpichrolide D)

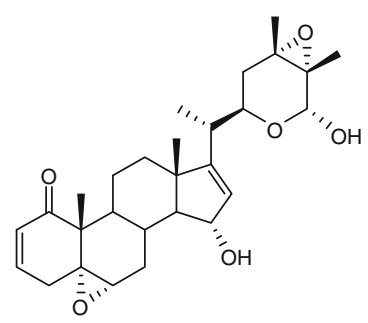

351 (salpichrolide L)

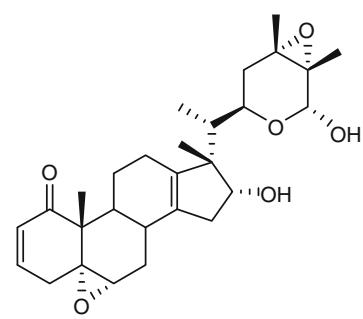

352 (salpichrolide $\mathrm{N}$ )

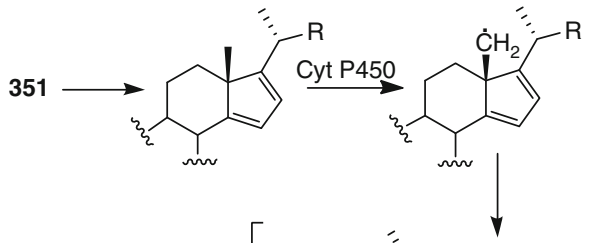

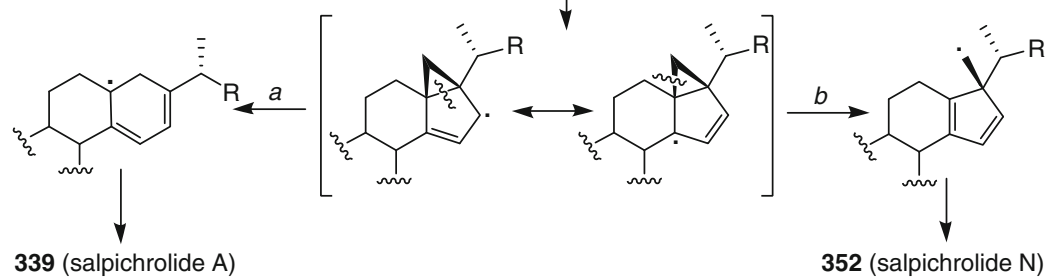

Fig. 7. Proposed biosynthesis pathways for the formation of withanolides with an aromatic D ring (e.g. salpichrolide A (339), pathway $a$ ) and for the rearranged skeleton in salpichrolide $\mathrm{N}(\mathbf{3 5 2})$ (pathway $b$ )

\subsubsection{Aromatic Ring-A Withanolides and 19-Hydroxywithanolides}

The first 19-hydroxylated withanolide, jaborosalactone $\mathrm{O}(\mathbf{3 5 3})$, was isolated from Jaborosa leucotricha collected in late spring in Argentina (162). Another three 19-hydroxywithanolides, jaborosalactones V (354), W (355), and X (356) were isolated from plants collected in the autumn together with jaborosalactone Q (357) (163) and jaborosalactone 7 (358) (68), with the latter two containing an aromatic A ring. Compound $\mathbf{3 5 7}$ had been previously found in plants of J. leucotricha collected at a different location (164). Cinerolide (359), isolated from Physalis cinerascens collected in Mexico is the only 19-hydroxywithanolide outside the Jaborosa genus (54). The coexistence of 19-hydroxywithanolides and A-ring aromatic 19-norwithanolides in J. leucotricha is indicative of an oxidative degradation pathway for the loss of $\mathrm{C}-19$ and aromatization. (+)-Jaborol and jaborosalactone 45 (see Sect. 5.4.2.) are the only other known withanolides with an aromatic A ring. 


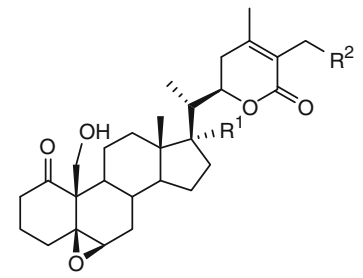

$353 \mathrm{R}^{1}=\mathrm{OH}, \mathrm{R}^{2}=\mathrm{H}$ (jaborosalactone $\mathrm{O}$ ) $355 \mathrm{R}^{1}=\mathrm{H}, \mathrm{R}^{2}=\mathrm{OH}$ (jaborosalactone $\mathrm{W}$ )

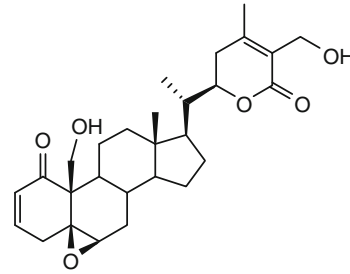

354 (jaborosalactone V)

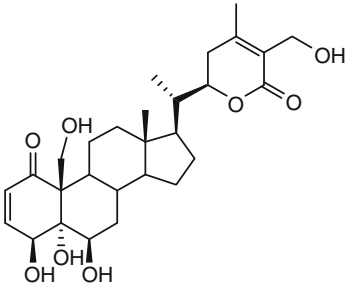

356 (jaborosalactone X)

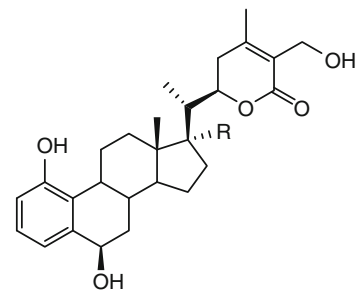

$357 \mathrm{R}=\mathrm{H}$ (jaborosalactone $\mathrm{Q}$ ) $358 \mathrm{R}=\mathrm{OH}$ (jaborosalactone 7)

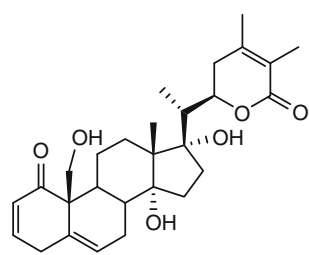

359 (cinerolide)

\subsection{Withanolides with a $\gamma$-Lactone Side Chain}

Ixocarpalactone A (360) was the first withanolide isolated with a $\gamma$-lactone side chain. It is the major withanolide of Physalis philadelphica (sub nom. Physalis ixocarpa), a plant with edible fruits (tomatillos) cultivated in Mexico and Guatemala (165). Nowadays several groups of withanolides containing variations of this $\gamma$-lactone moiety are known (see Fig. 3).

\subsubsection{Ixocarpalactones and Perulactones}

Kinghorn and coworkers reinvestigated Physalis philadelphica and isolated two new withanolides with a $\gamma$-lactone side chain of the ixocarpalactone type $(361,362)$, also the configuration of ixocarpalactone A was confirmed by X-ray crystallography $(104,105)$ (Fig. 8). The 3-methoxy derivatives of ixocarpalactones $\mathrm{A}$ and $\mathrm{B}$, resulting from the addition of methanol were also isolated and shown to be artifacts of the isolation procedure. The 4-acetate of 361 had been reported previously from fruits of the same plant (165). Huang et al. isolated two perulactones, taccalonolides $\mathrm{O}(\mathbf{3 6 3})$ and $\mathrm{P}(\mathbf{3 6 4})$, from rhizomes and tubers of Tacca 
Fig. 8. X-ray crystal structure of ixocarpalactone A (360, CCDC 171420) (104). The two atoms close to the 4-hydroxy group probably correspond to a solvent molecule. Structure drawing generated with Mercury 2.3

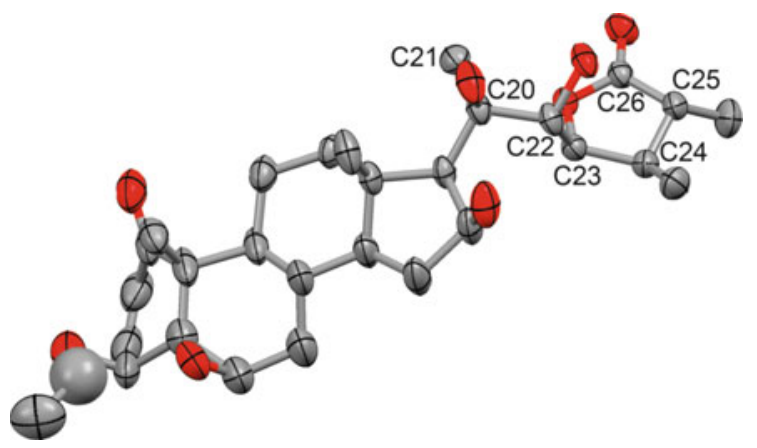

subflabellata $(166,167)$. Recently, perulactones C (365) and D (366) were reported from Physalis peruviana (168).

Physanolide A (367) was isolated from Physalis angulata by Kuo et al. (146). This withanolide has a novel skeleton related to the perulactones ( $\gamma$-lactone between $\mathrm{C}-26$ and $\mathrm{C}-28$ ) with a carbon-carbon bond between $\mathrm{C}-16$ and $\mathrm{C}-25$ that results in a seven-membered ring.

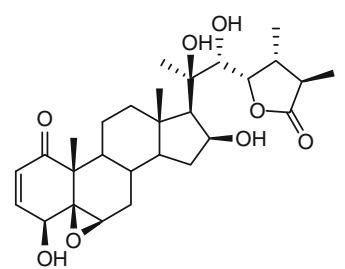

360 (ixocarpalactone A)

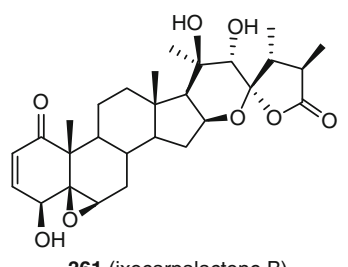

361 (ixocarpalactone B)

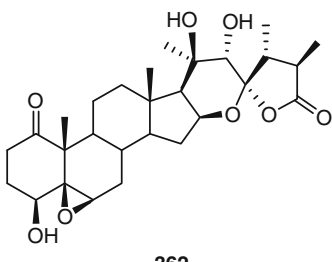

362

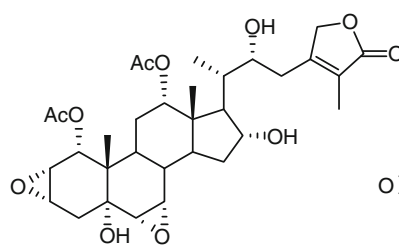

363 (taccalonolide O)

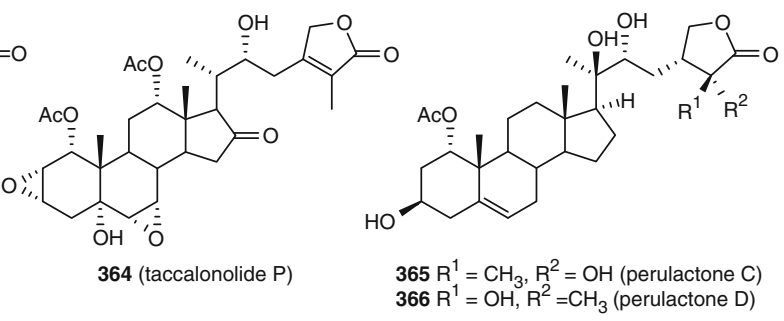

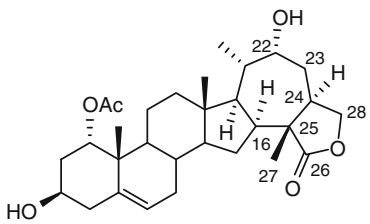

367 (physanolide A) 


\subsubsection{Trechonolides}

The first member of this group of withanolides was trechonolide A (368), isolated by Lavie et al. from Jaborosa laciniata (sub nom. Trechonaetes laciniata) collected in Argentina (169). Closely related to the ixocarpalactones, an unusual characteristic feature of this compound was a hemiketal bridge formed by the 22-hydroxy group and a ketone at $\mathrm{C}$-12, resulting in a six-membered ring with a $\beta$-oriented hydroxy at C-12. The same compound was later isolated by Parvez et al. from the Chilean J. magellanica (170). Curiously, although in both cases the structure was elucidated by X-ray crystallography, the configuration at C-23 was incorrectly assigned as $(R)$. In 2006 Nicotra et al. reported the isolation of the C-23 epimer of trechonolide A (jaborosalactone 32, 369) from J. rotacea (120). The configuration at C-23 was established by X-ray crystallography and shown to be $(R)$ (Fig. 9). Careful inspection of the original X-ray data for trechonolide A $(169,170)$ confirmed the $(23 S)$ configuration. The C-23 epimers of jaborotetrol and jaborochlorotriol (370 and 371) were also isolated from J. rotacea and shown to be $(23 R)(120)$. The chemical shift of C-23 and the sign of the Cotton effect at $218 \mathrm{~nm}$ may be used as direct indicators of the configuration at this position of trechonolides, thus the $(23 S)$ epimers have a negative Cotton effect and the C-23 resonance at $\delta 82.0-82.5 \mathrm{ppm}$, while the (23R) epimers exhibited a positive Cotton effect and a downfield shift for C-23 to $\delta 85.5-86.0 \mathrm{ppm}$. According to this, the structures of all previously known trechonolides that have been assigned the $(23 R)$ configuration upon comparison with trechonolide A should now be revised. For the above structures and in those that follow, the configuration at C-23 has been corrected according to Nicotra et al. when appropriate.

Fig. 9. X-ray crystal structure of jaborosalactone 32 (369, CCDC 255337), the C-23 epimer of trechonolide A showing the $(23 R)$ configuration (120). Hydrogens at positions 22 and 23 are included for clarity. Structure drawing generated with Mercury 2.3

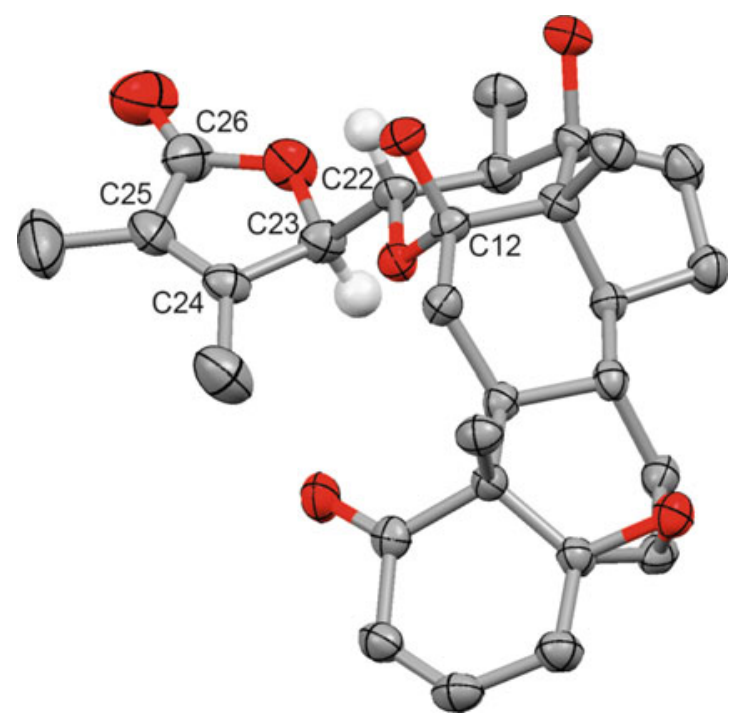


Several withanolides structurally related to trechonolide A with the classical variations in the substitution pattern of rings $\mathrm{A}$ and $\mathrm{B}$, have been subsequently isolated from different species of Jaborosa. Jaborotetrol (372), previously isolated from J. magellanica, and trechonolide A (368) are the most commonly found. As already observed with the sativolides, the C-12 hemiketal of the trechonolides is highly reactive towards alcohols and even small amounts of methanol or ethanol used during the isolation procedure will give the 12- $O$-methyl or ethyl derivatives. For example, when $\mathbf{3 7 0}$ was dissolved in deuterochloroform containing a few drops of deuteromethanol (to enhance solubility), the 12- $O$-trideuteromethyl derivative was formed (120). The clorohydrins jaborosalactone 42 (373) and jaborosalactone 49 (374) were isolated from J. caulescens var. bipinnatifida (121) and J. laciniata (171). Also from J. caulescens var. bipinnatifida were isolated two 21-hydroxytrechonolides epimeric at C-23, 375 and 376 (121). The 19-oxygenated trechonolides 377-379 were isolated from J. laciniata together with $\mathbf{3 8 0}$ (and its 12-O-methyl derivative) containing an aromatic ring A (171). Again, the 19-hydroxy withanolides appear as intermediates in an oxidative degradation pathway leading to the loss of the $\mathrm{C}-10$ methyl and aromatization of ring A (see Sect. 5.3.2.). As already mentioned, the $12-O$-methyl derivatives are most probably formed during the isolation procedure, with the 12-hydroxy compounds being the actual natural

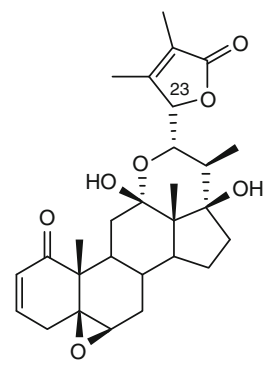

368 (23S) (trechonolide A) $369(23 R)$ (jaborosalactone 32)

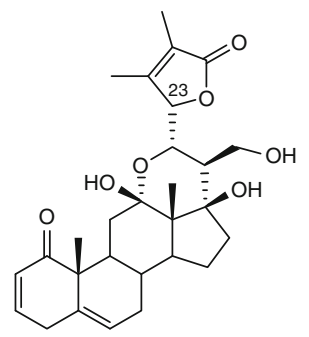

375 (23R) (jaborosalactone 40) 376 (23S) (jaborosalactone 41)

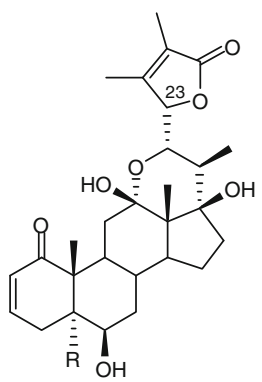

370 (23R), $\mathrm{R}=\mathrm{OH}$ (jaborosalactone 33) 372 (23S), $\mathrm{R}=\mathrm{OH}$ (jaborotetrol) $373(23 R), \mathrm{R}=\mathrm{Cl}$ (jaborosalactone 42) 374 (23S), $\mathrm{R}=\mathrm{Cl}$ (jaborosalactone 49)

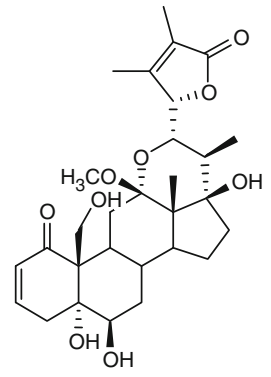

377 (jaborosalactone 46)

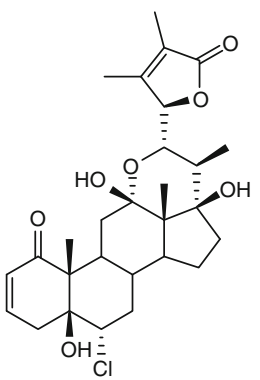

371 (jaborosalactone 34)

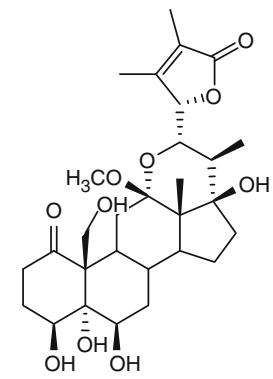

378 (jaborosalactone 47) 


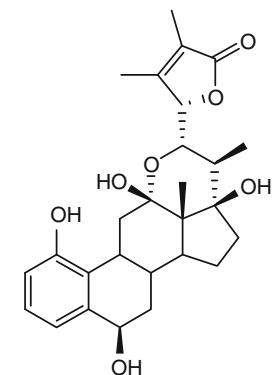

380 (jaborosalactone 45)

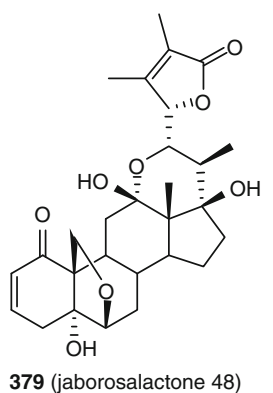

379 (jaborosalactone 48)

products. The 6,19-oxygen bridge present in $\mathbf{3 7 9}$ is an unusual functionality for a natural product. Interestingly, synthetic steroids with this moiety exhibit remarkable biological properties as selective glucocorticoid receptor modulators (172).

Although epoxy- $\delta$-lactones and lactols are quite common among the withanolides, this did not appear to be the case for the $\gamma$-lactone side chains. Jaborosalactone U (381) isolated from $J$. sativa (Argentina), is the only known example of a 24,25-epoxy- $\gamma$-lactone (119). The (23R) configuration was originally proposed for this compound based on NOE data, however, more recently X-ray crystallography showed that the configuration is (23S) (Fig. 10) (173). Recently, several 24,25-epoxy- $\gamma$-lactols were isolated from plants of $J$. parviflora (382-385); some $12-O$-ethyl derivatives were also reported (174). The authors used powder

Fig. 10. X-ray crystal structure of jaborosalactone $\mathrm{U}$ (381) showing the configuration of the side chain epoxylactone (173).

Hydrogens at positions 22 and 23 are included for clarity. Structure drawing generated with Mercury 2.3

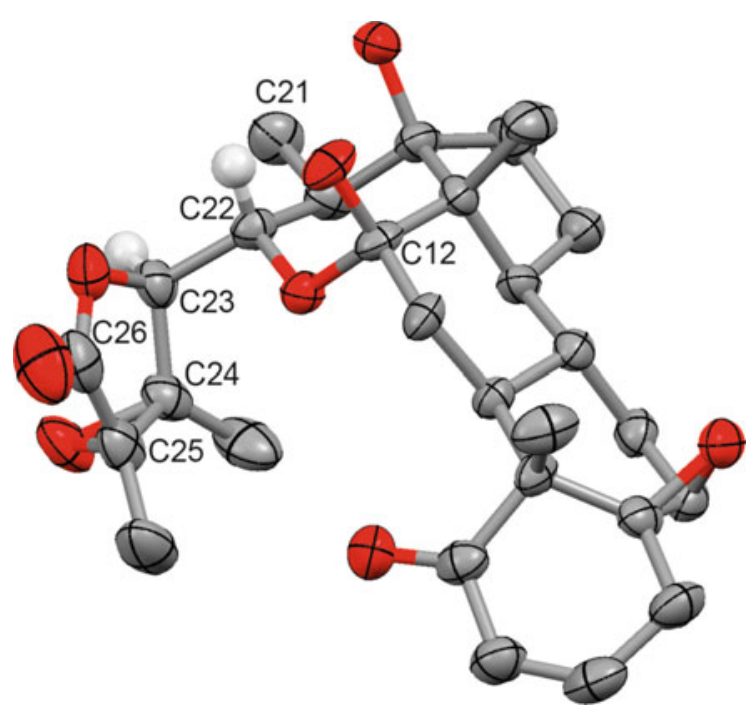


X-ray diffraction analysis and NMR spectroscopy residual dipolar couplings to establish the absolute configuration of the epoxy-lactol side chain of $\mathbf{3 8 2}$, confirming it was $(23 S)$. Both methodologies proved to be valid alternatives to single crystal X-ray diffraction. For the other compounds the same configuration was established by comparison of their ${ }^{13} \mathrm{C}$ NMR spectra.

Tettamanzi et al. had reported the isolation of a closely related epoxy$\gamma$-lactol from $J$. lanigera for which the $(23 R)$ configuration was proposed (175); this compound had ${ }^{13} \mathrm{C}$ NMR data identical to $\mathbf{3 8 2}$ for C-12-C-18 and C-20-C-28 indicating that both compounds should have the same configuration in the side chain, hence the revised structure $\mathbf{3 8 6}$ is proposed. Thus so far, all known epoxy- $\gamma$-lactones and lactols have the same configuration at C-23, opposite to that of trechonolide A. Jaborosalactones 35 (387) and 36 (388) isolated from $J$. rotacea would result from cyclization of a 21-hydroxy-epoxy- $\gamma$-lactone (120). It should be noted that to date, trechonolides have been reported in nine of the thirteen Jaborosa species studied. A group of closely related $\gamma$-lactones isolated from Larnax subtriflora (sub nom. Deprea subtriflora) is discussed in Sect. 5.5.2.

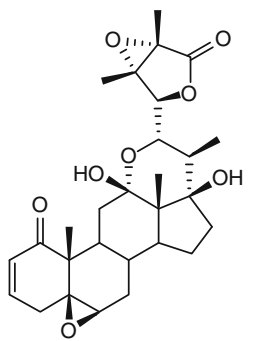

381 (jaborosalactone U)

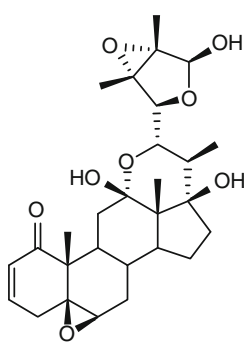

382 (jaborosalactol 24)

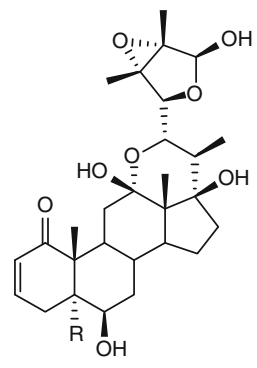

$383 \mathrm{R}=\mathrm{Cl}$ (jaborosalactol 25) $385 \mathrm{R}=\mathrm{OH}$ (jaborosalactol 27)

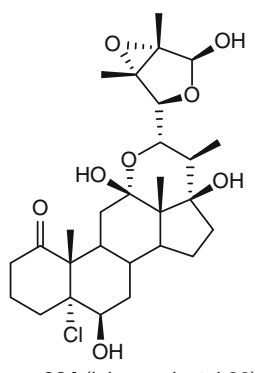

384 (jaborosalactol 26)

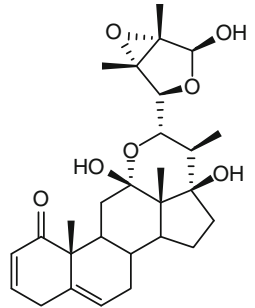

386

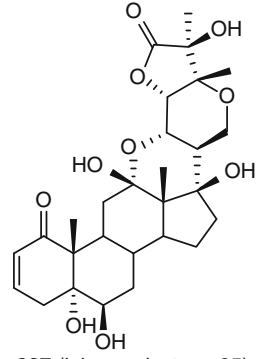

387 (jaborosalactone 35)

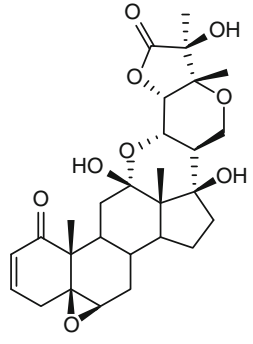

$\mathbf{3 8 8}$ (jaborosalactone 36) 


\subsubsection{Spiranoid- $\gamma$-Lactones}

The first withanolide with a spiranoid $\gamma$-lactone side chain, jaborosalactone $\mathrm{P}(\mathbf{3 8 9})$, was isolated by Monteagudo et al. from plants of Jaborosa odonelliana collected in Argentina (176). Cirigliano et al. reinvestigated this plant collected at different times of the year. Jaborosalactones 10 (390), 14 (391), and 15 (392) were found in plants collected in the summer while jaborosalactones 11 (393), 12 (394), 13 (395), and 14 (391) were present in plants collected in the autumn (177). Jaborosalactone $\mathrm{P}$ was the major component in both cases. The C-23 epimer of jaborosalactone $\mathrm{P}$, jaborosalactone 24 (396), was isolated as a minor component from plants collected in April and December (178). This is the only spiranoid withanolide with a $(23 R)$ configuration isolated so far.

A group of six spiranoid withanolides with a 17(20)-ene-22-keto system, jaborosalactones 1-6 (397-402) was isolated from Jaborosa runcinata collected in Argentina. Jaborosalactone 2 (398) was also isolated from Jaborosa araucana (179). More recently, jaborosalactone 25 (403) was isolated as a minor component of J. runcinata (178).

The structural similarity of jaborosalactone 2 (398) and trechonolide A (368), both present in $J$. araucana, suggests that these compounds may have a common biosynthetic precursor. In trechonolide $\mathrm{A}$, ring closure on $\mathrm{C}-12$ has occurred with a C-22 hydroxy group as shown in Fig. 11 pathway $a$. Oxidation of the intermediate or a related compound to the 22-ketone would allow cyclization between $\mathrm{C}-23$ and the $\mathrm{C}-12$ ketone to give the 22-keto-spiranoid withanolides (Fig. 11 pathway $b$ ).

Jaborosalactone 31 (404), isolated from $J$. rotacea, is closely related to the spiranoid withanolides isolated from J. odonelliana, J. runcinata, and

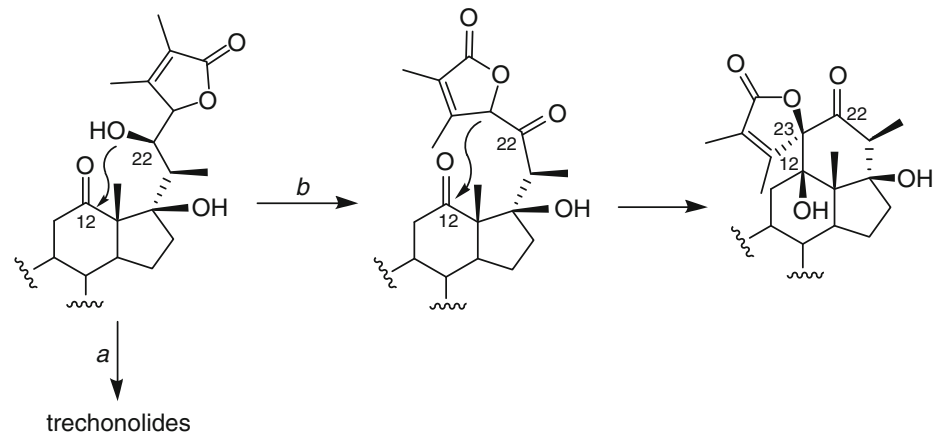

Fig. 11. Proposed biosynthetic routes to trechonolides (pathway $a$ ) and spiranoid withanolides (pathway $b$ ) via a common precursor 
$J$. araucana. In this case, the $\mathrm{C}-12-\mathrm{C}-23$ bond is still present but instead of the spiranoid- $\gamma$-lactone arrangement (there is no oxygenated function at $\mathrm{C}-23$ ), a $\delta$ lactone is formed between the $\mathrm{C}-26$ carboxyl and the $\mathrm{C}-12$ hydroxy group (120).

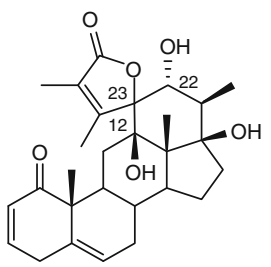

389 (23S) (jaborosalactone P) 396 (23R) (jaborosalactone 24)

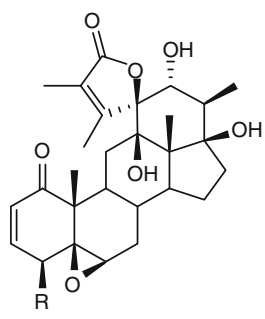

$393 \mathrm{R}=\mathrm{H}$ (jaborosalactone 11) $394 \mathrm{R}=\mathrm{OH}$ (jaborosalactone 12)

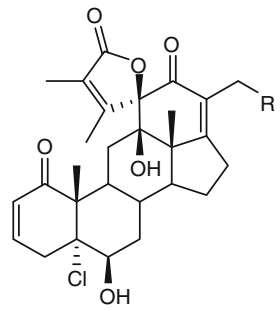

$399 \mathrm{R}=\mathrm{H}$ (jaborosalactone 3 ) $402 \mathrm{R}=\mathrm{OH}$ (jaborosalactone 6)

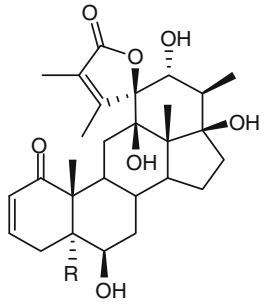

$390 \mathrm{R}=\mathrm{Cl}$ (jaborosalactone 10) $391 \mathrm{R}=\mathrm{OCH}_{3}$ (jaborosalactone 14) $395 \mathrm{R}=\mathrm{OH}$ (jaborosalactone 13)

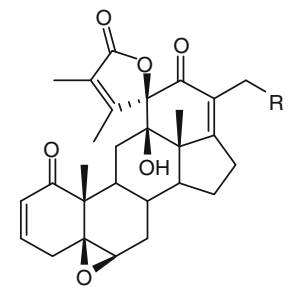

$397 \mathrm{R}=\mathrm{H}$ (jaborosalactone 1) $400 \mathrm{R}=\mathrm{OH}$ (jaborosalactone 4)

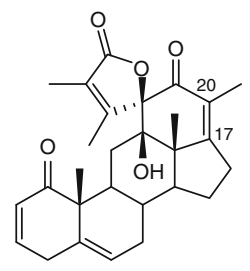

401 (jaborosalactone 5)

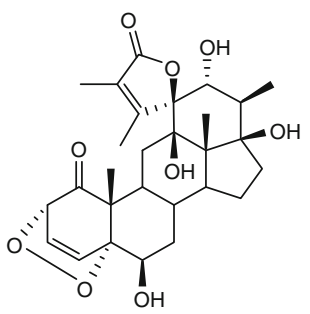

392 (jaborosalactone 15)

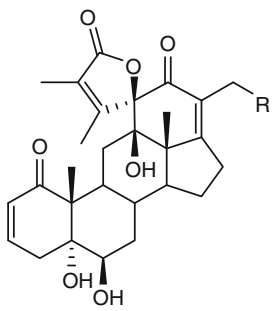

$398 \mathrm{R}=\mathrm{H}$ (jaborosalactone 2) $403 \mathrm{R}=\mathrm{OH}$ (jaborosalactone 25)

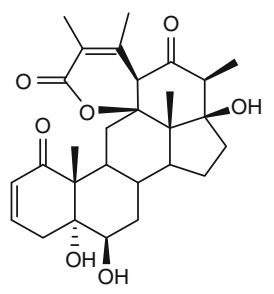

404 (jaborosalactone 31)

\subsubsection{Taccalonolides}

Tacca species contain highly oxygenated ixocarpalactone-type withanolides with an additional ring formed by a carbon-carbon bond between C-16 and C-24, taccalonolide A (405) being the first example of these compounds (3). Eight 
new withanolides related to taccalonolide A were isolated from Tacca plantaginea, taccalonolides L (406), M (407) (180), G, H, I, J, K (408-412) (181), and W (413) (182). Taccalonolides R, S, T, U, and V (414-418) were isolated from the Vietnamese plant Tacca paxiana together with the known taccalonolides A (405), K (412), B, E, and N (419-421) (183). A distinctive feature of most taccalonolides is the absence of a hydroxy group at C-22. Taccalonolide Q (422) (167) and Y (423) (182) containing a $\delta$-lactone side chain with a $\mathrm{C}-\mathrm{C}$ bond between $\mathrm{C}-16$ and $\mathrm{C}-24$ were isolated from $T$. subflabellata and $T$. plantaginea.

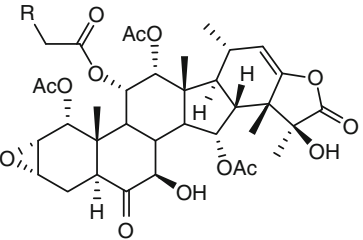

$405 \mathrm{R}=\mathrm{H}$ (taccalonolide $\mathrm{A}$ ) $406 \mathrm{R}=\mathrm{OH}$ (taccalonolide $\mathrm{L}$ )

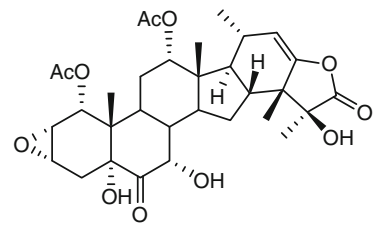

408 (taccalonolide G)

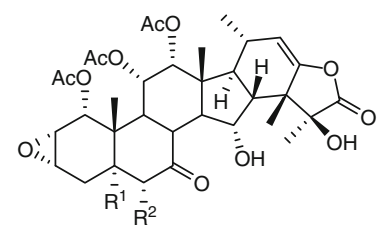

$410 \mathrm{R}^{1}=\mathrm{H}, \mathrm{R}^{2}=\mathrm{OH}$ (taccalonolide I) $411 \mathrm{R}^{1}=\mathrm{H}, \mathrm{R}^{2}=\mathrm{OAc}$ (taccalonolide $\mathrm{J}$ ) $412 \mathrm{R}^{1}=\mathrm{R}^{2}=\mathrm{OH}$ (taccalonolide $\mathrm{K}$ )

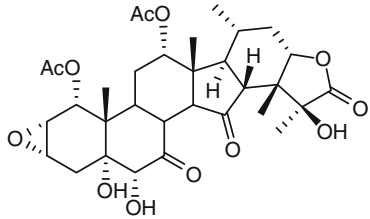

407 (taccalonolide M)

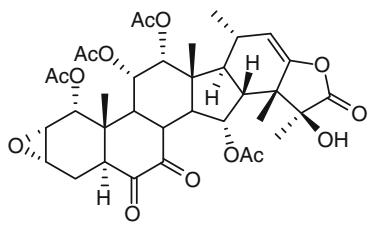

409 (taccalonolide $\mathrm{H}$ )

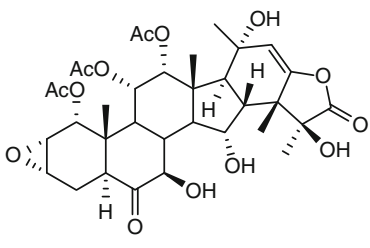

413 (taccalonolide W)

A sizeable number of steroids partially resembling withanolides have been isolated from Tacca species and some also dubbed taccalonolides, e.g. taccalonolide X (424) (182), but they are not included in this chapter. Other taccalonolides structurally related to the perulactones have been presented previously (see Sect. 5.4.1.). 


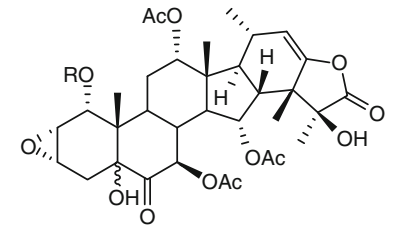

$414 \mathrm{R}=\mathrm{Ac}$ (taccalonolide $\mathrm{R}$ ) $416 \mathrm{R}=$ isovaleryloxy (taccalonolide $\mathrm{T}$ ) $417 \mathrm{R}=\mathrm{H}$ (taccalonolide $\mathrm{U}$ )

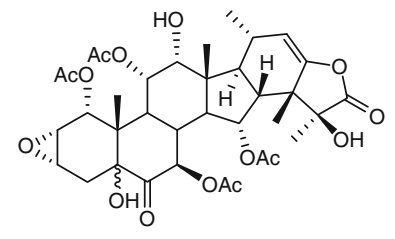

418 (taccalonolide V)

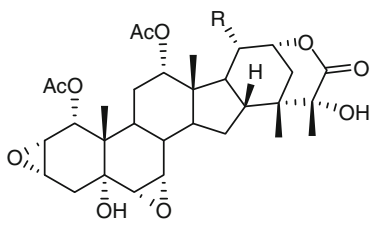

$422 \mathrm{R}=\mathrm{CO}_{2} \mathrm{H}$ (taccalonolide $\mathrm{Q}$ ) $423 \mathrm{R}=\mathrm{CH}_{2} \mathrm{OH}$ (taccalonolide $\mathrm{Y}$ )

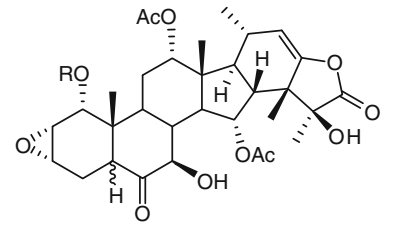

$415 \mathrm{R}=$ isobutyryloxy (taccalonolide $\mathrm{S}$ )

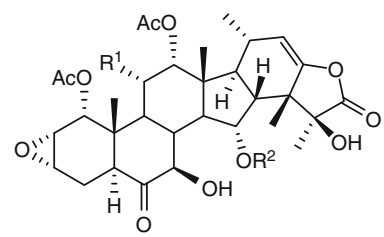

$419 R^{1}=O A c, R^{2}=H$ (taccalonolide $B$ ) $420 R^{1}=H, R^{2}=A c$ (taccalonolide $E$ ) $421 \mathrm{R}^{1}=\mathrm{R}^{2}=\mathrm{H}$ (taccalonolide $\mathrm{N}$ )

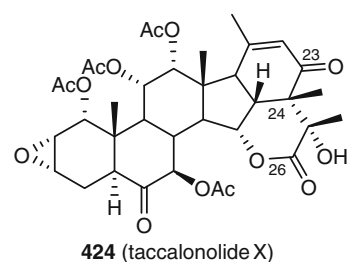

\subsection{8-Norwithanolides}

Kinghorn and coworkers used a quinone reductase induction assay for the activitymonitored fractionation of an extract of Larnax subtriflora (sub nom. Deprea subtriflora) collected in Peru. This led to the isolation of a novel group of highly oxygenated $\mathrm{C}_{27}$ 18-norwithanolides, dubbed subtrifloralactones. All subtrifloralactones found so far, have oxygenated functions at positions 12, 16, and 20 and a saturated lactone $\left(\gamma\right.$ or $\delta$ ) side chain (see Figs. 2 and 3) $(184,185)$. Another $\mathrm{C}_{27} 18$ norwithanolide related to the physalins, has been reported recently from a Physalis species. A small group of $\mathrm{C}_{28}$ 17-methyl-18-norwithanolides is also included in this section.

\subsubsection{Subtriflora- $\delta$-Lactones and Related Withanolides}

Subtrifloralactones D (425) and E (426) resemble the classic withanolide structure except for the lack of $\mathrm{C}-18$. On the other hand, subtrifloralactones $\mathrm{H}$, I, and $\mathrm{J}$ 
(427-429) have rings $\mathrm{C}$ and $\mathrm{D}$ cis fused, due to epimerization at position 13 (probably favored by the presence of the neighboring 12-ketone), allowing formation of a ketal bridge between a 20-hydroxy group and a 12-ketone (184). Due to the high reactivity of $\mathrm{C}-12$ hemiketals towards even traces of small alcohols (see Sect. 5.4.2.), the formation of the methyl and ethyl ketals in the latter compounds probably took place during isolation. Another distinctive feature of subtrifloralactones $\mathrm{H}, \mathrm{I}$, and $\mathrm{J}$ is the presence of a formate group esterifying the 16-hydroxy group. The isolation of $13 \beta$-hydroxymethylsubtrifloralactone $\mathrm{E}$ (430) from the same plant (185) indicates an oxidative pathway for the loss of C-18 that could end as the 16-formate group via rearrangement of a 16,18 hemiketal (Fig. 12).

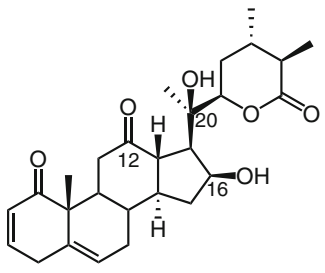

425(subtrifloralactone D)

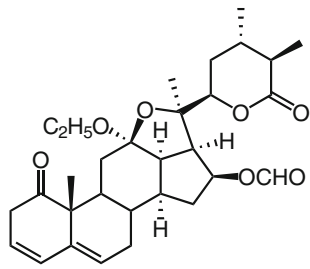

427 (subtrifloralactone $\mathrm{H}$ )

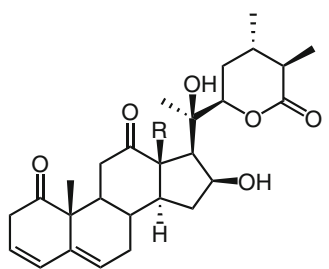

$426 \mathrm{R}=\mathrm{H}$ (subtrifloralactone $\mathrm{E})$ $430 \mathrm{R}=\mathrm{CH}_{2} \mathrm{OH}$

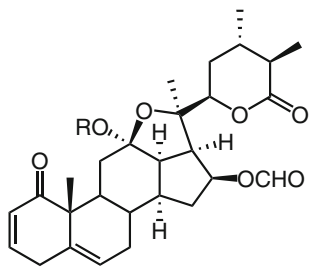

$428 \mathrm{R}=\mathrm{C}_{2} \mathrm{H}_{5}$ (subtrifloralactone I) $429 \mathrm{R}=\mathrm{CH}_{3}$ (subtrifloralactone $\mathrm{J}$ )

\subsubsection{Subtriflora- $\gamma$-Lactones}

Subtrifloralactones A (431), B (432), C (433), K (434), and L (435) present a side chain arrangement closely related to that observed in the trechonolides, with a $\gamma$-lactone between C-26 and C-23 and a ketal bridge between a 22-hydroxy and a 12-ketone $(184,185)$. However, the cis fusion of rings $\mathrm{C}$ and $\mathrm{D}$ and the presence of a 16-hydroxy group allow an additional ketal bridge involving this hydroxy and $\mathrm{C}-12$. In subtrifloralactones $\mathrm{F}$ (436) and $\mathrm{G}$ (437) the trans fusion of rings $\mathrm{C}$ and D results in an ixocarpalactone-type structure (184). 
Withanolides and Related Steroids

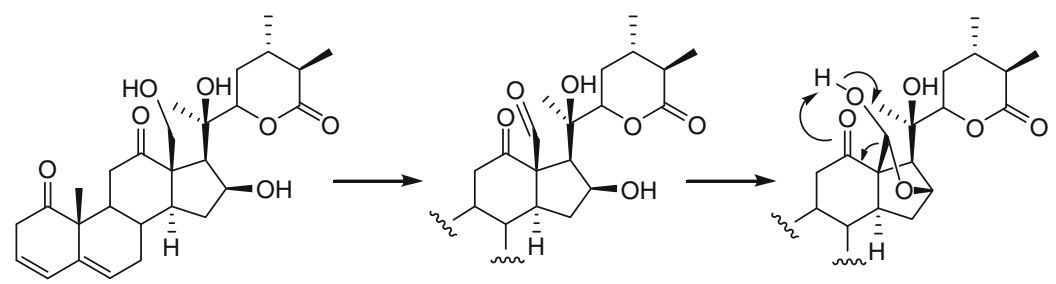

430

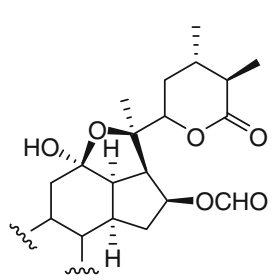

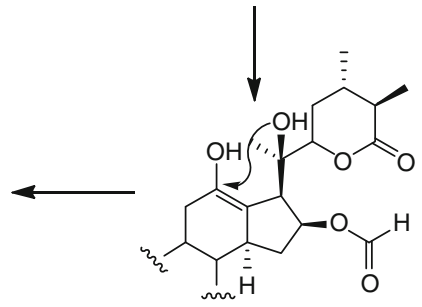

Fig. 12. Proposed biosynthetic pathway for the conversion of $13 \beta$-hydroxymethylsubtrifloralactone $\mathrm{E}(\mathbf{4 3 0})$ to subtriflora- $\delta$-lactones

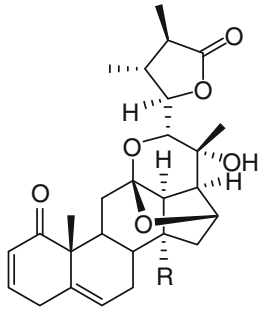

$431 \mathrm{R}=\mathrm{H}$ (subtrifloralactone $\mathrm{A})$ $433 \mathrm{R}=\mathrm{OH}$ (subtrifloractone $\mathrm{C}$ )

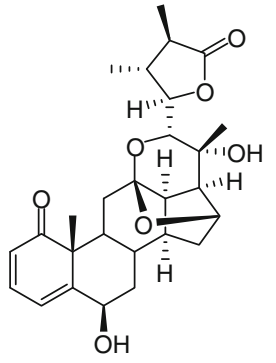

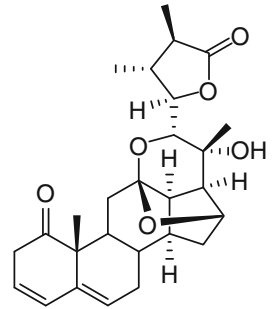

432 (subtrifloralactone B)

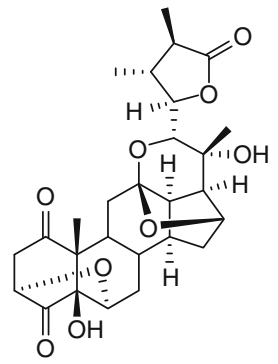

434 (subtrifloralactone K)<smiles>C[C@H]1C(=O)O[C@H]([C@H](O)[C@](C)(O)[C@H]2C(O)C[C@H]3C4CC=C5CC=CC(=O)[C@]5(C)C4CC(=O)[C@H]32)[C@@H]1C</smiles>

436 (subtrifloralactone F)<smiles>C[C@H]1C(=O)O[C@H]([C@H](O)[C@](C)(O)[C@H]2C(O)C[C@H]3C4CC=C5C=CCC(=O)[C@]5(C)C4CC(=O)[C@H]32)[C@@H]1C</smiles>

437 (subtrifloralactone G) 


\subsubsection{Other 18-Norwithanolides}

Recently, Ma et al. reported the isolation of another 18-norwithanolide structurally related to the physalins, withaphysanolide A (438), together with several known physalins and withaphysalins from Physalis divaricata collected in Pakistan (186). The structure and configuration of withaphysanolide A was confirmed by X-ray crystallography.

TH-6 (439) and TH-12 (440) are two 17-methyl-18-nor-ergostanes isolated in 1990 by Shingu et al. from the acid hydrolysate of a methanolic extract of Tubocapsicum anomalum (187). The authors related these compounds to a putative precursor with a withanolide side chain, that would rearrange in acid media. Recently Hsieh et al. isolated from the same plant three withanolides with the rearranged skeleton of TH-6 and TH-12 named tubocapsenolides A, F, and G (441-443) (107). Salpichrolide N (352) isolated from Salpichroa origanifolia (see Sect. 5.3.1.), was the first withanolide reported with this rearranged skeleton (159).

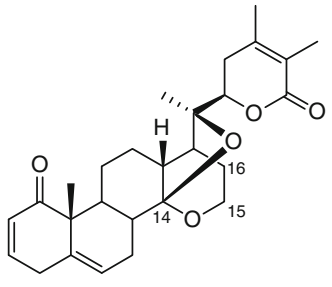

438 (withaphysanolide A)

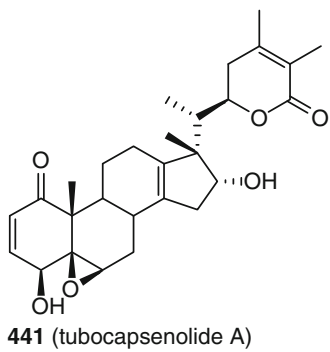

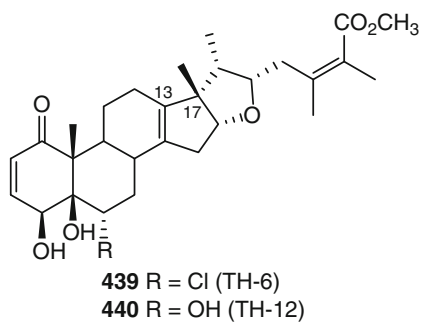

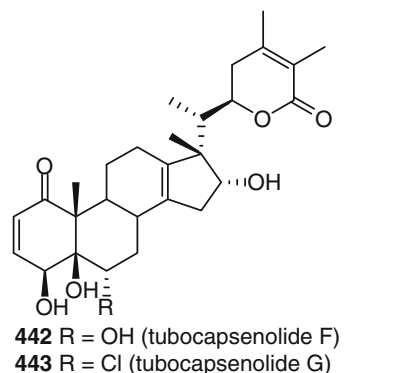

\subsection{Spiranoid Withanolides at C-22}

This group of withanolides has a hemiketal bridge between what must have originally been ketone functions at $\mathrm{C}-12$ and $\mathrm{C}-22$. This gives rise to a new 
six-membered ring with a $\beta$-oriented hydroxy group at $\mathrm{C}-12$ and a spiroketal at C-22 upon formation of the $\delta$-lactone. Jaborosalactones 26-30 (444-448) were isolated from Jaborosa rotacea (120) and jaborosalactone 43 (449) was isolated from J. kurtzii (76) both collected in Mendoza, Argentina. The 12-ketowithanolide jaborosalactone 44 (144) also present in J. kurtzii (see Sect. 4.2.3.) has been proposed as the biogenetic precursor of $\mathbf{4 4 9}$.

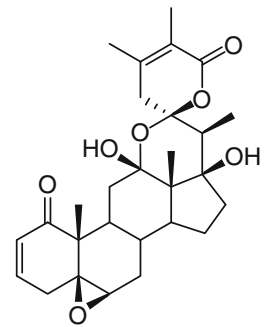

444 (jaborosalactone 26)

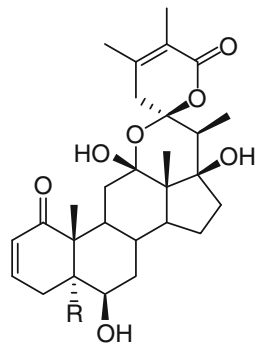

$445 \mathrm{R}=\mathrm{OH}$ (jaborosalactone 27) $446 \mathrm{R}=\mathrm{Cl}$ (jaborosalactone 28)

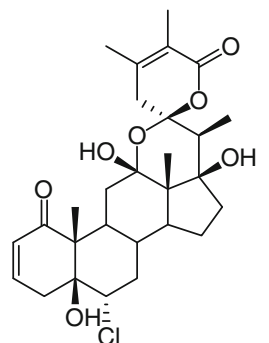

447 (jaborosalactone 29)

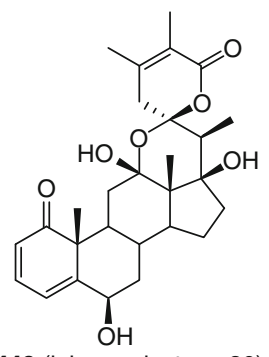<smiles>CC1=C(C)C(=O)OC2(C1)OC1(O)CC3C4CC=C5CC=CC(=O)C5(C)C4C3CCC1(O)C2C</smiles>

449 (jaborosalactone 43)

\section{Chemical and Bio-transformations of Withanolides}

The early synthesis work carried out on withanolides has been reviewed by Glotter (59), Ray and Gupta (3), and more recently by Kovganko and Kashkan (188). No new attempts on total or partial syntheses of withanolides have been reported in the last two decades. On the other hand, transformations usually involving interconversions of functional groups, of one withanolide into another or synthesis of simple derivatives, are fairly common and mostly used for structure confirmation or to study biological activities. 


\subsection{Chemical Transformations}

Reactivity of the $\Delta^{2}$-1-keto system of withanolides towards Michael addition (mostly of simple alcohols) has been discussed in the previous sections and several examples shown. As already mentioned, $5 \beta, 6 \beta$-epoxides are fairly common among the withanolides and also constitute a highly reactive center. Many chemical transformations involve the cleavage of the epoxide moiety to give the corresponding diols, chlorohydrins or alcohol addition products, with their configuration according to the Fürst-Plattner rule (16).

For the structure assignment of physalin $\mathrm{H}(\mathbf{3 1 2})$, Makino et al. treated physalin F (450) with aqueous hydrochloric acid to give a mixture of the diol 313 (physalin D) and the $5 \alpha, 6 \beta$-clorohydrin 312 (physalin H) (Chart 1). When concentrated hydrobromic acid in THF was used the brominated analog of physalin $\mathrm{H}$ (451) was obtained. Reaction of physalin D (313) with phosphorous oxychloride in dry pyridine gave the isomeric chlorohydrin 452 (148). Cleavage of the epoxide of physalin $\mathrm{F}$ (450) with concentrated hydrochloric acid in ethanol gave the $5 \alpha$-ethoxy-6 $\beta$-hydroxy withanolide $\mathbf{4 5 3}$ (151).

The $5 \alpha, 6 \alpha$-epoxide present in the salpichrolides and a few other withanolides, reacts in a similar way. Thus, treatment of salpichrolide A (339) with THF containing $0.75 \%$ of $1.5 \mathrm{~N}$ sulphuric acid gave the corresponding diol $\mathbf{3 4 2}$ (salpichrolide C)

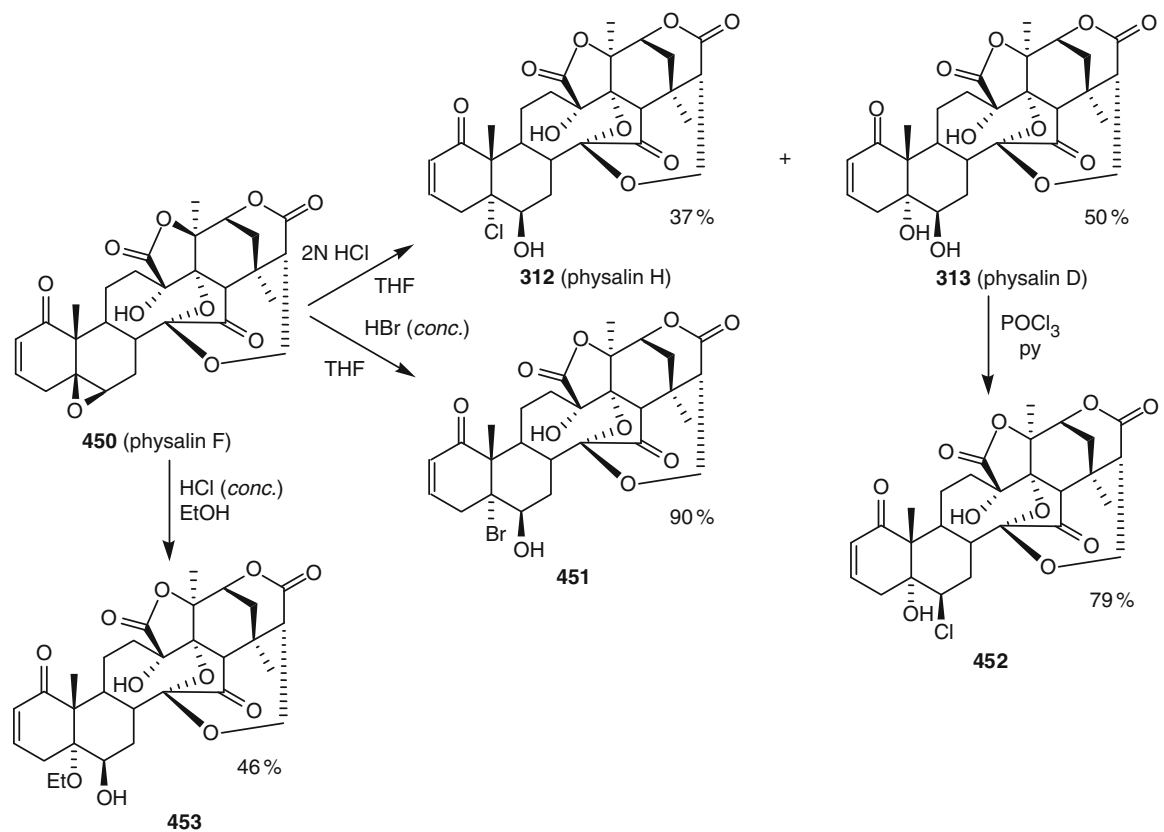

Chart 1 Cleavage reactions of the $5 \beta, 6 \beta$-epoxide of physalin $\mathrm{F}(\mathbf{4 5 0})$ 
(157); increasing the amount of acid 10-fold, resulted in the concomitant cleavage of the 24,25-epoxide (compound 454) (159). Reaction of salpichrolide A (339) with Jones reagent in acetone for $3 \mathrm{~h}$ gave the hydroxyketone $\mathbf{4 5 5}$ where oxidation of the side chain lactol to the lactone also occurred (189). On the other hand, cleavage of the epoxide with potassium bicarbonate in methanol gave the $\Delta^{2,4}-6 \alpha$-hydroxy withanolide 456 (Chart 2) (190). Reaction of physalin J (457) with sulfuric acid in ethanol gave the $5 \alpha$-hydroxy- $6 \beta$-ethoxy physalin 315 (151).

Misra et al. studied the reaction of 2-mercaptoethanol with several withanolides from $W$. somnifera. Withaferin A (1) and other $5 \beta, 6 \beta$-epoxywithanolides reacted readily under mild acid catalysis to give the $5 \beta, 6 \alpha$-oxyethylenethio derivatives (Chart 3) in 47-60\% yield. The additional ring would result from nucleophilic attack of the thiol at position 6 , followed by acid-catalyzed condensation of the $6 \alpha$ hydroxyethylthio intermediate. Withanolides with a $6 \alpha, 7 \alpha$-epoxide did not react

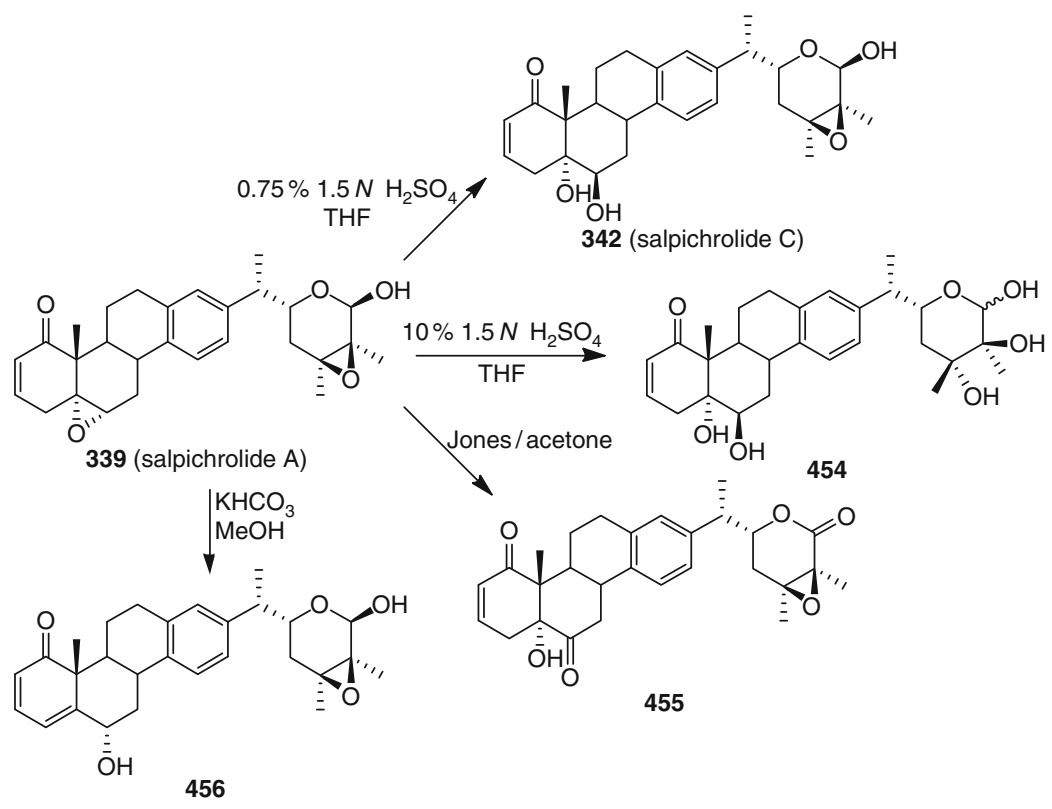

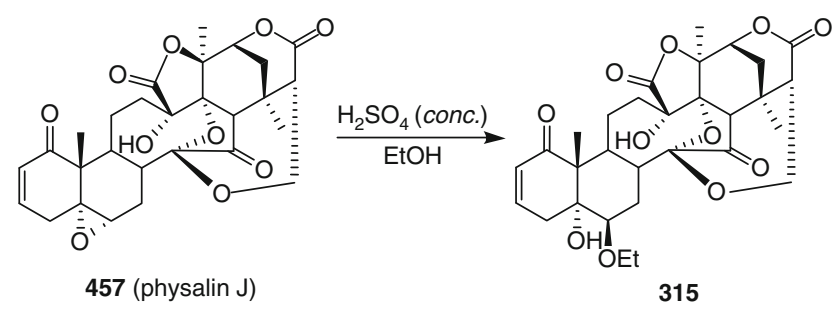

Chart 2 Cleavage reactions of $5 \alpha, 6 \alpha$-epoxy withanolides 


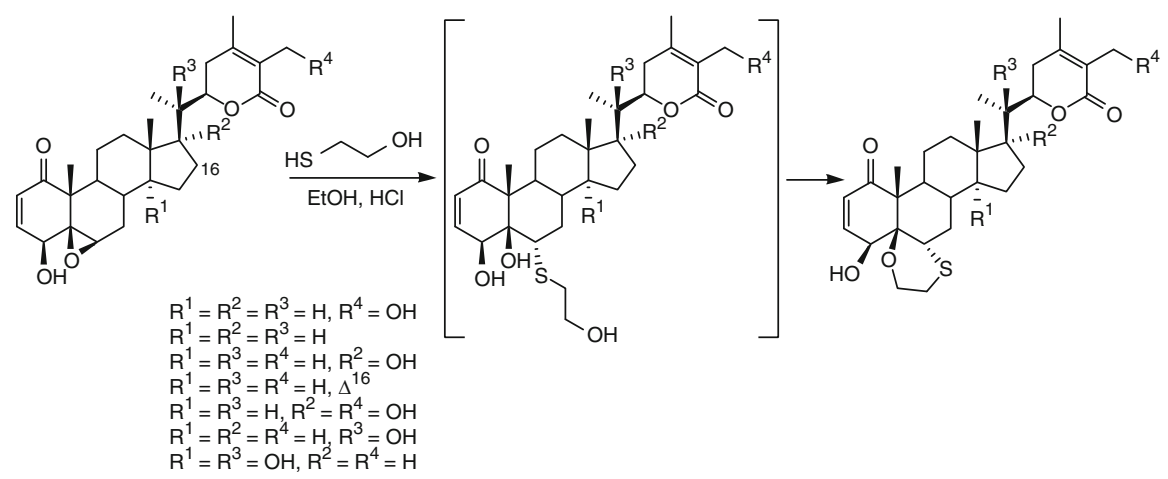

Chart 3 Reaction of withaferin $A\left(\mathrm{R}^{1}=\mathrm{R}^{2}=\mathrm{R}^{3}=\mathrm{H}, \mathrm{R}^{4}=\mathrm{OH}\right)$ and related 5 $\beta, 6 \beta$-epoxy withanolides with mercaptoethanol

under the same reaction conditions; attempts to force the reaction using a higher temperature and a lower $\mathrm{pH}$ resulted in complex mixtures (191).

Salpichrolide B (341), a minor constituent of S. origanifolia (see Sect. 5.3.1.), was obtained from the abundant salpichrolide A (339) by acetylation of the side chain hemiketal followed by stereoselective reduction of the $\mathrm{C}-1$ ketone with sodium borohydride; deacetylation of the side chain occurred during workup. Following a similar protection/deprotection sequence, salpichrolide C (342) was oxidized to the 6-ketone 458 (Chart 4) (190).

Modifications at the side chain are less common, and one interesting example by Mohan and coworkers is the synthesis of a biotinylated analog of withaferin A (459) (Chart 5) for use as a probe to study angiogenesis (see Sect. 7.6.3.) (192).

\subsection{Photochemical Transformations}

Physalins containing an endoperoxy moiety in ring A were prepared from the corresponding $\Delta^{2,4}$-6-hydroxy physalin by photosensitized oxygenation. Thus, a ca. 1:1 mixture of physalins $\mathrm{K}(\mathbf{3 1 1})$ and Q (297) was obtained in $65 \%$ yield, by bubbling oxygen through a solution of physalin $G$ (314) containing Rose Bengal and irradiated at $480 \mathrm{~nm}$ (Chart 6) (144). The same reaction carried out on 6-epiphysalin G (460) gave the $2 \beta, 5 \beta$-endoperoxide 461 as the major product $(76 \%$ yield) and a trace amount $(2 \%)$ of the $2 \alpha, 5 \alpha$-isomer $\mathbf{4 6 2}$. (Note that names of physalin $\mathrm{G}$ and its 6-epimer have been assigned according to the revised structure of the former; see Sect. 5.2.3.). Photosensitized oxygenation of physalin B (463) gave a mixture of physalin K (311), the isomeric endoperoxide 461, the $5 \alpha$-hydroperoxide 464 and the corresponding alcohol 465 (Chart 6) (144). 

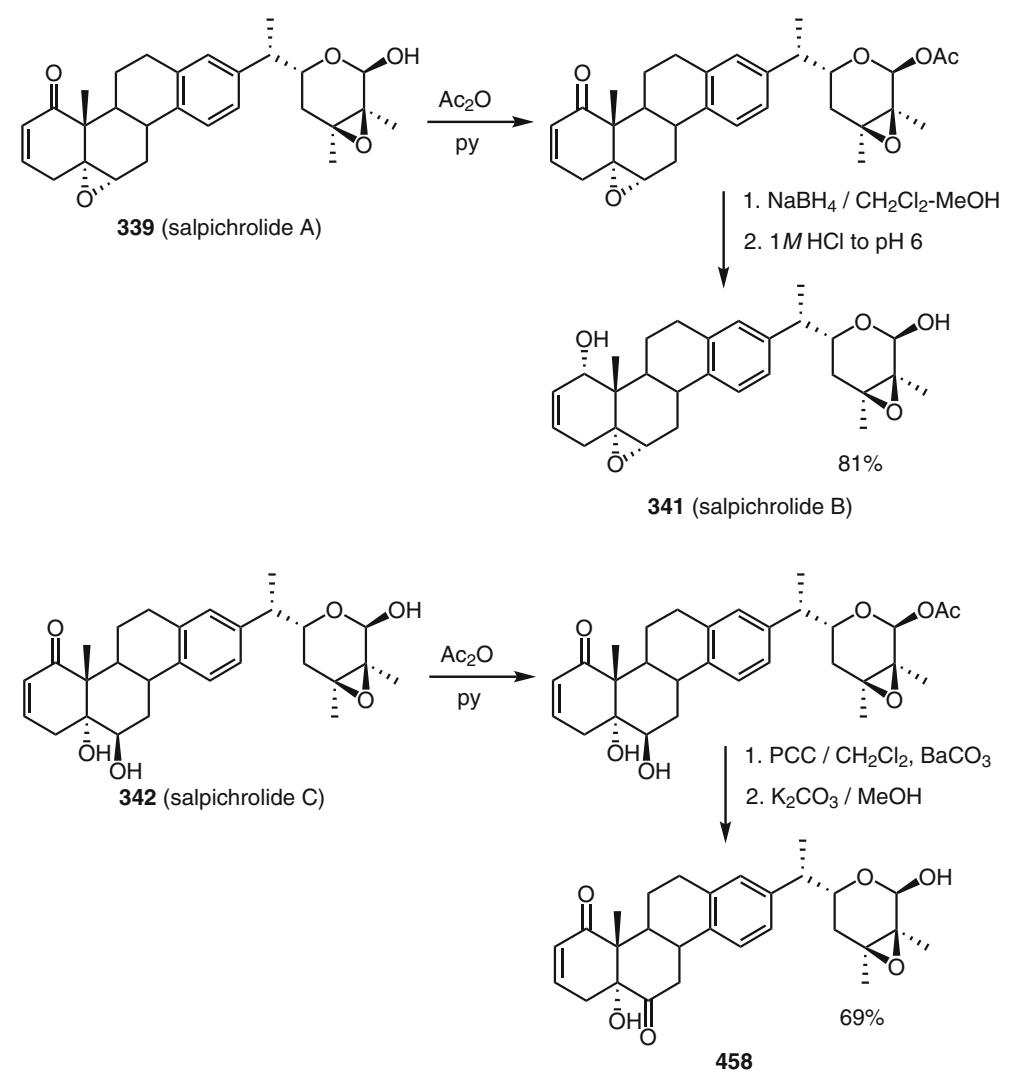

Chart 4 Chemical modification of salpichrolides A (339) and C (342)

Irradiation of an acetone solution of physalin B (463) with a tungsten-halogen lamp under argon, gave physalin R (310) in $49 \%$ yield. Irradiation of physalin $\mathrm{F}$ (450) under similar conditions gave the corresponding cyclophysalin (466). The $7 \alpha-$ hydroxy physalins, physalin $\mathrm{N}$ (467), A (468), and O (469), the latter two lacking the C-14-C-27 oxygen bridge, also gave the cyclophysalins (470-472) but required irradiation with a high-pressure mercury lamp (Chart 7) (142). The $\Delta^{2}$-1-ketone system of the physalins would be involved in a self-sensitizing mechanism, as 2,3dihydrophysalins failed to give the cyclized product.

\subsection{Biotransformations}

The modification of natural products by microorganisms may lead to new structures with potential biological activities. Application of this strategy to withanolides has been reviewed by Anjaneyulu et al. (4). Biotransformation of physalin $\mathrm{H}$ (312) by the fungus Rhizopus stolonifer gave the elimination product $\mathbf{4 7 3}$ in $2.1 \%$ 
R.I. Misico et al.
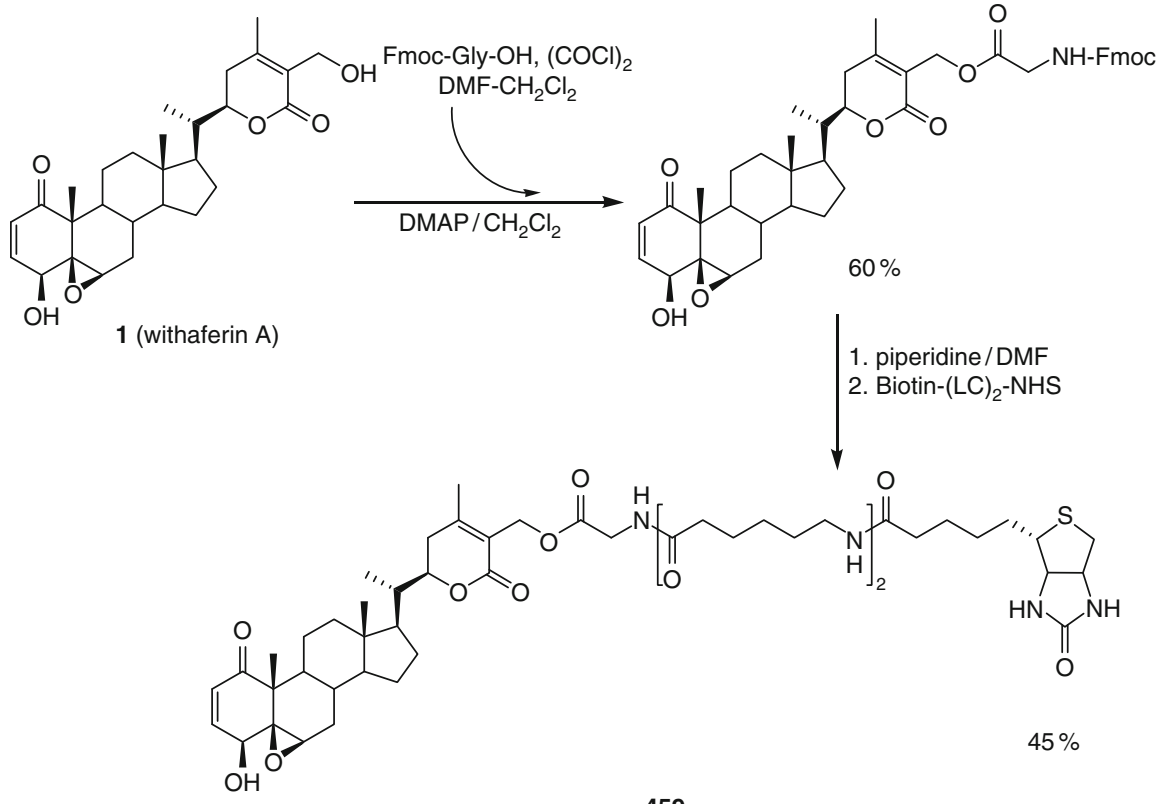

459

Chart 5 Synthesis of a biotinylated analog of withaferin A (1)
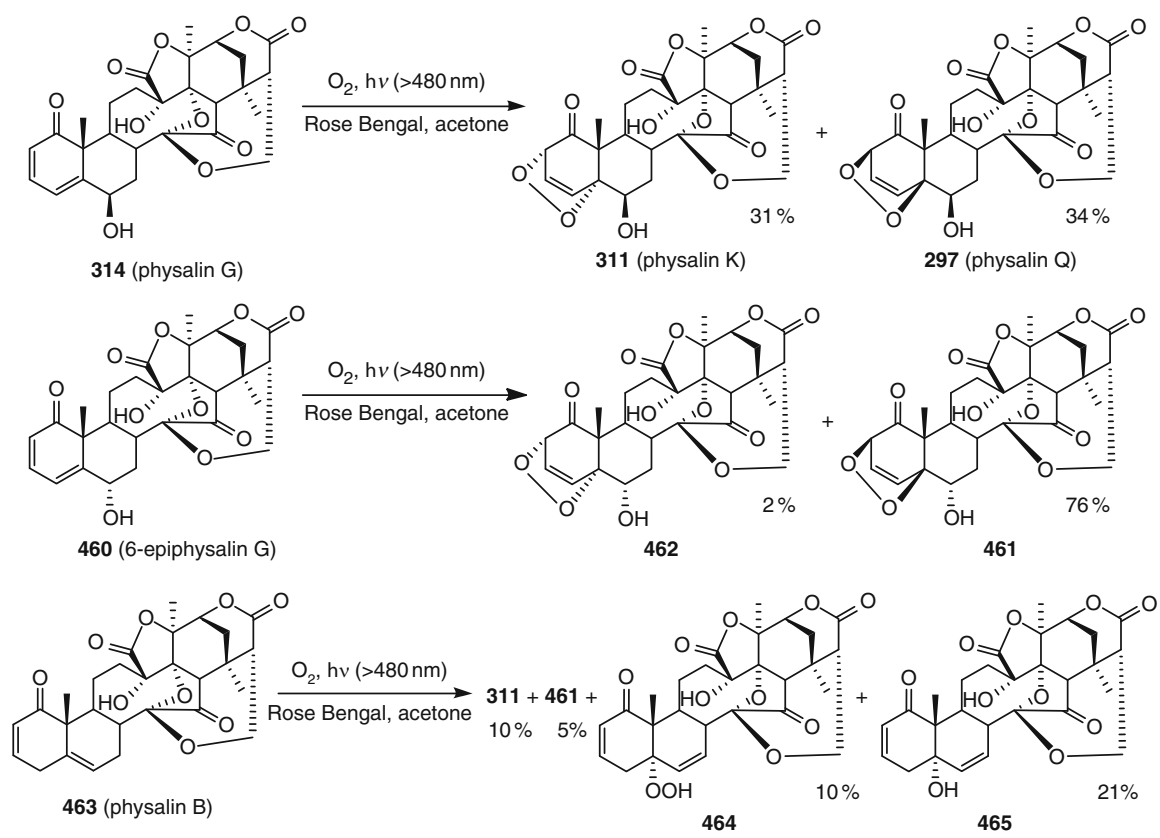

Chart 6 Photooxygenation of physalin G (314), 6-epiphysalin G (460) and physalin B (463) 

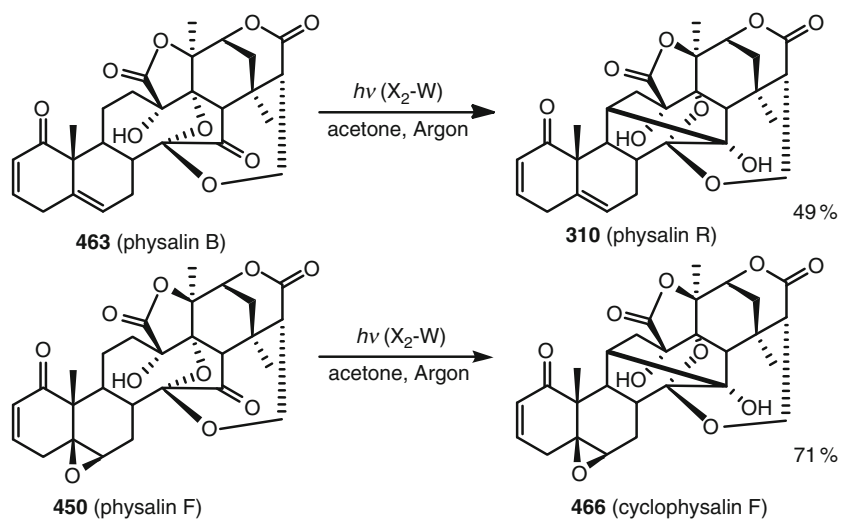

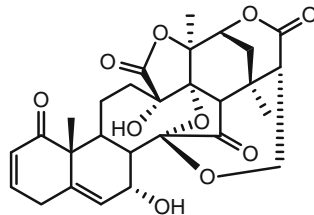

467 (physalin N)

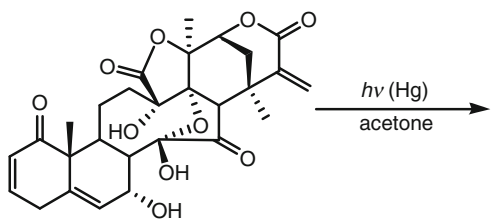

468 (physalin A)

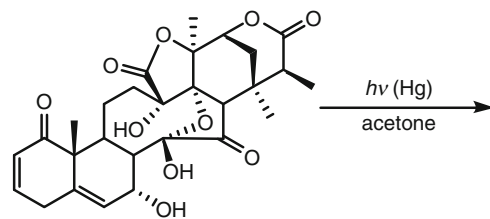

469 (physalin O)

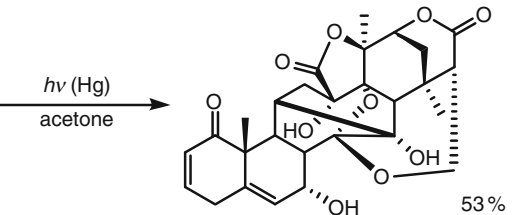

470 (cyclophysalin N)

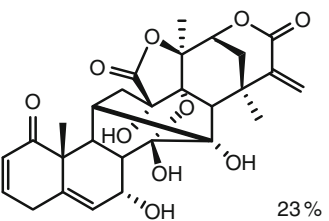

471 (cyclophysalin A)

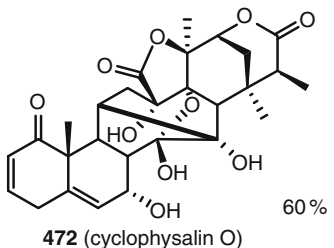

Chart 7 Photocyclization of physalins to cyclophysalins. $X_{2}$-W halogen-tungsten lamp; $H g$ high pressure mercury lamp

yield, while incubation with Cunninghamella elegans gave isophysalin B (474) and 6-deoxyphysalin H (475) in 9.4\% overall yield (Chart 8) (193). Both $\mathbf{4 7 3}$ and $\mathbf{4 7 5}$ are new compounds. Incubation of withaferin A (1) with Cunninghamella echinulata gave $12 \beta$-hydroxywithaferin A (476) and $15 \beta$-hydroxywithaferin A (477) (194); the same hydroxylated products have been obtained upon incubation with Cunninghamella elegans (4). Several reports also describe the production of withanolides (mostly withaferin A) by shoot cultures of Withania somnifera (195-198).

Tuli and coworkers isolated two specific glucosyltransferases from $W$. somnifera. The cytosolic $3 \beta$-hydroxy sterol glucosyltransferase was most active on 24-methylenecholesterol, and showed moderate activity for the $3 \beta$-O-monoglucosylation of the 

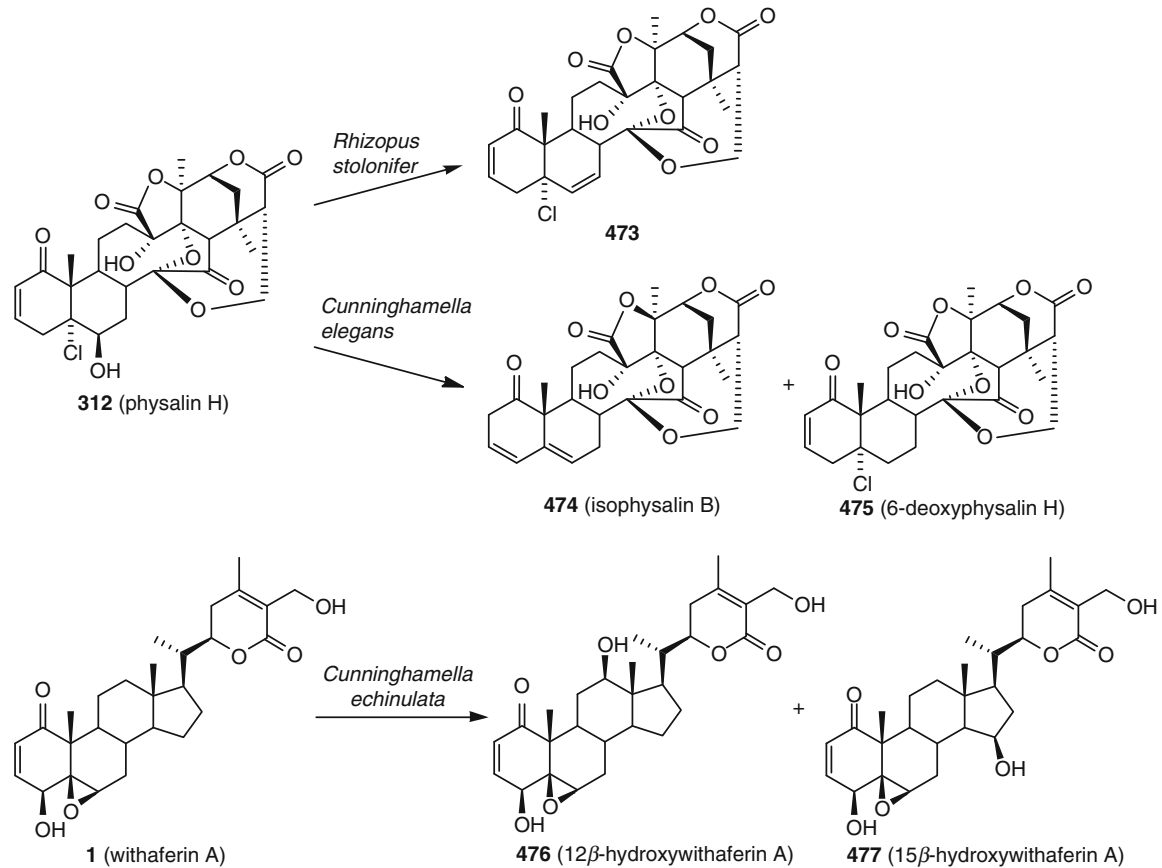

Chart 8 Biotransformations of physalin H (312) and withaferin A (1) with microorganisms

aglycone of withanoside V (478) (199). On the other hand the 27-hydroxy glucosyltransferase monoglucosylated several 27-hydroxywithanolides, provided a hydroxy group was also present at C-17 (Chart 9) (200).

\section{Biological Activities of the Withanolides}

As already mentioned, several withanolide-containing plants are used in traditional folk medicine throughout the world and many of the verified activities can be traced to their withanolide constituents. Withania somnifera used in Ayurvedic medicine in India since ancient times is the prototypical example, but similar uses have been accorded to Datura metel in traditional Chinese medicine and to several Physalis species in Asia and the Americas. Withanolides have proven active not only in a wide variety of assays related to human ailments, but also in potential applications as natural agrochemicals for pest and weed control. Despite the structural variety of withanolides and the many different activities they present, it is noteworthy, as will become evident in the following sections, that some structural characteristics are usually associated with biological activity (or the lack of it). One such feature is, with few exceptions, the lack of activity of $5 \alpha, 6 \beta$-diols as compared to the corresponding epoxides (or the $\Delta^{5}$ analogues) that are usually active. 

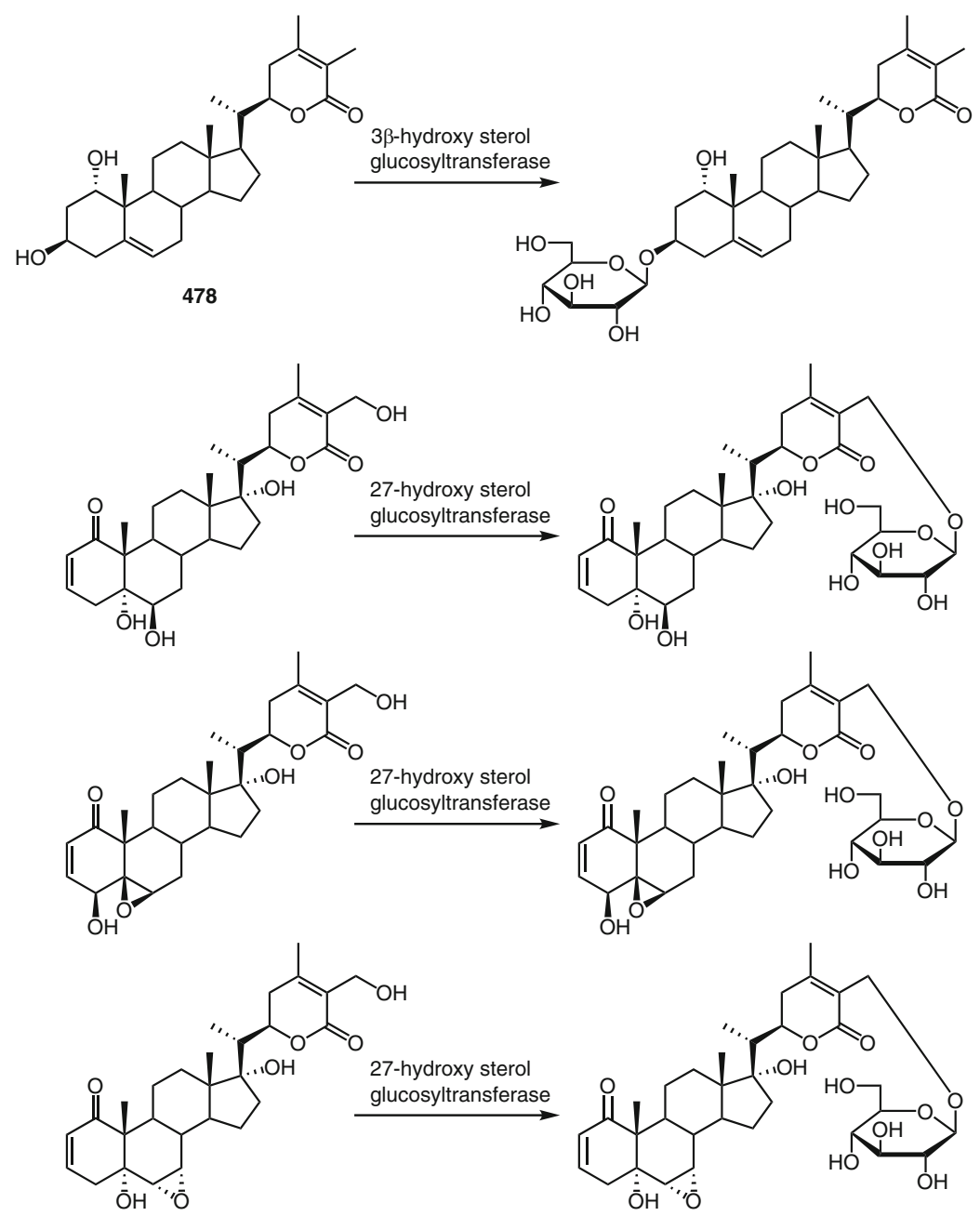

Chart 9 Enzymatic glucosylation of 3 $\beta$ - and 27-hydroxy withanolides

\subsection{Insecticidal Activities}

Insecticidal properties of withanolides were first noted for components isolated from the Peruvian plant Nicandra physalodes in the early 1960s. The major component of this plant, nicandrenone or Nic-1 (338), was later shown to be responsible for the insecticidal properties (59). Since then, several withanolides have been shown to exhibit insecticidal activity. 


\subsubsection{Antifeedant and Growth Inhibition}

Antifeedant effects and species-specific activity were initially shown for the cotton leafworm Spodoptera littoralis (Boisd.) (Lepidoptera), the Mexican bean beetle, Epilachna varivestis Muls. (Coleoptera), and the red flour beetle, Tribolium castaneum (Herbst) (59). Elliger and coworkers found that some chromatographic fractions of an extract of Physalis peruviana leaves had a strong inhibitory effect on the development of larvae of the corn earworm Helicoverpa zea, an economic pest of numerous crops including tobacco and tomato (201). Bioassay-directed fractionation led to the isolation of a series of saccharide esters structurally related to the withanolides, with the $\delta$-lactone side chain open and the carboxyl group esterified by mono-, di-, or trisacharides $(202,203)$. The most active compound in inhibiting larval growth was the $11 \beta$-hydroxy diglucoside ester $479\left(E D_{50} 5.4 \mathrm{ppm}\right)$ and the least active was the closely related monoglucoside ester $480\left(E D_{50} 110 \mathrm{ppm}\right)$. No clear structure-activity relationships could be established, but the lack of toxicity of the compounds led the authors to conclude that growth inhibition was a consequence of feeding deterrence resulting in semi-starvation of the animals. Previously, the feeding deterrent withanolides $4 \beta$-hydroxywithanolide E (481) and withanolide E (482) had been found in very high concentrations in the leaves and berries of $P$. peruviana (204).

The antifeedant activities of the major withanolides of Salpichroa origanifolia, salpichrolides A (339), C (342), and G (340), and some synthetic derivatives, were investigated on larvae of the common fly Musca domestica (189), the stored grain pest Tribolium castaneum (205), and the Mediterranean fly Ceratitis capitata (190). Salpichrolide A (339) was the most active in all cases producing a significant development delay in surviving larvae, when added to the diet at 500 ppm concentration. Similar delays were observed when medium and low nutrition diets (without withanolides) were offered as food, supporting the idea that these compounds act as feeding deterrents. The effects of salpichrolides C (342) and G (340) differed from one insect species to the other, thus both compounds produced development delays only at high concentrations $(2,000 \mathrm{ppm})$ in $M$. domestica and C. capitata, but salpichrolide $\mathrm{G}$ was almost as effective as salpichrolide A in T. castaneum. Regarding toxicity, the three salpichrolides produced significant mortality for M. domestica larvae ( $\left.E C_{50} 200-300 \mathrm{ppm}\right)$, but only salpichrolides A and G had this effect on $C$. capitata. The authors proposed that differences could be related to different detoxifying mechanisms.

Oxidation of the hemiketal in the side chain to give the $\delta$-lactone 483 eliminated the activity both for M. domestica and T. castaneum. However, acetylation to give 484 drastically reduced the activity only for the latter insect. Reduction of the $\Delta^{2}$ double bond had only a minor negative effect on activity $(189,205)$. The effect of functional group modifications in rings A and B on the resultant activity was evaluated on C. capitata larvae (190). Salpichrolide B (341), a minor component of S. origanifolia, was prepared from salpichrolide A in sufficient amounts for testing (see Sect. 6.1.). This compound was the most active of all salpichrolides tested, producing significant mortality when incorporated to the diet even at low doses $\left(E C_{50} 83 \mathrm{ppm}\right)$. It also produced clearly observed development delays in surviving 
larvae at $25 \mathrm{ppm}$. Reduction of the $\Delta^{2}$ double bond (485 and 486) produced a significant decrease in activity. Oxidation of salpichrolide $\mathrm{C}$ to the 6-ketone (458) or rearrangement of the 5,6-epoxide in salpichrolide A to the $\Delta^{2,4}-6 \alpha$-alcohol 456 resulted in inactive compounds.

The content of the salpichrolides in S. origanifolia was monitored during plant development, reaching a maximum during summer when insect populations are higher. These results, in conjunction with the observed toxic and feeding deterrent activities, suggest that these compounds may act as a chemical defense providing protection to the plant against phytophagous insects (189).

Feeding-deterrent activity of the major components of Jaborosa odonelliana, the spiranoid withanolides jaborosalactone $\mathrm{P}$ (389) and jaborosalactone 10 (390), was studied against $T$. castaneum (177). In this case, only jaborosalactone P (389) produced a significant delay in the development of neonate larvae. In the case of J. integrifolia, only jaborosalactone A (487) exhibited antifeedant activity on larvae of Spodoptera littoralis (206). Rearrangement of the epoxide to the allylic alcohol as in jaborosalactone B (488) or cleavage to the diol as in jaborosalactone D (489) resulted in complete loss of the activity. Jaborosalactone S (254) from J. sativa was a feeding deterrent for Tenebrio molitor (207) and the trechonolide-type withanolide $\mathbf{3 8 6}$ isolated from J. lanigera produced significant development delays in C. capitata larvae (175).

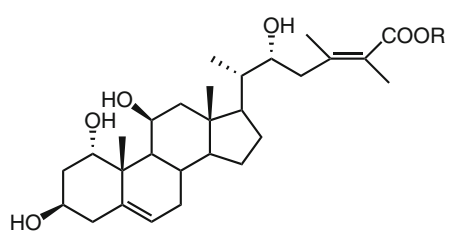

$479 \mathrm{R}=$ gluc $-(1-2)-$ gluc -6 '-Ac $480 \mathrm{R}=$ gluc

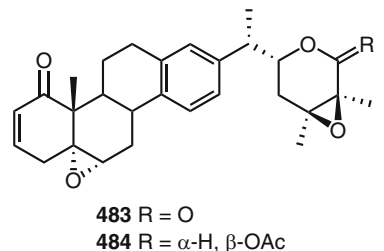

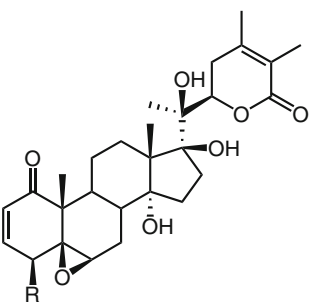

$481 \mathrm{R}=\mathrm{OH}(4 \beta$-hydroxywithanolide $\mathrm{E})$ $482 \mathrm{R}=\mathrm{H}$ (withanolide $\mathrm{E}$ )

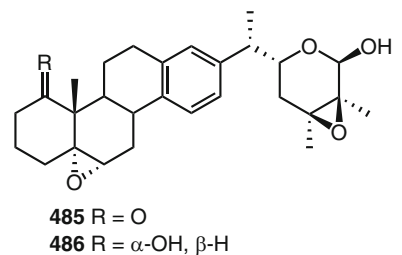<smiles></smiles>

487 (jaborosalactone A)<smiles></smiles>

488 (jaborosalactone B)<smiles>CC1=C(CO)C(=O)OC([C@H](C)C2CCC3C4C[C@H](O)[C@H]5CC=CC(=O)C5(C)C4CC[C@]32C)C1</smiles> 
Azambuja and coworkers studied the effect of several physalins from Physalis angulata on the blood-sucking insect Rhodnius prolixus, vector of Trypanosoma rangeli. Physalins B (463), D (313), F (450), and G (314) produced immune depression in $R$. prolixus, although apparently by different mechanisms. Without their defense system, insects infected with $T$. rangeli die (208-210).

\subsubsection{Ecdysteroid Agonists and Antagonists}

The ecdysteroid endocrine system is vital for insect development and a variety of secondary metabolites from plants have been shown to interfere with ecdysteroids, probably as a chemical defense mechanism. Dinan and coworkers developed a microplate-based bioassay with the ecdysteroid-responsive Drosophila melanogaster $\mathrm{B}_{11}$ cell line and used it to evaluate 16 withanolides isolated from Iochroma gesneriodes, for agonistic/antagonistic activity (211). Only withanolides containing an oxygenated functionality at C-3 (hydroxy or methoxy) and an $\alpha, \beta$-unsaturated lactone in the side chain showed antagonistic activity, with 2,3-dihydro-3 $\beta$ hydroxywithacnistine (490) being the most active $\left(E D_{50} 2.5 \mu M\right.$ versus $0.05 \mu M$ for 20-hydroxyecdysone). In a systematic study of 128 species of solanaceous plants including those known to contain high levels of withanolides, only a few of the methanolic extracts showed weak ecdysteroid antagonist activity (212). The high reactivity of the $\Delta^{2}$-1-keto system present in many withanolides, raises the possibility that, even though inactive in vitro, they could be activated by conversion to the 2,3-dihydro-3 $\beta$-hydroxywithanolides upon ingestion by insects (213). Further studies on 21 withanolides from different sources showed that withaperuvin D (491), with a C-3, C-6 oxygen bridge, had moderate agonistic activity $\left(E C_{50} 25 \mu M\right)(214)$.

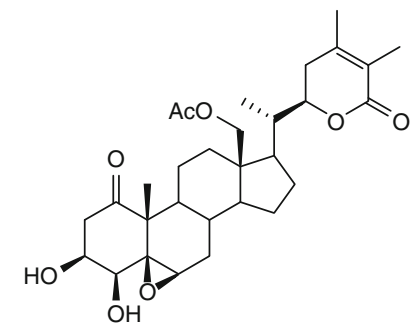

490 (2,3-dihydro-3 $\beta$-hydroxywithacnistine)

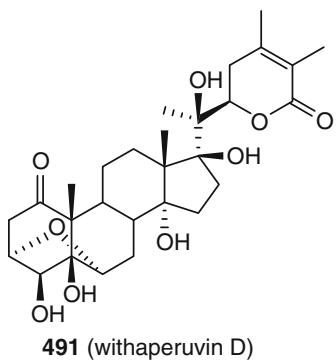

491 (withaperuvin D)

\subsection{Phytotoxic Activities}

Selective phytotoxicity has been reported for several withanolides. Three 7-oxygenated withanolides, 492-494, isolated from Iochroma australe, reduced 
radicle growth of the weeds Sorghum halepense (L.) Pers. (Monocot.) and Chenopodium album L. (Dicot.). Compound 493 inhibited radicle growth of Lactuca sativa L. (lettuce) but only at high concentration (1,000 ppm) (215). Jaborosalactol 18 (285) a major constituent of J. bergii (see Sect. 5.1.4.) showed significant inhibition of radicle growth at $2 \mathrm{~m} M$ on the dicotyledoneous species C. album, Ipomoea purpurea (L.) Roth and L. sativa (phytogrowth inhibitory activity $>49 \%$ ). On the other hand, 285 had a strong stimulatory effect in the monocotyledoneous species tested (Zea mays L. and Sorghum halepense) (69). Several withanolides isolated from $J$. rotacea also exhibited different activities towards mono- and dicotyledoneous species. Thus, jaborosalactones 29 (447), 30 (448), 31 (404), and 33 (370) had opposite effects on the dicotyledon L. sativa and the monocotyledon Phalaris canariensis L. Jaborosalactone 29 (447) was the most active, selectively inhibiting radicle growth, germination and the emergence rate index of $L$. sativa but with no effect on P. canariensis. Jaborosalactones 30 and $31(448,404)$ had a strong stimulatory effect on radicle growth of $P$. canariensis. The chlorohydrin jaborosalactone 28 (446) was the only withanolide that inhibited the radicle growth of $P$. canariensis (120). A similar selectivity was exhibited by the major component of $J$. kurtzii, jaborosalactone 43 (449) (spiranoid type), and by withanolides of $J$. caulescens, the 12-O-ethyl derivative of jaborosalactone 42 (12- $O$-ethyl-373) (trechonolide type) and the sativolides 258, and 12- $O$-methyl-258. All these compounds strongly inhibited radicle growth of L. sativa but exhibited a marginal effect on the monocotyledoneous Avena sativa L. $(76,121)$.

\subsection{Antiparasitic Activities}

The first withanolides with antileishmanial and antitrypanosomial activities were isolated from Dunalia brachyacantha when screening extracts of Bolivian plants against Trypanosoma cruzi (Chagas disease), and several Leishmania species. Bioassay-guided fractionation of the leaf extract gave the known 18-acetoxywithanolide $\mathrm{D}(\mathbf{1 4 2})$ and its $\Delta^{5}$ analogue 495, with the latter compound being the most active against epimastigote forms of $T$. cruzi and promastigote cultures of L. amazonensis, L. braziliensis, and L. donovani (84).

\subsubsection{Trypanocidal Activity}

In a systematic study of the trypanocidal activity of secondary metabolites isolated from plants from northeastern Brazil, Vieira et al. found withaphysalins $\mathrm{M}$ and $\mathrm{O}$ (323, 325) from Acnistus arborescens (see Sect. 5.2.4.) to be the most active compounds against epimastigotes of $T$. cruzi, with $I C_{50}$ values of 100 -fold less than the reference compound benznidazole (216). Reduction of the 2,3 double bond as in withaphysalin $\mathrm{N}$ (324) reduced the activity by an order of magnitude. Most 
interestingly, these withaphysalins had no cytotoxic activity against dividing normal cells. Physalin F (450) from Physalis angulata was shown to be moderately active. Abe and coworkers investigated the trypanocidal activity of ten withanolides from $P$. angulata growing in Japan, against $T$. cruzi epimastigotes and trypomastigotes (the infectious form of the parasite) (57, 66). Physagulins A-C (496-498), H (117) and I (118), and withangulatin A (499) had activity against both forms of T. cruzi similar to their cytotoxicity; activity against trypomastigotes was higher for these withanolides. Physagulins F (500), J (119), K (120), L (121), and M (103) and withaminimin (501) containing the $5 \alpha, 6 \beta$-diol moiety were weakly active against epimastigotes, but the first two of these compounds were moderately active against the infectious trypomastigote form. Physagulin N (106), the methoxy derivative of physagulin A, was also marginally active confirming that the A ring enone is required for activity.
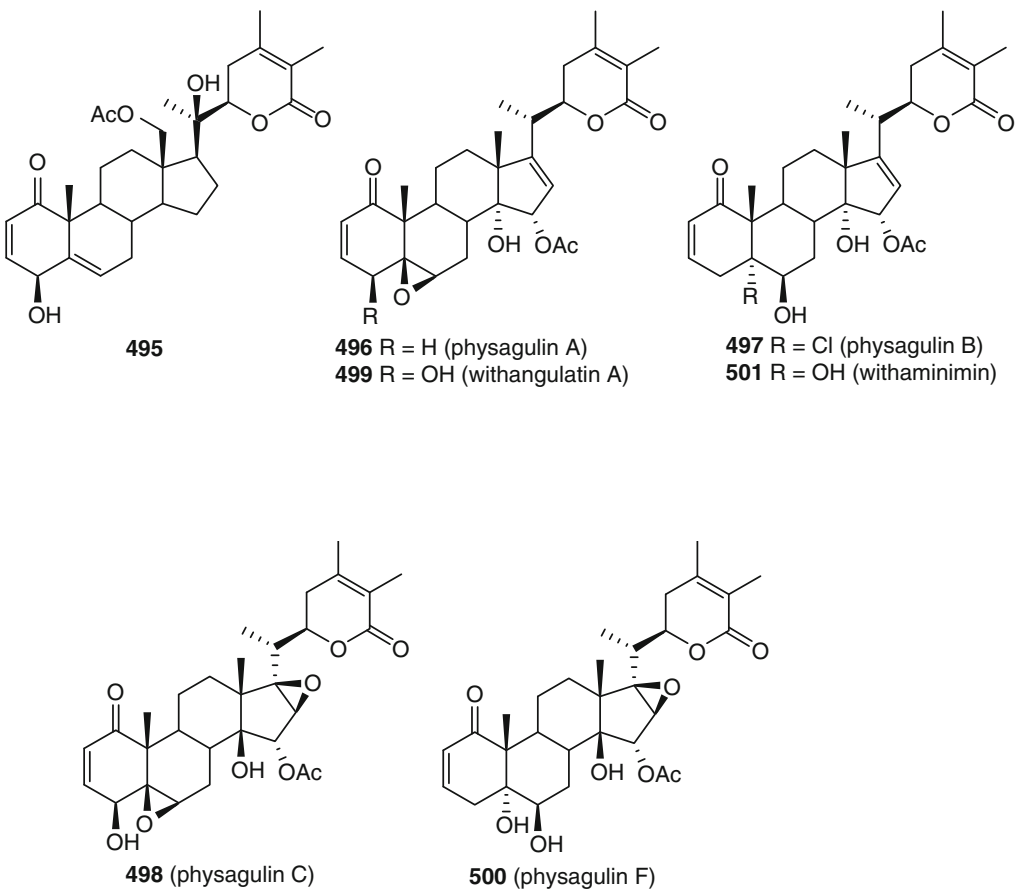

\subsubsection{Leishmanicidal Activity}

Atta-ur-Rahman and coworkers have reviewed the antileishmanial activity of withanolides from Physalis minima as well as some of their biotransformation products (217). Physalin 299 was the most active substance against Leishmania major 
promastigotes, (see Sect. 5.2.1.) while physalins $\mathbf{2 9 8}, \mathbf{3 0 0}, \mathbf{3 0 1}$, physalin $\mathrm{H}(\mathbf{3 1 2})$, isophysalin B (474), and 5 $3,6 \beta$-epoxyphysalin B (502) also had significant activity. The 3-methoxy derivative physalin $\mathrm{U}(\mathbf{3 0 4})$ and withanolide 107 with an unmodified skeleton were only marginally active $(60,145)$. Removal of the C-6 hydroxy group of physalin $\mathrm{H}(\mathbf{3 1 2})$ to give either the dehydration product $\mathbf{4 7 3}$ or the deoxygenated physalin $\mathbf{4 7 5}$ (see Sect. 6.3.) did not affect the antileishmanial activity (193).

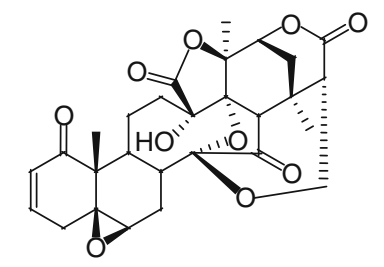

502 (5 $5,6 \beta$-epoxyphysalin B)

Echeverri and coworkers investigated the leishmanicidal activity of several acnistins (A, B, C, E, F, and G) and withajardins (A, B, and C) isolated from Dunalia solanacea and Deprea orinocensis, respectively (see Sects. 5.1.2. and 5.1.3.). Efficacy was evaluated using intracellular amastigotes of Leishmania (V) panamensis (218). Withajardin B (278) and acnistins A (259), C (262), and E (260) were the most active; withajardin A (277), and acnistins B (261), and F (264) were the least active. The 3-methoxy derivative of withajardin A was inactive. All compounds had poor selectivity, with antileishmanial activity closely paralleling cytotoxicity in all cases. The authors did a 3D-QSAR study and concluded that differences in bioactivity could be explained by the influence of steric and electrostatic fields in the vicinity of ring A. According to the model, bending of the steroid nucleus at the $\mathrm{A} / \mathrm{B}$ ring junction, an increase of positive charge near positions 2,3 , and 4 , or of a negative change near positions 5 and 6 , increased the bioactivity.

Withaferin A (1) inhibited growth of L. donovani promastigotes. In vitro studies showed that withaferin $\mathrm{A}$ inhibits protein kinase $\mathrm{C}$ in the parasite, leading to apoptosis (219). Withanolide Z (27), but not withaferin A, partially inhibited L. donovani topoisomerase I (28).

\subsection{Antimicrobial Activities}

The antibacterial and antifungal properties of withaferin A (1) have been known for a long time and many other withanolides are known to display these activities $(3,4)$. However, data are scattered throughout the literature involving the action of different compounds on different microorganisms thus making it difficult to rationalize the results. Withaferin A has been shown to be strongly active against Bacillus subtilis and moderately active for Escherichia coli and Staphylococcus aureus, but inactive against Pseudomonas aeruginosa. As an antifungal it exhibited 
strong activity against Aspergillus niger, but was inactive against Rhizopus oryzae and Candida albicans (220). 4-Deoxywithaperuvin (11) was moderately active against several Gram-positive (B. cereus, B. subtilis, Streptomyces spp.), and Gram-negative (Pseudomonas fluorescens, Serratia marcescens) bacteria, but inactive against Micrococcus luteus, $M$. roseus and $S$. aureus; antifungal activity was poor (20). On the other hand, the 18-oxygenated withanolides 18-acetoxywithanolide D (142) and its $\Delta^{5}$ analogue 495 from $D$. brachyacantha were active against $S$. aureus and B. subtilis and inactive against E. coli and Shigella flexneri (84).

$17 \beta$-Hydroxywithanolide $\mathrm{K}(\mathbf{5 1})$ and the closely related $14 \alpha, 20$-epoxywithanolide, 71 (see Sect. 4.1.4.) showed antifungal activity against the human pathogens (MIC $300 \mu \mathrm{g} / \mathrm{cm}^{3}$ ) Aspergillus niger, Stachybotrys atra, Allescheria boydii, Drechslera rostrata, Microsporum canis, and Curvularia lunata $(36,43)$.

Among the physalins, physalin B (463) was active against $S$. aureus (several strains) and $N$. gonorrhoeae but not active against E. coli and P. aeruginosa (221). Physalin D (313), but not physalin B, was moderately active against Mycobacterium tuberculosis (222).

\subsection{Anti-inflammatory and Glucocorticoid Related Activities}

\subsubsection{Anti-inflammatory Activity}

The antiinflammatory properties of several withanolides are well known (3). Souza and coworkers have shown that in the case of physalins B (463) and F (450), the anti-inflammatory activity parallels that of the synthetic glucocorticoid dexamethasone in preventing inflammatory injury and lethality after intestinal ischemia and reperfusion in mice (223). Furthermore, they found that the effect could be reversed by pretreatment with the glucocorticoid antagonist RU-486, indicating that the in vivo activity displayed by the physalins is mostly due to activation of the glucocorticoid receptor. As observed with dexamethasone, physalins also decreased TNF- $\alpha$ concentration and enhanced the anti-inflammatory interleukin IL-10 concentration in tissues. Physalins B (463) and F (450) have been shown to inhibit TNF- $\alpha$ induced activation of NF- $\kappa \mathrm{B}$ and either a 5,6 double bond or a $5 \beta, 6 \beta$-epoxide are required for activity; the $5 \alpha, 6 \beta$-diol physalin $\mathrm{D}$ (313) is inactive (138).

An ethanol extract of $W$. somnifera significantly suppressed lipopolysaccharide (LPS)-induced production of the pro-inflammatory cytokines TNF- $\alpha$, IL-1 $\beta$, and IL-12p40 in peripheral blood mononuclear cells of normal individuals and reumathoid arthritis patients, and inhibited nuclear translocation of the transcription factors NF- $\kappa \mathrm{B}$ and $\mathrm{AP}-1$ and phosphorylation of $\mathrm{I} \kappa \mathrm{B} \alpha$. The major component, withaferin $\mathrm{A}(\mathbf{1})$, inhibited $\mathrm{NF}-\kappa \mathrm{B}$ translocation and was associated with these effects (224). Withaferin A inhibited NF- $\kappa B$ activation by preventing the TNFinduced activation of I $\kappa \mathrm{B}$ kinase via a thioalkylation-sensitive redox mechanism 
(225). 12-Deoxywithastramonolide (503) and withanolide A (504) were much less effective. A more detailed study on the inhibition of $\mathrm{NF}-\kappa \mathrm{B}$ activation by various agents was conducted by Ichikawa et al. (226). The authors isolated a series of withanolides from a $W$. somnifera leaf extract, which included withaferin A (1), viscosalactone B (505), withanosides IV (31) and X (37), and related compounds. The $1 \alpha, 3 \beta$-dihydroxy- $\Delta^{5}$-withanolides and their glycosides did not inhibit NF- $\kappa \mathrm{B}$ activation while withaferin $\mathrm{A}$ and its diacetate were strong inhibitors. Reduction of the 2,3-double bond of withaferin A rendered the compound inactive but addition of a 3-hydroxy substituent (as in viscosalactone B) restored activity. Acetylation of the hydroxy groups of the latter compound did not affect activity, but glycosylation at C-27 gave an inactive compound.

Nair and coworkers reported the selective cyclooxygenase-2 (COX-2) inhibitory activity of leaf extracts of $W$. somnifera and related such information to the use of this plant as an antiinflammatory. From the methanolic extract they isolated 12 withanolides and evaluated their abilities to inhibit COX-1 and -2 . None of the withanolides inhibited COX-1 even at high doses but most of them exhibited some inhibitory activity on COX-2, with withaferin A (1) and viscosalactone B (505) being the most active (15). Molecular docking studies showed that most of the withanolides had more favorable binding to COX-2 than to COX-1 (227).

The 12-oxygenated withanolide 154 from Discopodium penninervium (see Sect. 4.2.3.) was a selective inhibitor of cyclooxygenase- 2 and also of leukotriene formation; as both these pathways are involved in cell proliferation and angioneogenesis, the dual inhibition of COX-2 and leukotriene formation by $\mathbf{1 5 4}$ has been proposed as a starting point for the development of anti-inflammatory and cancer chemopreventive agents (82).

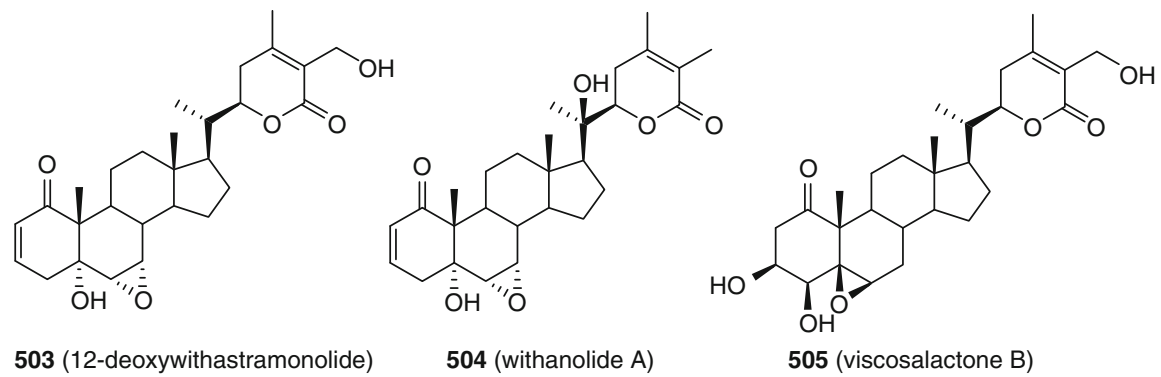

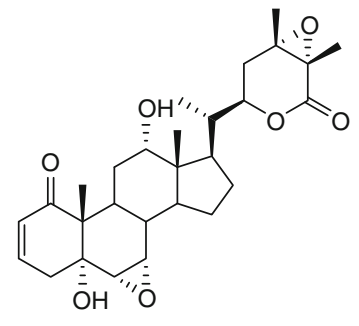

506 (daturalactone 1)

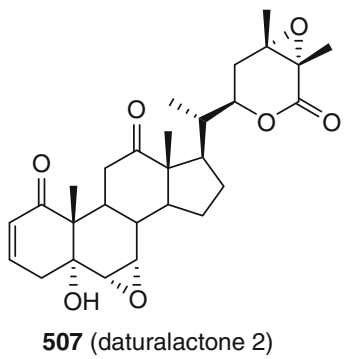




\subsubsection{Antistress Activity}

Withafastuosin D (168), the major withanolide in Datura fastuosa leaves, maintained corticosterone levels in male albino rats during experimental stress and exhibited antistress activity evidenced as an anxiolytic effect (228). Withafastuosin E (169) has also been found to increase the release of prostaglandins, which play an important role in the resistance to gastroduodenal mucosa to ulceration $(229,230)$. On the other hand, the antistress activity of $W$. somnifera glycowithanolides (e.g. sitoindosides) has been linked to their antioxidant activity (231, 232).

\subsubsection{Immunosuppressive and Immunomodulatory Activity}

The 16-oxygenated withanolides 188-190 isolated from Discopodium penninervium (see Sect. 4.2.4.) exhibited potent immunosuppresive activity; they inhibited the incorporation of $\left[{ }^{3} \mathrm{H}\right]$-thymidine in cultured rat spleen cells without being overtly toxic to the cells (233). Acnistins A (259), B (261), and E (260) from Dunalia solanacea significantly inhibited the incorporation of $\left[{ }^{3} \mathrm{H}\right]$-thymidine in human lymphocytes at doses as low as $0.1 \mu \mathrm{g} / \mathrm{cm}^{3}$ (124). Coagulin $\mathrm{H}(7)$ isolated from $W$. coagulans also was a strong inhibitor of incorporation of $\left[{ }^{3} \mathrm{H}\right]$-thymidine in stimulated human mononuclear cells. It inhibited T-cell proliferation with an activity similar to that of the synthetic glucocorticoid, prednisolone. Like prednisolone, the T-cell suppression effect was correlated with a decrease in production of the cytokine IL-2. However, at variance with the glucocorticoid, coagulin $\mathrm{H}$ did not have any damaging effects on the cells (234).

Immunomodulatory effects of three daturalactones from Datura quercifolia were evaluated by observing their effects on antibody production, T-cell and Bcell activation, and cytokine production from splenocytes. The $1 \beta$-alcohol 153 was immunosuppressive at lower doses while daturalactones 1 (506) and 2 (507) were immunostimulators $(81)$.

Physalins B (463), F (450), and G (314), but not D (313), inhibited nitric oxide production by activated macrophages. Addition of physalin B to lipopolysaccaride-stimulated peritoneal macrophage cultures induced decreases of TNF$\alpha$ IL-6, and IL-12 production. Physalins B, F, and G also protected mice against administration of a lethal dose of lipopolysaccaride (235). The effects of the above-mentioned physalins were not blocked by the antiglucocorticoid, RU-486, suggesting that they act by a mechanism different from that of the glucocorticoids. Physalins B, F, and G also have potent suppressive activities in vitro on splenocyte cultures and in vivo on allogeneic transplants (236). The effects of physalins on transplant rejection could be explained by a direct effect of these withanolides on lymphocytes. 
Several physalins isolated from Physalis alkekengi were found to be strong inhibitors of nitric oxide production induced by lipopolysaccaride, including the above-mentioned physalins $\mathrm{B}$ and $\mathrm{F}$ and also physalins $\mathrm{A}$ (468) and $\mathrm{O}$ (469). Compounds of the neophysalins class (see Sect. 5.2.2.) were inactive (139).

\subsection{Cancer-Related Activities}

Many studies have dealt with the potential antitumor activity of withanolides, and large amounts of data are available, mostly their cytotoxicity to cancer cell lines. However, other cancer-related activities specific to certain withanolide structural types have also been investigated in the last decade. Particularly interesting are those related to cancer chemoprevention, inhibition of angiogenesis, and microtubule stabilization.

\subsubsection{Cytotoxicity}

Most withanolides exhibit some level of cytotoxicity against different tumor cell lines, but usually this is non-selective and in the micromolar concentration range. Withaferin A (1) has been investigated extensively in this respect, with several recent studies also addressing its mechanism of action (191, 237-239).

Nair and coworkers assayed several withanolides from $W$. somnifera against human lung, breast, CNS, and colon cancer cell lines. Withaferin A (1), its diacetate, viscosalactone $\mathrm{B}$ (505), compound $\mathbf{6}$, and ashwagandhanolide (78) were the most active $\left(I C_{50}\right.$ range $\left.0.5-1 \mu M\right)$ and comparable in potency to a reference compound, adriamycin (47, 240). Compound 78 also inhibited lipid peroxidation and the activity of the enzyme cyclooxygenase-2 in vitro. Several withanolides from Acnistus arborescens were evaluated against panels of human cancer lines, including some 16-acetoxywithanolides and withaphysalins $\mathrm{F}$ (316), $\mathrm{M}(\mathbf{3 2 3}), \mathrm{N}(\mathbf{3 2 4})$, and $\mathrm{O}(\mathbf{3 2 5})$, with $I C_{50}$ values in the $0.2-2 \mu M$ range $(98,152$, 153, 241). The 16-oxygenated withanolides 188-190 isolated from Discopodium penninervium (see Sect. 4.2.4.) exhibited significant cytotoxicity only against murine RAW 264.7 carcinoma cell lines (233). The 12 $\beta$-acetoxywithanolide 156 did not show any cytotoxic activity up to $10 \mu M(83)$.

Bioassay of seventeen withanolides from Tubocapsicum anomalum showed significant cytotoxic activity (comparable to that of doxorubicin) against a panel of human cancer cell lines for eight of the compounds (107). From the 18-nor withanolides (see Sect. 5.5.3.), only tubocapsenolide A (441) exhibited potent cytotoxicity; this compound was shown to inhibit proliferation and induce apoptosis in MDA-MB-231 cells by thiol oxidation of heat shock proteins (242). Potent cytotoxicity was also exhibited by tubocapsanolide A (201) and 
its 20-hydroxy (204) and 23-hydroxy (205) derivatives, tubocapsanolide $\mathrm{F}$ (203), and anomanolide B (269) $(107,243)$. The other active withanolides isolated were the known withanolide $\mathrm{D}(\mathbf{5 0 8})$ and its $17 \alpha$-hydroxy derivative (509). Withaferin A (1), also used as a reference compound, was $c a .10$ times more active.

Withametelins I (235), K (237), L (238), and N (240), isolated from Datura metel, exhibited cytotoxicity against selected human cancer cell lines, namely, A549 (lung), BGC-823 (gastric), and K562 (leukemia), with $I C_{50}$ values of $0.05-3.5 \mu M$. Withametelin $\mathbf{J}$ (236) was only moderately active for the last two cell lines (92).

Withanolides from Physalis species have also been studied extensively in terms of their cytotoxicity against human and murine cancer cells. Among the physalins, physalins B (463), D (313), F (450), and H (312) showed strong cytotoxicity against multiple tumor cell lines, while physalins G (314), I (510), and physanolide A (367) were inactive. Physalins J (457) and U (304) were marginally active $(55,134,146,244,245)$. The 18-nor-physalin, withaphysanolide A (438), also was weakly active (186). For physalins B and D, the antineoplastic activity was confirmed in vivo by inhibition of tumor proliferation in mice bearing sarcoma 180 tumor cells (245). Both physalins B and F have been shown to inhibit hedgehog (Hh)/GLI-mediated transcriptional activation, which is involved directly in tumor formation and progression (246). Recently, Magalhães et al. reported different activities for physalins $\mathrm{D}$ and $\mathrm{E}$ isolated from $P$. angulata. However, as already mentioned in Sect. 5.2.3., the structure of physalin E was incorrectly assigned and later shown to be identical to physalin D (313) (244). Accordingly, these bioactivity results should be considered with caution. Among the Physalis withanolides with an unmodified skeleton, potent cytotoxic activity has been reported for withangulatins A (511), B (94), and I (102), physangulin B (512), phyperunolide A (101), withaphysacarpin (195), philadelphicalactones A (197) and B (198), 18-hydroxywithanolide D (128), and withanone (513) $(50,55,56,58,104,247)$.

Ixocarpolactones A (360) and B (361), isolated from P. philadelphica, exhibited significant inhibition of murine epidermal JB6 cell transformation (104) and ixocarpolactone A (360) present in the edible fruit of the plant showed potent antiproliferative and apoptotic activity in SW480 human colon cancer cells (247). Evaluation of 12 withaphysalins from $P$. minima and $P$. divaricata, including 331-334, showed only moderate cytotoxicity against the HCT-116 and H460 human cancer cell lines $(154,186)$.

The potential antitumor activities of an alcoholic extract of $W$. somnifera roots and of withaferin A (1) have also been studied in conjunction with radiation therapy in experimental tumors in vivo. Both exhibited significant antitumor and radiosensitizing effects without systemic toxicity (248-250). 


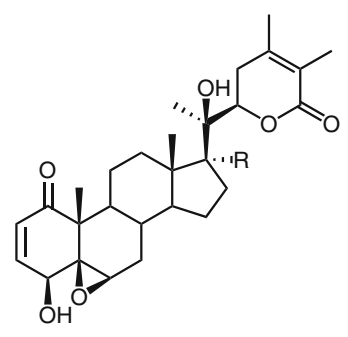

$508 \mathrm{R}=\mathrm{H}$ (withanolide D) $509 \mathrm{R}=\mathrm{OH}$

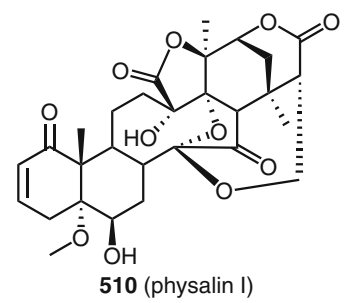

510 (physalin I)

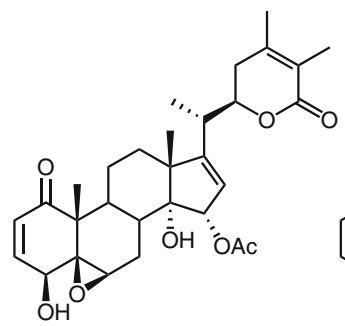

511 (withangulatin A)

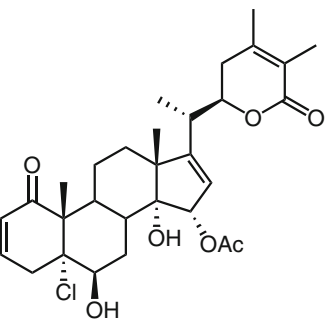

512 (physagulin B)

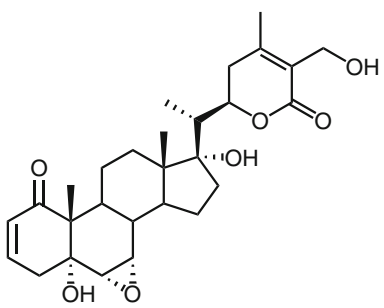

513 (withanone)

\subsubsection{Cancer Chemopreventive Activity}

Cancer chemoprevention by the ingestion of modulators of carcinogenesis from synthetic or natural origin has been proposed as a strategy to reduce cancer mortality in apparently healthy persons at risk of cancer $(6,251)$. Pezzuto, Kinghorn and collaborators have used a battery of in vitro bioassays to monitor inhibition of tumorigenesis at the stages of initiation, promotion, and progression by plant extracts and pure compounds. One key bioassay used, is based on the induction of the phase II drug-metabolizing enzyme $\mathrm{NAD}(\mathrm{P}) \mathrm{H}$ :quinone reductase $(\mathrm{QR})$, on Hepa 1c1c7 hepatoma cells; QR induction is indicative of potential cancer prevention at the initiation phase (252). A large number of compounds of plant origin have been evaluated as QR inducers, including many withanolides (6). Of particular interest are $\mathrm{QR}$ inducers that exhibit low cytotoxicity and thus a high selectivity measured as the chemopreventive index, the ratio between the concentration needed to double QR activity (CD) and the concentration that inhibits cell growth by $50 \%\left(I C_{50}\right)$.

Kinghorn and coworkers investigated QR induction by the withanolides in fruits and aerial parts of Physalis philadelphica (see Sect. 4.2.4.) (103-105). With the exception of withanone (513), all the withanolides were potent QR inducers with activity comparable to or better than the reference compound, sulforaphane, a known chemopreventive agent. Ixocarpalactone A (360), philadelphicalactone A (197), withaphysacarpin (195), and $4 \beta, 7 \beta,(20 R)$-trihydroxy-1-oxowitha-2,5dien-22,26-olide (199) exhibited the highest chemopreventive indexes. The fact 
that ixocarpolactone A (360), is present in the edible fresh fruit of $P$. philadelphica (tomatillo) at a concentration level of $143 \mathrm{ppb}$ (105), make these findings especially important.

In a broader study comprising withanolides from 13 Solanaceae species, 37 withanolides representative of a variety of structural types were evaluated for their potential to induce quinone reductase (253). Jaborosalactone 1 (397), jaborosalactone $\mathrm{O}(\mathbf{3 5 3})$, jaborosalactone $\mathrm{P}(\mathbf{3 8 9})$, trechonolide $\mathrm{A}(\mathbf{3 6 8})$, and withaphysalin $\mathrm{J}(\mathbf{3 2 0})$, were significant $\mathrm{QR}$ inducers with $\mathrm{CD}$ values in the range of $0.27-1.52 \mu \mathrm{M}$. Results indicated that a functionalized methyl-18 plays an important role in improving QR induction while the presence of $5 \alpha$-substituents is deleterious for the activity. Overall, spiranoid- and trechonolide-type withanolides exhibited good QR induction. Some of the active withanolides had low cytotoxicity, with chemopreventive indexes that compared favorably with the reference compound sulforaphane. One such compound, the spiranoid, jaborosalactone $\mathrm{P}$ (389), was selected to test its capacity to induce steady-state levels of quinone reductase in multiple organ sites of $\mathrm{BALB} / \mathrm{c}$ mice. With jaborosalactone P-treated mice, a significant induction was observed in liver and colon, but not in lung, stomach, or mammary gland (253). This in vivo study confirmed the in vitro results, indicating that withanolides may function as potent phase II enzyme inducers.

Withanolides 184 and 185 from A. arborescens, bearing acetates at positions $7 \beta$ and $16 \alpha$, were also very potent $\mathrm{QR}$ inducers, but exhibited high cytotoxicity resulting in poor selectivity (98). From Larnax subtriflora, subtrifloralactones A (431), C (433), D (425), F (436), I (428), and J (429) containing an $\alpha, \beta$ unsaturated ketone functionality in ring A (see Sect. 5.5.) had significant QR induction activity (184). Both $\delta$ - and $\gamma$-lactones were active, indicating that this part of the molecule was not critical for activity. Subtrifloralactone D was the most active, but subtrifloralactones $\mathrm{A}$ and $\mathrm{F}$ had the highest chemopreventive index (ca. 3 times that of sulforaphane). Subtrifloralactone L (435) with a doubly unsaturated ring A ketone, was inactive in the QR assay, while subtrifloralactone $\mathrm{K}$ (434) with the less common 3,6-epoxy arrangement, was active (185). The above data although limited, suggest that even though the presence of an $\alpha, \beta$ unsaturated ketone unit in ring $\mathrm{A}$ of withanolides appears to be important for inducing $\mathrm{QR}$, other structural features may compensate the lack of this functionality or block its beneficial effects.

Panjamurthy et al. have reported that pretreatment with withaferin A (1) significantly reduced in vivo 7,12-dimethylbenz $[a]$ anthracene (DMBA)-induced genotoxicity, in the bone marrow of golden Syrian hamsters (254). This effect could also be related to the induction of phase II detoxifying enzymes.

\subsubsection{Antiangiogenic Activity}

Formation of new blood vessels from existing vasculature or "angiogenesis" is characteristic of all solid tumors allowing for nutrition, oxygenation, and 
metastasis. Thus, angiogenesis inhibitors provide an alternative way of controlling the growth of tumor cells in both pre-invasive and invasive stages. Angiogenesis is also involved in the pathogenesis of several non-malignant inflammatory diseases (age-related macular degeneration, arthritis, endometriosis, etc.). Mohan et al. reported the antiangiogenic activity of extracts of $W$. somnifera containing noncytotoxic levels of withanolides and also of withaferin A (1) (255). Thus, withaferin A inhibited cell proliferation in human umbilical vein endothelial cells (HUVECs) $\left(I C_{50} 12 \mathrm{nM}\right)$ through a process associated with inhibition of cyclin D1 expression. A potent antiangiogenic effect was also observed in vivo, at doses that are 500-fold lower than those previously reported to exert antitumor activity. The authors proposed that the inhibition of $\mathrm{NF}-\kappa \mathrm{B}$ by withaferin $\mathrm{A}$ in HUVECs occurs by interference with the ubiquitin-mediated proteasome pathway as suggested by the increased levels of poly-ubiquitinated proteins. The biotinylated derivative $\mathbf{4 5 9}$ was used to identify protein targets of withaferin A in HUVECs (see Sect. 6.1.). Preliminary results showed that withaferin A binds irreversibly with a $56 \mathrm{kDa}$ protein target and a less abundant $180 \mathrm{kDa}$ species but interacts reversibly with a $70 \mathrm{kDa}$ protein species (192). Withaferin A and withanolide D (508) also displayed antiangiogenic activity in human choroidal endothelial cells (HCECs). These results may lead to novel treatments of choroidal neovascularization, the major contributor to age-related macular degeneration and one of the leading causes of irreversible blindness in the Western hemisphere (256). Physalin B (463) has been identified recently as an inhibitor of the ubiquitin-mediated proteasome pathway in the DLD-1 human colon cancer cell line, producing an accumulation of ubiquitinated proteins and inhibiting $\mathrm{TNF} \alpha$-induced $\mathrm{NF}-\kappa \mathrm{B}$ activation (257). The antiangiogenic activity of this compound remains to be tested.

\subsubsection{Microtubule Stabilizing Activity}

The microtubule stabilizing activity of taccalonolides A (405) and E (420) was reported by Mooberry and coworkers after bioassay-directed fractionation of an extract of Tacca chantrieri (258). Microtubule stabilizers are highly effective drugs used in the treatment of many types of cancers. The taccalonolides are particularly interesting as they appear to have a unique mechanism of action, which does not involve direct binding to tubulin. Special attention has been drawn to these compounds and also to their closely related analogues, taccalonolides B (419) and $\mathrm{N}(\mathbf{4 2 1})$, as they retain efficacy in taxane- and epothiloneresistant models (259). Although these taccalanolides are less potent than other microtubule stabilizers in drug-sensitive cell lines, they are effective at similar concentrations against taxane-resistant cell lines. The microtubule stabilizing activity of taccalonolides has been reviewed recently by Risinger and Mooberry (260). 


\subsection{CNS-Related Activities}

Reports on activities affecting the CNS by withanolides are mostly based on properties attributed to "Ashwagandha" in ayurvedic medicine and are restricted to withanolides from $W$. somnifera.

\subsubsection{Synaptogenesis and Neuritic Outgrowth}

Facilitating synaptogenesis and reconstructing neuronal networks in the damaged brain is required for the therapeutic treatment of neurodegenerative diseases that produce neuronal degeneration and atrophy. Several withanolides isolated from the methanolic extract of $W$. somnifera roots as well as the extract itself, have been shown to possess neurite outgrowth activity $(21,261)$. Withanoside IV (31) and VI (32) predominantly induced dendritic outgrowth in normal cortical neurons, while withanolide A (504) predominantly induced axon outgrowth (262). These withanolides also showed neuritic regeneration and synaptic reconstruction of damaged cortical neurons and prevented both dendritic and axonal atrophy induced by $A \beta(25-35)(261,263)$. Oral administration of withanoside IV significantly improved memory deficit in $\mathrm{A} \beta(25-35)$ treated mice, and sominone, the aglycone of withanoside IV, was shown to be the major metabolite after administration. Sominone was more active than withanoside IV (264).

\subsubsection{Cholinesterase Inhibition}

Natural cholinesterase inhibitors are of special interest in drug development due to the involvement of cholinesterases in Alzheimer's disease and other related dementias. Acetylcholinesterase (AChE) inhibitors activate central cholinergic function by increasing the acetylcholine levels in the brain. Bracteosins A (206), B (207), and C (208), isolated from Ajuga bracteosa (108), and withanolide A (504) and withaferin A (1) from $W$. somnifera, were moderate inhibitors of AChE and BChE (butyrylcholinesterase) (11). Molecular docking studies indicated that all compounds are imbedded in the aromatic gorge of AChE. All these withanolides also showed dose-dependent spasmolytic and $\mathrm{Ca}^{2+}$ antagonistic activities that may help in prolonging neuron survival and function (265). Withanoside VI (32) and withaferin A attenuated the desensitization to clonidine of smooth muscle, and this effect was related to the effect of $W$. somnifera on morphine tolerance and dependence (27). It should be noted that clonidine inhibits the release of acetylcholine by acting on $\alpha_{2}$-adrenoceptors in these tissues. 


\section{Chemotaxonomic Considerations}

As already mentioned, $c a$. 650 withanolides have been described, most of them from genera of the Solanaceae, subfamily Solanoideae. The absence so far of withanolides in members of the other subfamilies is curious. In Table 3, the genera of subfamily Solanoideae containing withanolides are arranged according to the most recent phylogenetic classification (10). As different groups of withanolides have been reported in 23 genera and $c a$. 70 species of the Solanoideae, some chemotaxonomic considerations can be made.

Withanolides with an unmodified skeleton (Fig. 2) are the most common, occurring in 14 genera of the different tribes (Physaleae, Datureae, Hyoscyameae, Lycieae, and Solaneae). Among the six genera still not assigned phylogenetically to

Table 3. Genera of the subfamily Solanoideae containing withanolides arranged according to a established phylogenetic system

\begin{tabular}{|c|c|c|}
\hline Tribe (subtribe) & Genus (section) & Main withanolide types \\
\hline \multirow[t]{4}{*}{$\begin{array}{l}\text { Physaleae } \\
\quad \text { (Physalinae) }\end{array}$} & Physalis & $\begin{array}{l}\text { Physalins, neophysalins, cyclophysalins, } \\
\text { withaphysalins, unmodified skeleton }\end{array}$ \\
\hline & Margaranthus & Physalins, unmodified skeleton \\
\hline & Witheringia & Physalins \\
\hline & Brachistus & Physalins \\
\hline \multirow{5}{*}{$\begin{array}{l}\text { Physaleae } \\
\text { (Iochrominae) }\end{array}$} & Acnistus & Acnistins, withaphysalins, unmodified skeleton \\
\hline & Iochroma & Unmodified skeleton \\
\hline & Eriolarynx & Withaphysalins, unmodified skeleton \\
\hline & Vassobia & Unmodified skeleton \\
\hline & Dunalia & Acnistins, withaphysalins, unmodified skeleton \\
\hline \multirow{3}{*}{$\begin{array}{l}\text { Physaleae } \\
\text { (Withaninae) }\end{array}$} & Withania & Unmodified skeleton \\
\hline & Tubocapsicum & Acnistins \\
\hline & Discopodium & Acnistins, unmodified skeleton \\
\hline Physaleae $^{\mathrm{a}}$ & Larnax & Subtrifloralactones, unmodified skeleton \\
\hline \multirow[t]{2}{*}{ Datureae } & Datura (Datura) & Unmodified skeleton \\
\hline & Datura (Dutra) & Withametelins, unmodified skeleton \\
\hline Hyoscyameae & Hyoscyamus & Unmodified skeleton \\
\hline Lycieae & Lycium & Unmodified skeleton \\
\hline Solaneae & Solanum & Unmodified skeleton \\
\hline \multirow{7}{*}{$\begin{array}{l}\text { Genera not assigned } \\
\text { to a more } \\
\text { inclusive clade }\end{array}$} & Deprea & Withajardins \\
\hline & Exodeconus & Unmodified skeleton \\
\hline & $\begin{array}{l}\text { Jaborosa } \\
\qquad \text { (Jaborosa) }\end{array}$ & $\begin{array}{l}\text { Aromatic ring A, spiranoid- } \gamma \text {-lactones, } \\
\text { unmodified skeleton }\end{array}$ \\
\hline & $\begin{array}{l}\text { Jaborosa } \\
\quad(\text { Lonchestigma })\end{array}$ & $\begin{array}{l}\text { 15,21-cyclowithanolides, sativolides, spiranoid- } \\
\gamma \text {-lactones, spiranoid at C-22, trechonolides, } \\
\text { unmodified skeleton }\end{array}$ \\
\hline & Nicandra & Aromatic ring $\mathrm{D}$, unmodified skeleton \\
\hline & Salpichroa & Aromatic ring D, unmodified skeleton \\
\hline & Schraderanthus & Physalins \\
\hline
\end{tabular}

${ }^{\mathrm{a}}$ Genus not assigned to a subtribe 
a more inclusive clade but within the Solanoideae (Table 3), withanolides with an unmodified skeleton have now been reported only in the Larnax (Deprea) and Schraderanthus genera.

\subsection{Tribe Physaleae}

Different withanolides with modified skeletons are present within this tribe (Plates 1 and 2). Physalins and related withanolides (Fig. 2) are frequent in the subtribe Physalinae (Plate 1, a-f), particularly in Physalis, Margaranthus, Witheringia, and Brachistus. The occurrence of physalins and the non-occurrence of the unmodified skeletons in Witheringia and Brachistus support the close phylogenetic relationship between both genera, which appear together in a small clade and are sisters to one another (10). In addition, the presence of physalins in Schraderanthus is noteworthy, which is a monotypic genus recently segregated from Leucophysalis (tribe Physaleae, subtribe Physalinae). Schraderanthus still remains unassigned to any tribe due to the lack of molecular analysis; the chemical information would support the inclusion of Schraderanthus in the subtribe Physalinae, the only subtribe where physalins have been found.

In the subtribe Physalinae, withaphysalins (Fig. 2), ixocarpalactones, and perulactones (Fig. 3) have been reported in certain Physalis species ( $P$. minima, $P$. philadelphica, and $P$. peruviana); since this genus comprises $c a$. 90 species, these metabolites may probably appear in other species. As more information emerges from research conducted in other Physalis species, it will be able to evaluate the potential chemotaxonomical value of these compounds, either as chemical generic markers or as an exception in the genus.

Withaphysalins are more frequent in the subtribe Iochrominae (Plate 2), a wellsupported clade but with the relationships within this clade poorly resolved (10). The chemical data presented in this chapter, support some taxonomic changes proposed by morphological data (9) and confirmed by molecular evidence (10), as is the case for the segregation of Eriolarynx containing withaphysalins F-L (see Sect. 5.2.4.) from Vassobia (no withaphysalins).

Acnistins (Fig. 2) appear in the subtribes Iochrominae and Withaninae and are absent in all the remaining genera investigated so far. Within the latter subtribe, three small clades have been identified with unresolved relationships between them (10). One clade includes Aureliana and Athenaea, two South American genera not investigated phytochemically up to now. The second clade comprises a monotypic Asiatic genus (Mellisia) and Withania, the "parent genus" of the withanolides (Plate 1,g-j); finally, Nothocestrum, Tubocapsicum and Discopodium are included in the third clade. The chemical evidence is consistent with this proposal since Withania is characterized by the presence of a large number of withanolides with the unmodified parent skeleton of withaferin A (1). In contrast, Discopodium and Tubocapsicum produce withanolides with structural variations. The close affinity 
Withanolides and Related Steroids
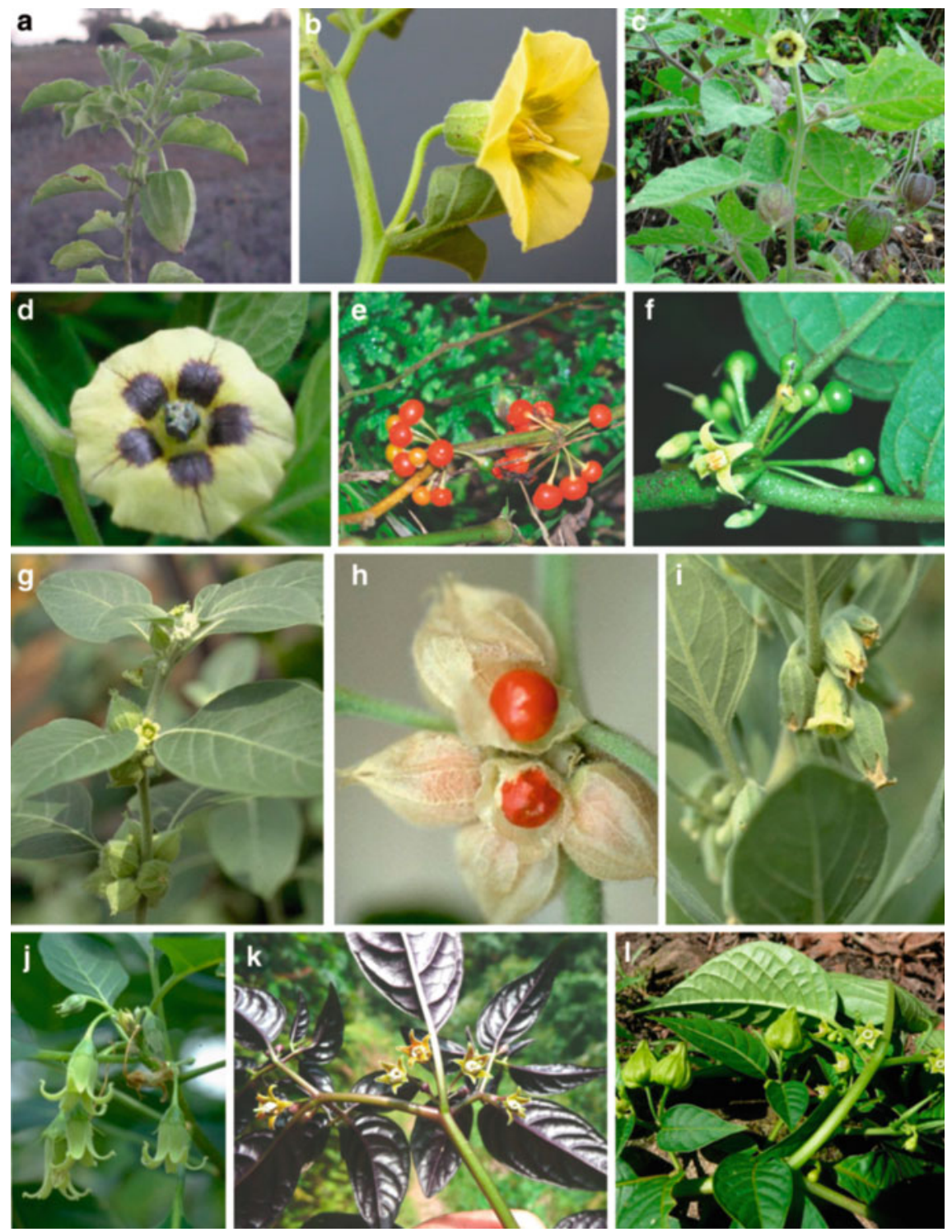

Plate 1. Solanaceae species of Tribe Physaleae. Subtribe Physalinae: (a) Physalis viscosa, branch with fruit; (b) P. viscosa, flower (photographs: J. Toledo and M.T. Cosa). (c) P. pubescens, plant with flower and fruits (photograph: G. Barboza); (d) P. peruviana, detail of corolla (photograph: J. Toledo); (e) Witheringia solanacea, stem with fruits; (f) W. solanacea, flower and immature fruits (photograph: G. Beltrán). Subtribe Withaninae (photographs with permission of the Experimental Garden and Genebank of the Radboud University of Nijmegen, The Netherlands): (g) Withania somnifera, flowering branch; (h) W. somnifera, fruits; (i) W. adpressa, flowers; (j) W. aristata, flowering branch. Genus not assigned to a subtribe: (k) Larnax sp., branch with flowers and fruits; (I) Larnax sp., flowering branch (photographs: S. Leiva) 

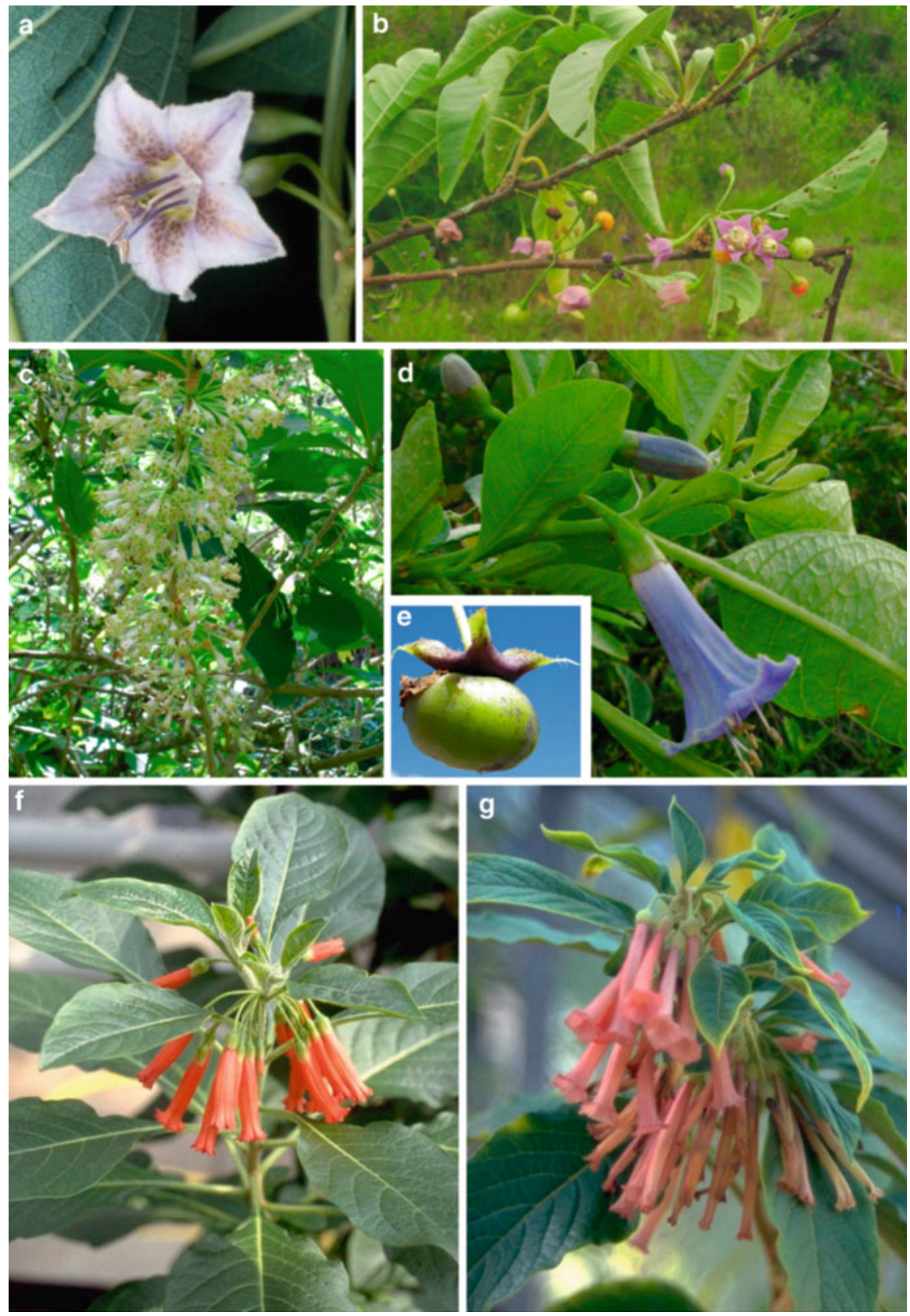

Plate 2. Solanaceae species of Tribe Physaleae subtribe Iochrominae. (a) Eriolarynx lorentzii, flower; (b) Vassobia breviflora, branch with flowers and fruits; (c): Acnistus arborescens, flowering branch (photographs: F. Chiarini); (d) Iochroma australe, flowering branch; (e) I. australe, fruit (photographs: M. T. Cosa and G. Barboza); (f) I. fuchsioides, flowering branch and (g) I. gesneroides, flowering branch (photographs with permission of Experimental Garden and Genebank of the Radboud University of Nijmegen, The Netherlands) 
between the latter two genera is evidenced by them both producing the 17epiacnistins, which, are absent in Withania.

\subsection{Tribes Hyoscyameae, Lycieae, and Solaneae}

In these tribes (Plate 3, d-i), only five species have been investigated (Tables 1 and 3), thus, only preliminary chemotaxonomic suggestions may be proposed. These species are consistent in always containing withanolides with an unmodified skeleton. Worth mentioning is the fact that in the largest genus of the family, Solanum (with $\mathrm{ca}$. 1,500 species), withanolides have been reported in only two species (S. ciliatum and S. sisymbriifolium) (See Sect. 4.2.5.).

\subsection{Tribe Datureae}

The tribe comprises two genera, Brugmansia and Datura, but, however, no information is available on Brugmansia. In the conventional classification, the 14 species of Datura are included in three sections: sect. Datura (D. quercifolia and D. stramonium), sect. Ceratocaula (D. ceratocaula), and sect. Dutra (the remaining species) (Plate 3, a-c). Withanolides from seven taxa have been investigated extensively, and more than 70 different compounds have been reported. The withametelin skeleton (Fig. 2), occurring in ca. 30 compounds, is exclusive to Datura. Withametelins were reported in D. inoxia and D. metel. Genetic similarity and phylogenetic analysis both suggest that $D$. metel is related more closely to D. inoxia than to the other taxa of section Dutra, based upon the small genetic distance between them $(266,267)$, which is supported by the available chemical information. Other chemical coincidence with conventional and phylogenetic proposals is represented by the close relationship between the two members of the section Datura (266), i.e. D. quercifolia and D. stramonium, which share the occurrence of $12 \alpha$-hydroxylated unmodified withanolides.

\subsection{Genera with Uncertain Positions in the Solanaceae Taxonomic System}

Some genera (Jaborosa, Nicandra, Salpichroa) contain withanolides with exclusive arrangements, which can be considered as chemotaxonomic markers at the generic level. Jaborosa is a good example since more than $50 \%$ of its species have been studied (Plate 4). In this genus, several peculiar modified skeletons of the 

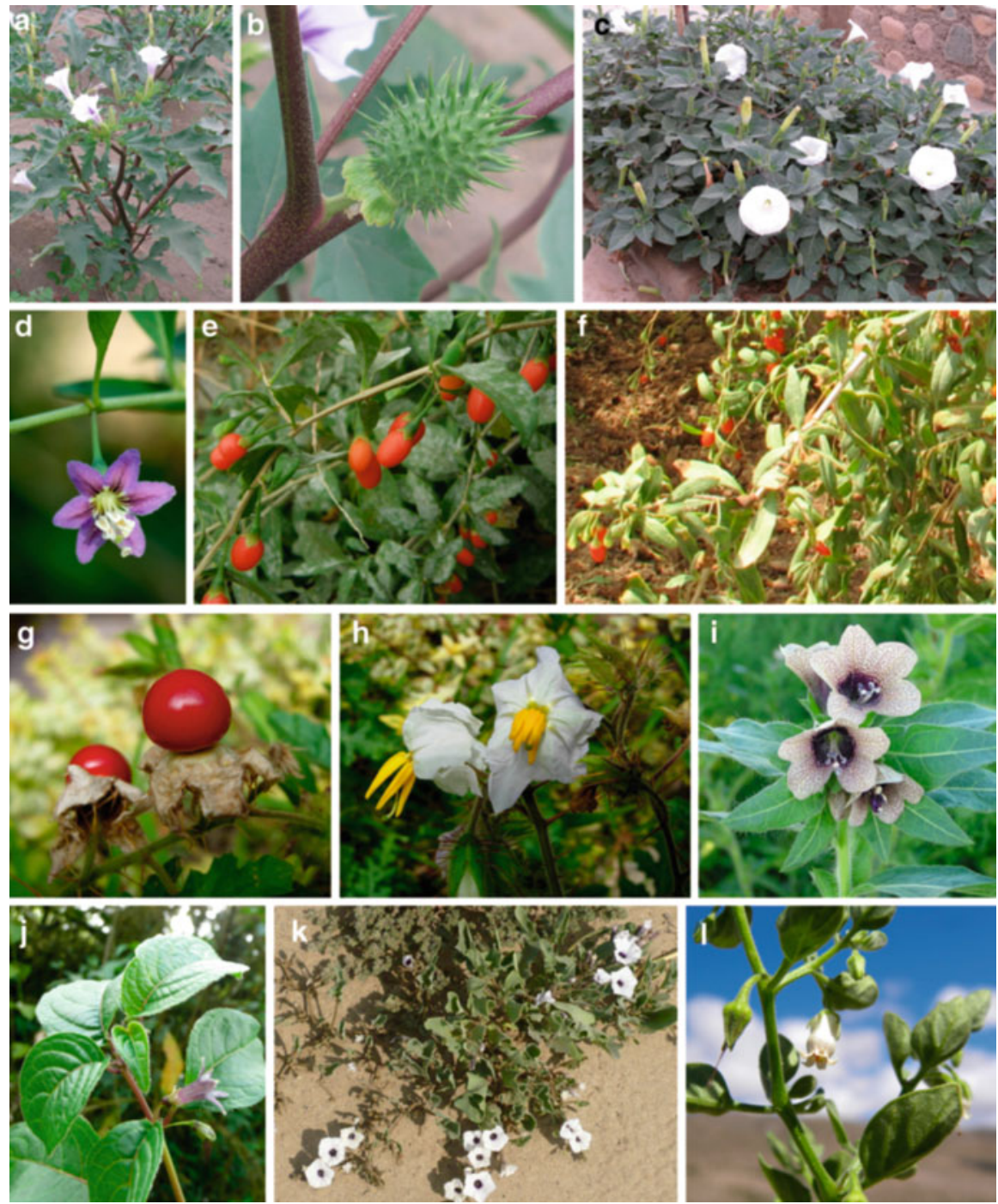

Plate 3. Solanaceae species of Tribe Datureae: (a) Datura ferox, plant; (b) D. ferox, fruit (photograph: F. Chiarini); (c) D. inoxia, plant (photograph: M.T. Cosa). Species of Tribe Lycieae: (d) Lycium chinense, flower; (e) L. chinense, fruits (photograph: B. Liu); (f) L. barbarum, branches with fruits (photograph: M. Li). Species of Tribe Solaneae: (g) Solanum sisymbriifolium, fruits; (h) S. sisymbriifolium, flowers (photographs: M.T. Cosa). Species of Tribe Hyoscyameae: (i) Hyoscyamus niger, flowering branch (photograph: B. Liu). Species not assigned to a tribe: (j) Deprea sp., Flower (photograph: S. Leiva); (k) Exodeconus maritimus, plant (photograph: E. Rodríguez R.); (I) Salpichroa origanifolia, flowering branch (photograph: G. Barboza) 
Withanolides and Related Steroids
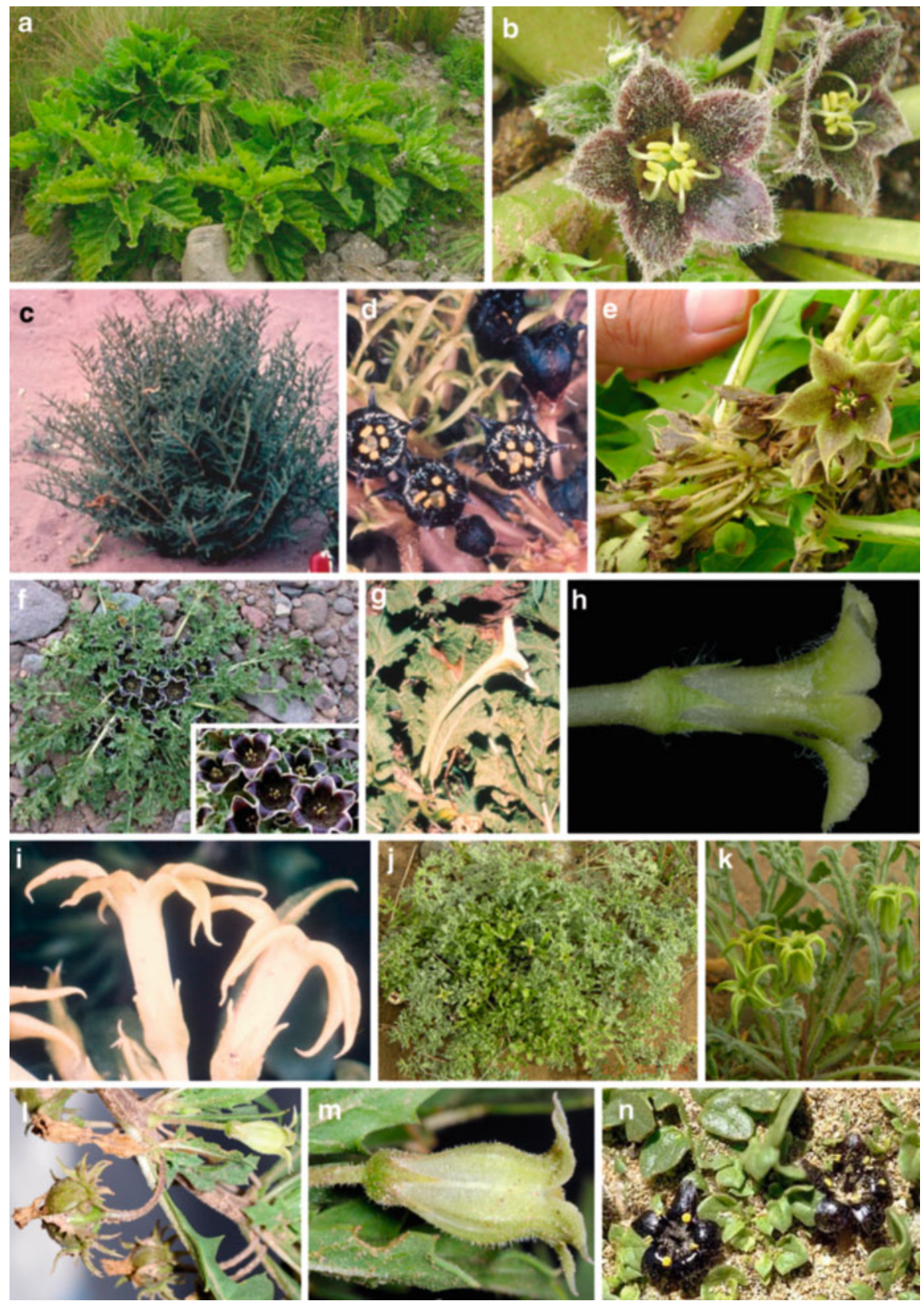

Plate 4. Jaborosa spp.: (a) J. rotacea, plant; (b) J. rotacea, flower (photographs: F. Chiarini); (c) J. leucotricha, plant; (d) J. leucotricha, flowers (photographs: G. Barboza). (e) J. sativa, flowering branch (photograph: F. Chiarini); (f) J. laciniata, plant and flowers in detail; (g) J. odonelliana, flower (photographs: G. Barboza); (h) J. caulescens, flower (photograph: A.A. Cocucci); (i) J. kurtzii, flowers (photograph: G. Barboza); (j) J. reflexa, plant; (k) J. reflexa, flowers (photographs: G. Barboza); (I) J. bergii, fruits; (m) J. bergii, flower (photographs: A.A. Cocucci); (n) J. magellanica, plant (photograph: G. Barboza) 
withanolides appear repeatedly in different species, such as the sativolides, trechonolides, spiranoid withanolides at C-22, and spiranoid- $\gamma$-lactones (Figs. 2 and 3).

The trechonolides, sativolides, and spiranoid withanolides at C-22 are exclusive to species in Jaborosa section Lonchestigma. The trechonolides are the most widespread in the genus, being present in nine species (J.araucana, J. caulescens, J. laciniata, J. lanigera, J. leucotricha, J. magellanica, J. parviflora, J. rotacea, and $J$. sativa); sativolides appear in $J$. caulescens, J. rotacea, and J. sativa, while the spiranoid withanolides at $\mathrm{C}-22$ are only present in $J$. kurtzii and $J$. rotacea.

Spiranoid- $\gamma$-lactones have been isolated from J. odonelliana, J. runcinata and J.integrifolia (unpublished data), all belonging to Jaborosa sect. Jaborosa. Only one spiranoid- $\gamma$-lactone, jaborosalactone 2, was obtained from J. araucana (section Lonchestigma). As was stated in Sect. 5.4.3., the structural similarity of jaborosalactone 2 with trechonolide A, both present in J. araucana, suggests that these compounds may have a common biosynthetic precursor, and probably this species could be a link between section Jaborosa and section Lonchestigma.

Other distinctive variations with modified skeletons are the withanolides and related steroids with an aromatic ring $\mathrm{D}$, the nicandrenoids isolated from Nicandra, and the salpichrolides from Salpichroa (Plate 3, 1). Moreover, both genera exhibit the same $\delta$-lactol side chain at C-17. In spite of this chemical similarity, Nicandra and Salpichroa are not phylogenetically close (10).

Nicandra has been suggested as being close to Exodeconus (10) (Plate 3, k). Although the withanolides isolated from Exodeconus have an unmodified skeleton and the major components of Nicandra have an aromatic ring D, all the withanolides found in both genera share the same 1-oxo-2-ene- $5 \alpha$-hydroxy- $6 \alpha, 7 \alpha$-epoxy substitution pattern in rings $\mathrm{A}$ and $\mathrm{B}$. In this case, the phytochemical evidence coincides with the phylogenetic proposal. Salpichroa and Jaborosa have traditionally been placed in tribe Jaboroseae (9). However, the phylogenetic evidence proposes Salpichroa in a clade informally named "Salpichroina", from which Jaborosa is excluded. Again, chemical information supports this proposal.

Despite the fragmentary chemical contribution described in this section of the chapter, it is evident that a large and species-rich study in Solanaceae in both molecular and phytochemical aspects would provide a better comprehension of the relationships among the species contained therein.

Acknowledgments We thank CONICET, Universidad de Buenos Aires and Universidad de Córdoba for financial support.

\section{References}

1. Lavie D, Glotter E, Shvo Y (1965) Constituents of Withania somnifera Dun. The Structure of Withaferin A. J Chem Soc: 7517

2. Kupchan SM, Doskotch RW, Bollinger P, MacPhail AT, Sim GA, Renauld JAS (1965) The Isolation and Structural Elucidation of a Novel Steroidal Tumor Inhibitor from Acnistus arborescens. J Am Chem Soc 87: 5805 
3. Ray AB, Gupta M (1994) Withasteroids, a Growing Group of Naturally Occurring Steroidal Lactones. Prog Chem Org Nat Prod 63: 1

4. Anjaneyulu ASR, Rao DS, Lequesne PW (1998) Withanolides, Biologically Active Natural Steroidal Lactones: A Review. Stud Nat Prod Chem 20: 135

5. Veleiro AS, Oberti JC, Burton G (2005) Chemistry and Bioactivity of Withanolides from South American Solanaceae. Stud Nat Prod Chem 32: 1019

6. Su B-N, Gu J-Q, Kang Y-H, Park E-J, Pezzuto JM, Kinghorn AD (2004) Induction of the Phase II Enzyme, Quinone Reductase, by Withanolides and Norwithanolides from Solanaceous Species. Mini-Rev Org Chem 1: 115

7. Budhiraja RD, Krishan P, Sudhir S (2000) Biological Activity of Withanolides. J Sci Ind Res 59: 904

8. D’Arcy WG (1991) Solanaceae III. Taxonomy, Chemistry, Evolution. Royal Botanic Gardens, Kew. In: Hawkes JG, Lester RN, Nee M, Estrada N (eds): The Solanaceae since 1976, with a Review of Its Biogeography. Royal Botanic Gardens, Kew, U.K., p 75

9. Hunziker AT (2001) Genera Solanacearum. The Genera of Solanaceae Illustrated, Arranged According to a New System, Koeltz Scientific Books, Konigstein, Germany

10. Olmstead RG, Bohs L, Abdel Migid H, Santiago-Valentín E, García VF, Collier SM (2008) A Molecular Phylogeny of the Solanaceae. Taxon 57: 1159

11. Choudhary MI, Yousuf S, Nawaz SA, Ahmed S, Atta-ur-Rahman (2004) Cholinesterase Inhibiting Withanolides from Withania somnifera. Chem Pharm Bull 52: 1358

12. Misra L, Lal P, Sangwan RS, Sangwan NS, Uniyal GC, Tuli R (2005) Unusually Sulfated and Oxygenated Steroids from Withania somnifera. Phytochemistry 66: 2702

13. Benjumea D, Martin-Herrera D, Abdala S, Gutierrez-Luis J, Quinones W, Cardona D, Torres F, Echeverri F (2009) Withanolides from Whitania aristata and Their Diuretic Activity. J Ethnopharmacol 123: 351

14. Choudhary MI, Abbas S, Jamal SA, Atta-ur-Rahman (1996) Withania somnifera - a Source of Exotic Withanolides. Heterocycles 42: 555

15. Jayaprakasam B, Nair MG (2003) Cyclooxygenase-2 Enzyme Inhibitory Withanolides from Withania somnifera Leaves. Tetrahedron 59: 841

16. March J (1992): Advanced Organic Chemistry Reactions, Mechanisms, and Structure. John Wiley \& Sons, New York, p 755

17. Atta-ur-Rahman, Yousaf M, Gul W, Qureshi S, Choudhary MI, Voelter W, Hoff A, Jens F, Naz A (1998) Five New Withanolides from Withania coagulans. Heterocycles 48: 1801

18. Nur-e-Alam M, Yousaf M, Qureshi S, Baig I, Nasim S, Atta-ur-Rahman, Choudhary MI (2003) A Novel Dimeric Podophyllotoxin-Type Lignan and a New Withanolide from Withania coagulans. Helv Chim Acta 86: 607

19. Kuroyanagi M, Shibata K, Umehara K (1999) Cell Differentiation Inducing Steroids from Withania somnifera L. (Dun.). Chem Pharm Bull 47: 1646

20. Abou-Douh AM (2002) New Withanolides and Other Constituents from the Fruit of Withania somnifera. Arch Pharm 335: 267

21. Zhao J, Nakamura N, Hattori M, Kuboyama T, Tohda C, Komatsu K (2002) Withanolide Derivatives from the Roots of Withania somnifera and Their Neurite Outgrowth Activities. Chem Pharm Bull 50: 760

22. Sahai M, Ali A, Ray AB, Slatkin DJ, Kirson I (1983) Withaperuvin D, a Novel Withanolide from Physalis peruviana. J Chem Res (S): 152

23. Neogi P, Sahai M, Ray AB (1987) Withaperuvins F and G, Two Withanolides of Physalis peruviana Roots. Phytochemistry 26: 243

24. Anjaneyulu ASR, Rao DS (1997) New Withanolides from the Roots of Withania somnifera. Indian J Chem B 36: 424

25. Lal P, Misra L, Sangwan RS, Tuli R (2006) New Withanolides from Fresh Berries of Withania somnifera. Z Naturforsch, B: Chem Sci 61: 1143

26. Misra L, Mishra P, Pandey A, Sangwan RS, Sangwan NS, Tuli R (2008) Withanolides from Withania somnifera Roots. Phytochemistry 69: 1000 
27. Matsuda H, Murakami T, Kishi A, Yoshikawa M (2001) Structures of Withanosides I, II, III, IV, V, VI, and VII, New Withanolide Glycosides, from the Roots of Indian Withania somnifera Dunal. and Inhibitory Activity for Tachyphylaxis to Clonidine in Isolated Guinea-Pig Ileum. Bioorg Med Chem 9: 1499

28. Pramanick S, Roy A, Ghosh S, Majumder HK, Mukhopadhyay S (2008) Withanolide Z, a New Chlorinated Withanolide from Withania somnifera. Planta Med 74: 1745

29. Jayaprakasam B, Strasburg GA, Nair MG (2004) Potent Lipid Peroxidation Inhibitors from Withania somnifera Fruits. Tetrahedron 60: 3109

30. Atta-ur-Rahman, Shabbir M, Yousaf M, Qureshi S, Dur-e-Shahwar, Naz A, Choudhary MI (1999) Three Withanolides from Withania coagulans. Phytochemistry 52: 1361

31. Abdeljebbar LH, Humam M, Christen P, Jeannerat D, Vitorge B, Amzazi S, Benjouad A, Hostettmann K, Bekkouche K (2007) Withanolides from Withania adpressa. Helv Chim Acta 90: 346

32. Maurya R, Akanksha, Jayendra, Singh AB, Srivastava AK (2008) Coagulanolide, a Withanolide from Withania coagulans Fruits and Antihyperglycemic Activity. Bioorg Med Chem Lett 18: 6534

33. Vande Velde V, Lavie D (1981) New Withanolides of Biogenetic Interest from Withania somnifera. Phytochemistry 20: 1359

34. Atta-ur-Rahman, Dur-e-Shahwar, Naz A, Choudhary MI (2003) Withanolides from Withania coagulans. Phytochemistry 63: 387

35. Huang C-F, Ma L, Sun L-J, Ali M, Arfan M, Liu J-W, Hu L-H (2009) Immunosuppressive Withanolides from Withania coagulans. Chem Biodivers 6: 1415

36. Choudhary MI, Dur-e-Shahwar, Parveen Z, Jabbar A, Ali I (1995) Antifungal Steroidal Lactones from Withania coagulance. Phytochemistry 40: 1243

37. Jahan E, Perveen S, Fatima I, Malik A (2010) Coagulansins A and B, New Withanolides from Withania coagulans Dunal. Helv Chim Acta 93: 530

38. Atta-ur-Rahman, Choudhary MI, Yousaf M, Gul W, Qureshi S (1998) New Withanolides from Withania coagulans. Chem Pharm Bull 46: 1853

39. Kumar A, Ali M, Mir SR (2004) A New Withanolide from the Roots of Withania somnifera. Indian J Chem, Sect B 43B: 2001

40. Atta-ur-Rahman, Abbas S, Dur-e-Shahwar, Jamal SA, Choudhary MI (1993) New Withanolides from Withania sp. J Nat Prod 56: 1000

41. Atta-ur-Rahman,, Shabbir M, Dur-e-Shahwar, Choudhary MI, Voelter W, Hohnholz D (1998) New Steroidal Lactones from Withania coagulance. Heterocycles 47: 1005

42. Atta-ur-Rahman, Choudhary MI, Qureshi S, Gul W, Yousaf M (1998) Two New ErgostaneType Steroidal Lactones from Withania coagulans. J Nat Prod 61: 812

43. Ahmad S, Malik A, Muhammad P, Gul W, Yasmin R, Afza N (1998) A New Withanolide from Physalis peruviana. Fitoterapia 69: 433

44. Ahmad S, Malik A, Afza N, Yasmin R (1999) A New Withanolide Glycoside from Physalis peruviana. J Nat Prod 62: 493

45. Khan PM, Ahmad S, Rubnawaz H, Malik A (1999) The First Report of a Withanolide from the Family Labiatae. Phytochemistry 51: 669

46. Ali M, Shuaib M, Ansari SH (1997) Withanolides from the Stem Bark of Withania somnifera. Phytochemistry 44: 1163

47. Subbaraju GV, Vanisree M, Rao CV, Sivaramakrishna C, Sridhar P, Jayaprakasam B, Nair MG (2006) Ashwagandhanolide, a Bioactive Dimeric Thiowithanolide Isolated from the Roots of Withania somnifera. J Nat Prod 69: 1790

48. Mulabagal V, Subbaraju GV, Rao CV, Sivaramakrishna C, DeWitt DL, Holmes D, Sung B, Aggarwal BB, Tsay H-S, Nair M (2009) Withanolide Sulfoxide from Ahswagandha Roots Inhibits Nuclear Transcription Factor-Kappa-B, Cyclooxygenase and Tumor Cell Proliferation. Phytother Res 23: 987

49. Xu Y-m, Marron MT, Seddon E, McLaughlin SP, Ray DT, Whitesell L, Gunatilaka AAL (2009) 2,3-Dihydrowithaferin A-3 $\beta-O$-Sulfate, a New Potential Prodrug of Withaferin A from Aeroponically Grown Withania somnifera. Bioorg Med Chem 17: 2210 
50. Lan Y-H, Chang F-R, Pan M-J, Wu C-C, Wu S-J, Chen S-L, Wang S-S, Wu M-J, Wu Y-C (2009) New Cytotoxic Withanolides from Physalis peruviana. Food Chem 116: 462

51. Dinan LN, Sarker SD, Sik V (1997) 28-Hydroxywithanolide E from Physalis peruviana. Phytochemistry 44: 509

52. Ahmad S, Malik A, Yasmin R, Ullah N, Gul W, Khan PM, Nawaz HR, Afza N (1999) Withanolides from Physalis peruviana. Phytochemistry 50: 647

53. Ahmad S, Yasmin R, Malik A (1999) New Withanolide Glycosides from Physalis peruviana L. Chem Pharm Bull 47: 477

54. Maldonado E, Alvarado VE, Torres FR, Martinez M, Perez-Castorena AL (2005) Androstane and Withanolides from Physalis cinerascens. Planta Med 71: 548

55. Damu AG, Kuo P-C, Su C-R, Kuo T-H, Chen T-H, Bastow KF, Lee K-H, Wu T-S (2007) Isolation, Structures, and Structure-Cytotoxic Activity Relationships of Withanolides and Physalins from Physalis angulata. J Nat Prod 70: 1146

56. Lee S-W, Pan M-H, Chen C-M, Chen Z-T (2008) Withangulatin I, a New Cytotoxic Withanolide from Physalis angulata. Chem Pharm Bull 56: 234

57. Abe F, Nagafuji S, Okawa M, Kinjo J (2006) Trypanocidal Constituents in Plants 6. Minor. Withanolides from the Aerial Parts of Physalis angulata. Chem Pharm Bull 54: 1226

58. He Q-P, Ma L, Luo J-Y, He F-Y, Lou L-G, Hu L-H (2007) Cytotoxic Withanolides from Physalis angulata $\mathrm{L}$. Chem Biodivers 4: 443

59. Glotter E (1991) Withanolides and Related Ergostane-Type Steroids. Nat Prod Rep 8: 415

60. Choudhary MI, Yousaf S, Ahmed S, Samreen, Yasmeen K, Atta-ur-Rahman (2005) Antileishmanial Physalins from Physalis minima. Chem Biodivers 2: 1164

61. Nawaz HR, Riaz M, Malik A, Khan PM, Ullah N (2000) Withanolides and Alkaloid from Ajuga parviflora. J Chem Soc Pak 22: 138

62. Khan PM, Malik A, Ahmad S, Nawaz HR (1999) Withanolides from Ajuga parviflora. J Nat Prod 62: 1290

63. Khan PM, Nawaz HR, Ahmad S, Malik A (1999) Ajugins C and D, New Withanolides from Ajuga parviflora. Helv Chim Acta 82: 1423

64. Nawaz HR, Malik A, Khan PM, Ahmed S (1999) Ajugins E and F: Two Withanolides from Ajuga parviflora. Phytochemistry 52: 1357

65. Nawaz HR, Malik A, Muhammad P, Ahmed S, Riaz M (2000) Chemical Constituents of Ajuga parviflora. Z Naturforsch, B: Chem Sci 55: 100

66. Nagafuji S, Okabe H, Akahane H, Abe F (2004) Trypanocidal Constituents in Plants 4. Withanolides from the Aerial Parts of Physalis angulata. Biol Pharm Bull 27: 193

67. Li Y-Z, Pan Y-M, Huang X-Y, Wang H-S (2008) Withanolides from Physalis alkekengi var. francheti. Helv Chim Acta 91: 2284

68. Misico RI, Veleiro AS, Burton G, Oberti JC (1997) Withanolides from Jaborosa leucotricha. Phytochemistry 45: 1045

69. Nicotra VE, Gil RR, Vaccarini C, Oberti JC, Burton G (2003) 15,21-Cyclowithanolides from Jaborosa bergii. J Nat Prod 66: 1471

70. Misico RI, Gil RR, Oberti JC, Veleiro AS, Burton G (2000) Withanolides from Vassobia lorentzii. J Nat Prod 63: 1329

71. Silva GL, Burton G, Oberti JC (1999) 18,20-Hemiacetal-Type and Other Withanolides from Dunalia brachyacantha. J Nat Prod 62: 949

72. Alfonso D, Kapetanidis I (1994) Withanolides from Iochroma gesnerioides. Phytochemistry 36: 179

73. Maldonado E, Torres FR, Martínez M, Pérez-Castorena AL (2004) 18-Acetoxywithanolides from Physalis chenopodifolia. Planta Med 70: 59

74. Perez-Castorena A-L, Oropeza RF, Vazquez AR, Martinez M, Maldonado E (2006) Labdanes and Withanolides from Physalis coztomatl. J Nat Prod 69: 1029

75. Carcamo C, Fajardo V (1993) (-)-Jaboromagellonine: New Withanolide from Seeds of Jaborosa magellanica. Heterocycles 36: 1771

76. Ramacciotti NS, Nicotra VE (2007) Withanolides from Jaborosa kurtzii. J Nat Prod 70: 1513 
77. Cirigliano A, Veleiro AS, Oberti JC, Burton G (1995) A 15ß-Hydroxywithanolide from Datura ferox. Phytochemistry 40: 611

78. Veleiro AS, Cirigliano AM, Oberti JC, Burton G (1999) 7-Hydroxywithanolides from Datura ferox. J Nat Prod 62: 1010

79. Yang B, Wang Q, Xia Y, Feng W, Kuang H (2007) Withanolide Compounds from the Flower of Datura metel L. Helv Chim Acta 90: 1522

80. Kuang H, Yang B, Tang L, Xia Y, Dou D (2009) Baimantuoluosides A - C, Three New Withanolide Glucosides from the Flower of Datura metel L. Helv Chim Acta 92: 1315

81. Bhat BA, Dhar KL, Puri SC, Qurishi MA, Khajuria A, Gupta A, Qazi GN (2005) Isolation, Characterization and Biological Evaluation of Datura Lactones as Potential Immunomodulators. Bioorg Med Chem 13: 6672

82. Wube AA, Wenzig E-M, Gibbons S, Asres K, Bauer R, Bucar F (2008) Constituents of the Stem Bark of Discopodium penninervium and Their $\mathrm{LTB}_{4}$ and COX-1 and -2 Inhibitory Activities. Phytochemistry 69: 982

83. Cordero CP, Morantes SJ, Páez A, Rincón J, Aristizábal FA (2009) Cytotoxicity of Withanolides Isolated from Acnistus arborescens. Fitoterapia 80: 364

84. Bravo B JA, Sauvain M, Gimenez T A, Balanza E, Serani L, Laprevote O, Massiot G, Lavaud C (2001) Trypanocidal Withanolides and Withanolide Glycosides from Dunalia brachyacantha. J Nat Prod 64: 720

85. Lischewski M, Nguyen Thi Bich H, Porzel A, Adam G, Massiot G, Lavaud C (1992) Withanolide Glycosides from Dunalia australis. Phytochemistry 31: 939

86. Yokosuka A, Mimaki Y, Sashida Y (2003) Chantriolides A and B, Two New Withanolide Glucosides from the Rhizomes of Tacca chantrieri. J Nat Prod 66: 876

87. Liu H-Y, Ni W, Xie B-B, Zhou L-Y, Hao X-J, Wang X, Chen C-X (2006) Five New Withanolides from Tacca plantaginea. Chem Pharm Bull 54: 992

88. Yokosuka A, Mimaki Y (2007) New Glycosides from the Rhizomes of Tacca chantrieri. Chem Pharm Bull 55: 273

89. Manickam M, Awasthi SB, Oshima Y, Hisamichi K, Takeshita M, Sahai M, Ray AB (1994) Additional C-21-Oxygenated Withanolides from Datura fastuosa. J Chem Res (S): 306

90. Manickam M, Srivastava A, Ray AB (1998) Withanolides from the Flowers of Datura fastuosa. Phytochemistry 47: 1427

91. Manickam M, Kumar S, Sinha-Bagchi A, Sinha SC, Ray AB (1994) Withametelin H and Withafastuosin C, Two New Withanolides from the Leaves of Datura Species. J Indian Chem Soc 71: 393

92. Pan Y, Wang X, Hu X (2007) Cytotoxic Withanolides from the Flowers of Datura metel. J Nat Prod 70: 1127

93. Yang B, Wang Q, Xia Y, Feng W, Kuang H (2008) Baimantuoluolines D-F, Three New Withanolides from the Flower of Datura metel L. Helv Chim Acta 91: 964

94. Manickam M, Awasthi SB, Sinha-Bagchi A, Sinha SC, Ray AB (1996) Withanolides from Datura tatula. Phytochemistry 41: 981

95. Srivastava A, Manickam M, Sinha-Bagchia A, Sinhaa SC, Ray AB (1996) Withasteroids. 28. Novel Withanolides from the Flowers of Datura tatula. Nat Prod Sci 2: 9

96. Manickam M, Ray AB (1996) Structure of Withatatulin E, a Minor Withanolide of Datura tatula. Indian J Chem, Sect B 35B: 1311

97. Gil RR, Misico RI, Sotes IR, Oberti JC, Veleiro AS, Burton G (1997) 16-Hydroxylated Withanolides from Exodeconus maritimus. J Nat Prod 60: 568

98. Minguzzi S, Barata LES, Shin YG, Jonas PF, Chai H-B, Park EJ, Pezzuto JM, Cordell GA (2002) Cytotoxic Withanolides from Acnistus arborescens. Phytochemistry 59: 635

99. Ma C-Y, Williams ID, Che C-T (1999) Withanolides from Hyoscyamus niger Seeds. J Nat Prod 62: 1445

100. Habtemariam S, Gray AI, Waterman PG (1993) 16-Oxygenated Withanolides from the Leaves of Discopodium penninervium. Phytochemistry 34: 807

101. Maldonado E, Amador S, Martinez M, Perez-Castorena AL (2010) Virginols A-C, Three New Withanolides from Physalis virginiana. Steroids 75: 346 
102. Habtemariam S, Gray AI (1998) Withanolides from the Roots of Discopodium penninervium. Planta Med 64: 275

103. Kennelly EJ, Gerhaeuser C, Song LL, Graham JG, Beecher CWW, Pezzuto JM, Kinghorn AD (1997) Induction of Quinone Reductase by Withanolides Isolated from Physalis philadelphica (Tomatillos). J Agric Food Chem 45: 3771

104. Su B-N, Misico RI, Park EJ, Santarsiero BD, Mesecar AD, Fong HHS, Pezzuto JM, Kinghorn AD (2002) Isolation and Characterization of Bioactive Principles of the Leaves and Stems of Physalis philadelphica. Tetrahedron 58: 3453

105. Gu J-Q, Li W, Kang Y-H, Su B-N, Fong HHS, van Breemen RB, Pezzuto JM, Kinghorn AD (2003) Minor Withanolides from Physalis philadelphica: Structures, Quinone Reductase Induction Activities, and Liquid Chromatography (LC)-MS-MS Investigation as Artifacts. Chem Pharm Bull 51: 530

106. Cardona D, Quinones W, Torres F, Velez ID, Orozco-P CI, Garzon J, Echeverri F (2005) Structure and Leishmanicidal Activity of Larnaxolide A and B, New Withanolides from Larnax glabra (Standl.) Sawyer. Actual Biol (Medellin, Colomb) 27: 81

107. Hsieh P-W, Huang Z-Y, Chen J-H, Chang F-R, Wu C-C, Yang Y-L, Chiang MY, Yen M-H, Chen S-L, Yen H-F, Luebken T, Hung W-C, Wu Y-C (2007) Cytotoxic Withanolides from Tubocapsicum anomalum. J Nat Prod 70: 747

108. Riaz N, Malik A, Nawaz SA, Muhammad P, Choudhary MI (2004) Cholinesterase-Inhibiting Withanolides from Ajuga bracteosa. Chem Biodivers 1: 1289

109. Ma L, Xie C-M, Li J, Lou F-C, Hu L-H (2006) Daturametelins H, I, and J: 3 New Withanolide Glycosides from Datura metel L. Chem Biodivers 3: 180

110. Zhu XH, Takagi M, Ikeda T, Midzuki K, Nohara T (2001) Withanolide-Type Steroids from Solanum cilistum. Phytochemistry 56: 741

111. Zhu X-H, Ando J, Takagi M, Ikeda T, Nohara T (2001) Six New Withanolide-Type Steroids from the Leaves of Solanum cilistum. Chem Pharm Bull 49: 161

112. Zhu X-H, Ando J, Takagi M, Ikeda T, Yoshimitsu A, Nohara T (2001) Four Novel Withanolide-Type Steroids from the Leaves of Solanum cilistum. Chem Pharm Bull 49: 1440

113. Niero R, Da Silva IT, Tonial GC, Camacho BDS, Gacs-Baitz E, Delle Monache G, Delle Monache F (2006) Cilistepoxide and Cilistadiol, 2 New Withanolides from Solanum sisymbiifolium. Nat Prod Res Part A 20: 1164

114. Vankar PS, Srivastava J, Molcanov K, Kojic-Prodic B (2009) Withanolide A Series Steroidal Lactones from Eucalyptus globulus Bark. Phytochemistry Lett 2: 67

115. Siddiqui BS, Afreen S, Begum S (1999) Two New Withanolides from the Aerial Parts of Datura innoxia. Aust J Chem 52: 905

116. Siddiqui BS, Hashmi IA, Begum S (2002) Two New Withanolides from the Aerial Parts of Datura innoxia. Heterocycles 57: 715

117. Siddiqui BS, Arfeen S, Afshan F, Begum S (2005) Withanolides from Datura innoxia. Heterocycles 65: 857

118. Siddiqui BS, Arfeen S, Begum S, Sattar FA (2005) Daturacin, a New Withanolide from Datura innoxia. Nat Prod Res 19: 619

119. Bonetto GM, Gil RR, Oberti JC, Veleiro AS, Burton G (1995) Novel Withanolides from Jaborosa sativa. J Nat Prod 58: 705

120. Nicotra VE, Ramacciotti NS, Gil RR, Oberti JC, Feresin GE, Guerrero CA, Baggio RF, Garland MT, Burton G (2006) Phytotoxic Withanolides from Jaborosa rotacea. J Nat Prod 69: 783

121. Nicotra VE, Gil RR, Oberti JC, Burton G (2007) Withanolides with Phytotoxic Activity from Jaborosa caulescens var. caulescens and J. caulescens var. bipinnatifida. J Nat Prod 70: 808

122. Usubillaga A, de Castellano G, Zabel V, Watson WH (1980) Acnistins, a New Class of Steroidal Lactones from Acnistus ramiflorum Miers, X-Ray Structure of Acnistin E. J Chem Soc, Chem Commun: 854 
123. Luis JG, Echeverri F, Quiñones W, González AG, Torres F, Cardona G, Archbold R, Rojas M, Perales A (1994) Unambiguous ${ }^{13}$ C NMR Assignment of Acnistins and Absolute Configuration of Acnistin A. Steroids 59: 299

124. Luis JG, Echeverri F, García F, Rojas M (1994) The Structure of Acnistin B and the Immunosuppressive Effects of Acnistins A, B, and E. Planta Med 60: 348

125. Luis JG, Echeverri F, Gonzalez AG (1994) Acnistins C and D, Withanolides from Dunalia solanacea. Phytochemistry 36: 1297

126. Luis JG, Echeverri F, Gonzalez AG (1994) Acnistins F-H, Withanolides from Dunalia solanacea. Phytochemistry 36: 769

127. Habtemariam S, Skelton BW, Waterman PG, White AH (2000) 17-Epiacnistin-A, a Further Withanolide from the Leaves of Discopodium penninervium. J Nat Prod 63: 512

128. Kiyota N, Shingu K, Yamaguchi K, Yoshitake Y, Harano K, Yoshimitsu H, Ikeda T, Nohara T (2007) New C28 Steroidal Glycosides from Tubocapsicum anomalum. Chem Pharm Bull 55: 34

129. Luis JG, Echeverri F, Quinones W, Gonzalez AG, Torres F, Cardona G, Archbold R, Perales A (1994) Withajardins, Withanolides with a New Type of Skeleton Structure of Withajardins A, B, C and D. Absolute Configuration of Withajardin C. Tetrahedron 50: 1217

130. Echeverri F, Quinones W, Forres F, Cardona G, Archbold R, Luis JG, Gonzalez AG (1995) Withajardin E, a Withanolide from Deprea orinocensis. Phytochemistry 40: 923

131. Kiyota N, Shingu K, Yamaguchi K, Yoshitake Y, Harano K, Yoshimitsu H, Miyashita H, Ikeda T, Tagawa C, Nohara T (2008) New C28 Steroidal Glycosides from Tubocapsicum anomalum. Chem Pharm Bull 56: 1038

132. Glotter E, Abraham A, Guenzberg G, Kirson I (1977) Naturally Occurring Steroidal Lactones with a $17 \alpha$-Oriented Side Chain. Structure of Withanolide E and Related Compounds. J Chem Soc, Perkin Trans 1: 341

133. Tomassini TCB, Barbi NS, Ribeiro IM, Xavier DCD (2000) Genero Physalis - Uma Revisao Sobre Vitaesteroides. Quim Nova 23: 47

134. Fang L, Chai H-B, Castillo JJ, Soejarto DD, Farnsworth NR, Cordell GA, Pezzuto JM, Kinghorn AD (2003) Cytotoxic Constituents of Brachistus stramoniifolius. Phytother Res 17: 520

135. Karikas GA, Gupta MP, Ravelo AG, Gonzales AG (1998) Physalin B from Witheringia hunzikeri. Fitoterapia 69: 468

136. Pérez-Castorena AL, García M, Martínez M, Maldonado E (2004) Physalins from Physalis solanaceus. Biochem Syst Ecol 32: 1231

137. Ripperger H, Kamperdick C (1998) First Isolation of Physalins from the Genus Saracha of Solanaceae. Pharmazie 53: 144

138. Jacobo-Herrera NJ, Bremner P, Marquez N, Gupta MP, Gibbons S, Munoz E, Heinrich M (2006) Physalins from Witheringia solanacea as Modulators of the NF- $\kappa$ B Cascade. J Nat Prod 69: 328

139. Qiu L, Zhao F, Jiang Z-H, Chen L-X, Zhao Q, Liu H-X, Yao X-S, Qiu F (2008) Steroids and Flavonoids from Physalis alkekengi var. franchetii and Their Inhibitory Effects on Nitric Oxide Production. J Nat Prod 71: 642

140. Sunayama R, Kuroyanagi M, Umehara K, Ueno A (1993) Physalin and Neophysalins from Physalis alkekengi var. francheti and Their Differentiation Inducing Activity. Phytochemistry 34: 529

141. Qiu L, Jiang Z-H, Liu H-X, Chen L-X, Yao X-S, Qiu F (2008) A Pair of 3-Epimeric Physalins from Physalis alkekengi L. var. franchetii. J Asian Nat Prod Res 10: 881

142. Makino B, Kawai M, Kito K, Yamamura H, Butsugan Y (1995) New Physalins Possessing an Additional Carbon-Carbon Bond from Physalis alkekengi var. francheti. Tetrahedron 51: 12529

143. Kawai M, Yamamoto T, Makino B, Yamamura H, Araki S, Butsugan Y, Saito K (2001) The Structure of Physalin T from Physalis alkekengi var. francheti. J Asian Nat Prod Res 3: 199 
144. Makino B, Kawai M, Iwata Y, Yamamura H, Butsugan Y, Ogawa K, Hayashi M (1995) Physalins Possessing an Endoperoxy Structure from Physalis alkekengi var. francheti. Structural Revision of Physalin K. Bull Chem Soc Jpn 68: 219

145. Choudhary MI, Yousuf S, Samreen, Ahmed S, Atta-ur-Rahman (2007) New Leishmanicidal Physalins from Physalis minima. Nat Prod Res 21: 877

146. Kuo P-C, Kuo T-H, Damu AG, Su C-R, Lee E-J, Wu T-S, Shu R, Chen C-M, Bastow KF, Chen T-H, Lee K-H (2006) Physanolide A, a Novel Skeleton Steroid, and Other Cytotoxic Principles from Physalis angulata. Org Lett 8: 2953

147. Chen R, Liang J-Y, Liu R (2007) Two Novel Neophysalins from Physalis alkekengi L. var. franchetii. Helv Chim Acta 90: 963

148. Makino B, Kawai M, Ogura T, Nakanishi M, Yamamura H, Butsugan Y (1995) Structural Revision of Physalin H Isolated from Physalis angulata. J Nat Prod 58: 1668

149. Chen R, Liang JY, Yang Y, Liu R (2007) Chemical Constituents from Physalis alkekengi and Structural Revision of Physalin G. Chin J Nat Med 5: 186

150. Sen G, Pathak HD (1995) Physalin L, a 13,14-Seco-16,24 Cyclosteroid from Physalis minima. Phytochemistry 39: 1245

151. Kawai M, Makino B, Yamamura H, Butsugan Y (1996) Upon "Physalin L" Isolated from Physalis minima. Phytochemistry 43: 661

152. Veras ML, Bezerra MZB, Braz-Filho R, Pessoa ODL, Montenegro RC, Do Ó Pessoa C, De Moraes MO, Costa-Lotufo LV (2004) Cytotoxic Epimeric Withaphysalins from Leaves of Acnistus arborescens. Planta Med 70: 551

153. Veras ML, Bezerra MZB, Lemos TLG, Uchoa DEDA, Braz-Filho R, Chai HB, Cordell GA, Pessoa ODL (2004) Cytotoxic Withaphysalins from the Leaves of Acnistus arborescens. J Nat Prod 67: 710

154. Ma L, Gan X-W, He Q-P, Bai H-Y, Arfan M, Lou F-C, Hu L-H (2007) Cytotoxic Withaphysalins from Physalis minima. Helv Chim Acta 90: 1406

155. Sahai M, Kirson I (1984) Withaphysalin D, a New Withaphysalin from Physalis minima Linn. var. indica. J Nat Prod 47: 527

156. Veleiro AS, Oberti JC, Burton G (1992) A Ring D Aromatic Withanolide from Salpichroa origanifolia. Phytochemistry 31: 935

157. Veleiro AS, Burton G, Bonetto GM, Gil RR, Oberti JC (1994) New Withanolides from Salpichroa origanifolia. J Nat Prod 57: 1741

158. Tettamanzi MC, Veleiro AS, Oberti JC, Burton G (1998) New Hydroxylated Withanolides from Salpichroa origanifolia. J Nat Prod 61: 338

159. Tettamanzi MC, Veleiro AS, de la Fuente JR, Burton G (2001) Withanolides from Salpichroa origanifolia. J Nat Prod 64: 783

160. Tettamanzi MC, Veleiro AS, Oberti JC, Burton G (1996) Ring D Aromatic Ergostane Derivatives from Salpichroa origanifolia. Phytochemistry 43: 461

161. Gill HK, Smith RW, Whiting DA (1990) Ring D Expansion and Aromatisation in the Biosynthesis of Nic-1, an Antifeedant Steroid from Nicandra physaloides. J Chem Soc, Perkin Trans 1: 2989

162. Monteagudo ES, Burton G, Gros EG, Gonzalez CM, Oberti JC (1989) A 19Hydroxywithanolide from Jaborosa leucotricha. Phytochemistry 28: 1514

163. Misico RI, Oberti JC, Veleiro AS, Burton G (1996) New 19-Hydroxywithanolides from Jaborosa leucotricha. J Nat Prod 59: 66

164. Veleiro AS, Trocca CE, Burton G, Oberti JC (1992) A Phenolic Withanolide from Jaborosa leucotricha. Phytochemistry 31: 2550

165. Kirson IA, Cohen M, Greenberg M, Gottlieb HE, Varenne P, Abraham A (1979) Ixocarpalactone A and B. Two Unusual Naturally Occurring Steroids of the Ergostane Type. J Chem Res (S): 103

166. Huang Y, Müehlbauer A, Henkel T, Liu J-K (2003) Two New Taccalonolides from Tropic Plant Tacca subflaellata. Chin Chem Lett 14: 68

167. Huang Y, Liu J-K, Mühlbauer A, Henkel T (2002) Three Novel Taccalonolides from the Tropical Plant Tacca subflaellata. Helv Chim Acta 85: 2553 
168. Fang S-T, Li B, Liu J-K (2009) Two New Withanolides from Physalis peruviana. Helv Chim Acta 92: 1304

169. Lavie D, Besalle R, Pestchanker MJ, Gottlieb HE, Frolow F, Giordano OS (1987) Trechonolide A, a New Withanolide Type from Trechonaetes laciniata. Phytochemistry 26: 1791

170. Parvez M, Fajardo V, Shamma M (1988) (+)-Jaborosalactone M, a Hemiketal Withanolide from Jaborosa magellanica. Acta Crystallogr, Sect C: Cryst Struct Commun 44: 553

171. Cirigliano AM, Veleiro AS, Misico RI, Tettamanzi MC, Oberti JC, Burton G (2007) Withanolides from Jaborosa laciniata. J Nat Prod 70: 1644

172. Pecci A, Alvarez LD, Veleiro AS, Ceballos NR, Lantos CP, Burton G (2009) New Lead Compounds in the Search for Pure Antiglucocorticoids and the Dissociation of Antiglucocorticoid Effects. J Steroid Biochem Mol Biol 113: 155

173. Baggio RF (2005). Personal communication

174. Garcia ME, S. P, Navarro-Vázquez A, Phillips DD, Gayathri C, Krakauer H, Stephens PW, Nicotra VE, Gil RR (2009) Stereochemistry Determination by Powder X-Ray Diffraction Analysis and NMR Spectroscopy Residual Dipolar Couplings. Angew Chem Int Ed 48: 5670

175. Tettamanzi MC, Biurrun FN, Cirigliano AM (2007) A New Antifeedant Withanolide from Jaborosa lanigera. Z Naturforsch, B: Chem Sci 62: 573

176. Monteagudo ES, Oberti JC, Gros EG, Burton G (1990) A Spiranic Withanolide from Jaborosa odonelliana. Phytochemistry 29: 933

177. Cirigliano AM, Veleiro AS, Oberti JC, Burton G (2002) Spiranoid Withanolides from Jaborosa odonelliana. J Nat Prod 65: 1049

178. Cirigliano AM, Misico RI (2005) Spiranoid Withanolides from Jaborosa odonelliana and Jaborosa runcinata. Z Naturforsch, B: Chem Sci 60: 867

179. Cirigliano AM, Veleiro AS, Bonetto GM, Oberti JC, Burton G (1996) Spiranoid Withanolides from Jaborosa runcinata and Jaborosa araucana. J Nat Prod 59: 717

180. Shen J, Chen Z, Gao Y (1996) Taccalonolides from Tacca plantaginea. Phytochemistry 42: 891

181. Chen Z-1, Shen J-h, Gao Y-s, Wichtl M (1997) Five Taccalonolides from Tacca plantaginea. Planta Med 63: 40

182. Yang J-Y, Zhao R-H, Chen C-X, Ni W, Teng F, Hao X-J, Liu H-Y (2008) Taccalonolides W - Y, Three New Pentacyclic Steroids from Tacca plantaginea. Helv Chim Acta 91: 1077

183. Mühlbauer A, Seip S, Nowak A, Tran VS (2003) Five Novel Taccalonolides from the Roots of the Vietnamese Plant Tacca paxiana. Helv Chim Acta 86: 2065

184. Su B-N, Park EJ, Nikolic D, Santarsiero BD, Mesecar AD, Vigo JS, Graham JG, Cabieses F, van Breemen RB, Fong HHS, Farnsworth NR, Pezzuto JM, Kinghorn AD (2003) ActivityGuided Isolation of Novel Norwithanolides from Deprea subtriflora with Potential Cancer Chemopreventive Activity. J Org Chem 68: 2350

185. Su B-N, Park EJ, Nikolic D, Vigo JS, Graham JG, Cabieses F, Van Breemen RB, Fong HHS, Farnsworth NR, Pezzuto JM, Kinghorn AD (2003) Isolation and Characterization of Miscellaneous Secondary Metabolites of Deprea subtriflora. J Nat Prod 66: 1089

186. Ma L, Ali M, Arfan M, Lou L-G, Hu L-H (2007) Withaphysanolide A, a Novel C-27 Norwithanolide Skeleton, and Other Cytotoxic Compounds from Physalis divericata. Tetrahedron Lett 48: 449

187. Shingu K, Marubayashi N, Ueda I, Yahara S, Nohara T (1990) Two New Ergostane Derivatives from Tubocapsicum anomalum (Solanaceae). Chem Pharm Bull 38: 1107

188. Kovganko NV, Kashkan ZhN (1997) Advances in the Chemical Synthesis of Withanolides. Chem Nat Compd 33: 133

189. Mareggiani G, Picollo MI, Zerba E, Burton G, Tettamanzi MC, Benedetti-Doctorovich MOV, Veleiro AS (2000) Antifeedant Activity of Withanolides from Salpichroa origanifolia on Musca domestica. J Nat Prod 63: 1113 
190. Bado S, Mareggiani G, Amiano N, Burton G, Veleiro AS (2004) Lethal and Sublethal Effects of Withanolides from Salpichroa origanifolia and Analogues on Ceratitis capitata. J Agric Food Chem 52: 2875

191. Misra L, Lal P, Chaurasia ND, Sangwan RS, Sinha S, Tuli R (2008) Selective Reactivity of 2-Mercaptoethanol with $5 \beta, 6 \beta$-Epoxide in Steroids from Withania somnifera. Steroids $\mathbf{7 3}$ : 245

192. Yokota Y, Bargagna-Mohan P, Ravindranath PP, Kim KB, Mohan R (2006) Development of Withaferin A Analogs as Probes of Angiogenesis. Bioorg Med Chem Lett 16: 2603

193. Choudhary MI, Yousuf S, Samreen, Shah SAA, Ahmed S, Atta-ur-Rahman (2006) Biotransformation of Physalin $\mathrm{H}$ and Leishmanicidal Activity of its Transformed Products. Chem Pharm Bull 54: 927

194. Wijeratne EMK, Xu Y, Marron MT, Whitesell L, Gunatilaka AAL (2008) Isolation and Synthesis of Analogs of the Anticancer Natural Product Withaferin A for Structure-Activity Relationship Studies. Abstracts, 42nd Western Regional Meeting of the American Chemical Society, Las Vegas, NV, United States, September 23-27.

195. Jha S, Bandyopadhyay M, Chaudhuri KN, Ghosh S, Ghosh B (2005) Biotechnological Approaches for the Production of Forskolin, Withanolides, Colchicine and Tylophorine. Plant Genet Resour 3: 101

196. Ray S, Jha S (2001) Production of Withaferin A in Shoot Cultures of Withania somnifera. Planta Med 67: 432

197. Sangwan RS, Das Chaurasiya N, Lal P, Misra L, Uniyal GC, Tuli R, Sangwan NS (2007) Withanolide a Biogeneration in in Vitro Shoot Cultures of Ashwagandha (Withania somnifera Dunal), a Main Medicinal Plant in Ayurveda. Chem Pharm Bull 55: 1371

198. Sharada M, Ahuja A, Suri KA, Vij SP, Khajuria RK, Verma V, Kumar A (2007) Withanolide Production by in Vitro Cultures of Withania somnifera and its Association with Differentiation. Biologia Plantarum 51: 161

199. Madina BR, Sharma LK, Chaturvedi P, Sangwan RS, Tuli R (2007) Purification and Physico-Kinetic Characterization of 3 $\beta$-Hydroxy Specific Sterol Glucosyltransferase from Withania somnifera (L) and its Stress Response. Biochim Biophys Acta 1774: 392

200. Madina BR, Sharma LK, Chaturvedi P, Sangwan RS, Tuli R (2007) Purification and Characterization of a Novel Glucosyltransferase Specific to $27 \beta$-Hydroxy Steroidal Lactones from Withania somnifera and its Role in Stress Responses. Biochim Biophys Acta 1774: 1199

201. Elliger CA, Waiss AC, Jr. (1989) Insect Growth Inhibitors from Petunia and Other Solanaceous Plants. In: Arnason JT, Philogene BJR, Morand P (eds): Pesticides of Plant Origin, ACS Symposium Series No. 387. American Chemical Society, Washington DC, p 188

202. Waiss AC, Elliger CA, Haddon WF, Benson M (1993) Insect Inhibitory Steroidal Saccharide Esters from Physalis peruviana. J Nat Prod 56: 1365

203. Elliger CA, Haddon WF, Harden L, Waiss AC, Wong RY (1994) Insect Inhibitory Steroidal Saccharide Esters from Physalis peruviana. J Nat Prod 57: 348

204. Baumann TW, Meier CM (1993) Chemical Defense by Withanolides During Fruit Development in Physalis peruviana. Phytochemistry 33: 317

205. Mareggiani G, Picollo MI, Veleiro AS, Tettamanzi MC, Benedetti-Doctorovich MOV, Burton G, Zerba E (2002) Response of Tribolium castaneum (Coleoptera, Tenebrionidae) to Salpichroa origanifolia Withanolides. J Agric Food Chem 50: 104

206. Vaccarini CE, Bonetto GM (2000) Antifeedant Activity Evaluation of Withanolides from Jaborosa integrifolia. Molecules 5: 422

207. Enriz RD, Baldoni HA, Zamora MA, Jauregui EA, Sosa ME, Tonn CE, Luco JM, Gordaliza M (2000) Structure-Antifeedant Activity Relationship of Clerodane Diterpenoids. Comparative Study with Withanolides and Azadirachtin. J Agric Food Chem 48: 1384

208. Garcia ES, Castro DP, Ribeiro IM, Tomassini TCB, Azambuja P (2006) Trypanosoma rangeli: Effects of Physalin B on the Immune Reactions of the Infected Larvae of Rhodnius prolixus. Exp Parasitol 112: 37 
209. Castro DP, Figueiredo MB, Ribeiro IM, Tomassini TCB, Azambuja P, Garcia ES (2008) Immune Depression in Rhodnius prolixus by Seco-Steroids, Physalins. J Insect Physiol 54: 555

210. Castro DP, Figueiredo MB, Genta FA, Ribeiro IM, Tomassini TCB, Azambuja P, Garcia ES (2009) Physalin B Inhibits Rhodnius prolixus Hemocyte Phagocytosis and Microaggregation by the Activation of Endogenous PAF-Acetyl Hydrolase Activities. J Insect Physiol 55: 532

211. Dinan L, Whiting P, Alfonso D, Kapetanidis I (1996) Certain Withanolides from Iochroma gesnerioides Antagonize Ecdysteroid Actin in a Drosophila melanogaster Cell Line. Entomol Exp Appl 80: 415

212. Savchenko T, Whiting P, Germade A, Dinan L (2000) Ecdysteroid Agonist and Antagonist Activities in Species of the Solanaceae. Biochem Syst Ecol 28: 403

213. Dinan L, Savchenko T, Whiting P, Sarker SD (1999) Plant Natural Products as Insect Steroid Receptor Agonists and Antagonists. Pestic Sci 55: 331

214. Dinan L, Bourne PC, Meng Y, Sarker SD, Tolentino RB, Whiting P (2001) Assessment of Natural Products in the Drosophila melanogaster BII Cell Bioassay for Ecdysteroid Agonist and Antagonist Activities. Cell Mol Life Sci 58: 321

215. Vaccarini CE, Bonetto GM (2000) Selective Phytotoxic Activity of Withanolides from Iochroma australe to Crop and Weed Species. J Chem Ecol 26: 2187

216. Vieira NC, Espíndola LS, Santana JM, Veras ML, Pessoa ODL, Pinheiro SM, de Araújo RM, Lima MAS, Silveira ER (2008) Trypanocidal Activity of a New Pterocarpan and Other Secondary Metabolites of Plants from Northeastern Brazil Flora. Bioorg Med Chem 16: 1676

217. Atta-ur-Rahman, Samreen, Atia-tul-Wahab, Choudhary MI (2008) Discovery of Leishmanicidal Agents from Medicinal Plants. Pure Appl Chem 80: 1783

218. Cardona D, Quiñones W, Torres F, Robledo S, Vélez ID, Cruz V, Notario R, Echeverri F (2006) Leishmanicidal Activity of Withajardins and Acnistins. An Experimental and Computational Study. Tetrahedron 62: 6822

219. Sen N, Banerjee B, Das BB, Ganguly A, Sen T, Pramanik S, Mukhopadhyay S, Majumder HK (2006) Apoptosis is Induced in Leishmanial Cells by a Novel Protein Kinase Inhibitor Withaferin A and is Facilitated by Apoptotic Topoisomerase I-DNA Complex. Cell Death Differ 14: 358

220. Kannan ND, Kulandaivelu G (2007) Novel Method to Isolate Withaferin A from Withania somnifera Roots and Its Bioactivity. Allelopathy J 20: 213

221. Silva MTG, Simas SM, Batista TG, Cardarelli P, Tomassini TCB (2005) Studies on Antimicrobial Activity, in Vitro, of Physalis angulata L. (Solanaceae) Fraction and Physalin B Bringing out the Importance of Assay Determination. Mem Inst Oswaldo Cruz 100: 779

222. Januário AH, Rodrigues Filho E, Pietro RCLR, Kashima S, Sato DN, França SC (2002) Antimycobacterial Physalins from Physalis angulata L. (Solanaceae). Phytother Res 16: 445

223. Vieira AT, Pinho V, Lepsch LB, Scavone C, Ribeiro IM, Tomassini T, Ribeiro-dos-Santos R, Soares MBP, Teixeira MM, Souza DG (2005) Mechanisms of the Anti-Inflammatory Effects of the Natural Secosteroids Physalins in a Model of Intestinal Ischaemia and Reperfusion Injury. Br J Pharmacol 146: 244

224. Singh D, Aggarwal A, Maurya R, Naik S (2007) Withania somnifera Inhibits NF- $\kappa$ B and AP1 Transcription Factors in Human Peripheral Blood and Synovial Fluid Mononuclear Cells. Phytother Res 21: 905

225. Kaileh M, Vanden Berghe W, Heyerick A, Horion J, Piette J, Libert C, De Keukeleire D, Essawi T, Haegeman G (2007) Withaferin A Strongly Elicits IкB Kinase Hyperphosphorylation Concomitant with Potent Inhibition of Its Kinase Activity. J Biol Chem 282: 4253

226. Ichikawa H, Takada Y, Shishodia S, Jayaprakasam B, Nair MG, Aggarwal BB (2006) Withanolides Potentiate Apoptosis, Inhibit Invasion, and Abolish Osteoclastogenesis

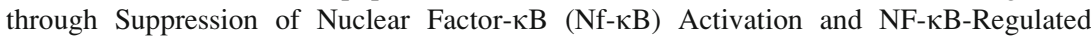
Gene Expression. Mol Cancer Ther 5: 1434 
227. Punetha H, Gaur AK, Pant AK, Mishra DP (2006) Cyclooxygenase (Cox) Inhibitory Activity of Withanolides from Withania somnifera (L.) Dunal as Revealed by Molecular Docking. Bioinf Trends 1: 41

228. Manickam M, Padma P, Chansouria JPN, Ray AB (1997) Evaluation of Antistress Activity of Withafastuosin D, a Withanolide of Datura fastuosa. Phytother Res 11: 384

229. Goel RK, Maiti RN, Manickam M, Ray AB (1997) Effect of Withafastuosin E on Prostanoid Synthesis by Human Intestinal Mucosa 'in Vitro'. Fitoterapia 68: 345

230. Maiti RN, Manickam M, Ray AB, Goel RK (1997) Effect of Withafastuosin E on Gastric Mucosal Offensive and Defensive Factors in Rats. Indian J Exp Biol 35: 751

231. Bhattacharya A, Ghosal S, Bhattacharya SK (2001) Anti-Oxidant Effect of Withania somnifera Glycowithanolides in Chronic Footshock Stress-Induced Perturbations of Oxidative Free Radical Scavenging Enzymes and Lipid Peroxidation in Rat Frontal Cortex and Striatum. J Ethnopharmacol 74: 1

232. Bhattacharya SK, Satyan KS, Ghosal S (1997) Antioxidant Activity of Glycowithanolides from Withania somnifera. Indian J Exp Biol 35: 236

233. Habtemariam S (1997) Cytotoxicity and Immunosuppressive Activity of Withanolides from Discopodium penninervium. Planta Med 63: 15

234. Mesaik MA, Zaheer Ul H, Murad S, Ismail Z, Abdullah NR, Gill HK, Atta-ur-Rahman, Yousaf M, Siddiqui RA, Ahmad A, Choudhary MI (2006) Biological and Molecular Docking Studies on Coagulin-H: Human Il-2 Novel Natural Inhibitor. Mol Immunol 43: 1855

235. Soares MBP, Bellintani MC, Ribeiro IM, Tomassini TCB, Ribeiro dos Santos R (2003) Inhibition of Macrophage Activation and Lipopolysaccaride-Induced Death by SecoSteroids Purified from Physalis angulata L. Eur J Pharmacol 459: 107

236. Soares MBP, Brustolim D, Santos LA, Bellintani MC, Paiva FP, Ribeiro YM, Tomassini TCB, Ribeiro dos Santos R (2006) Physalins B, F and G, Seco-Steroids Purified from Physalis angulata L., Inhibit Lymphocyte Function and Allogeneic Transplant Rejection. Int Immunopharm 6: 408

237. Yang H, Shi G, Dou QP (2007) The Tumor Proteasome is a Primary Target for the Natural Anticancer Compound Withaferin A Isolated from "Indian Winter Cherry". Mol Pharmacol 71: 426

238. Mandal C, Dutta A, Mallick A, Chandra S, Misra L, Sangwan RS (2008) Withaferin A Induces Apoptosis by Activating P38 Mitogen-Activated Protein Kinase Signaling Cascade in Leukemic Cells of Lymphoid and Myeloid Origin through Mitochondrial Death Cascade. Apoptosis 13: 1450

239. Stan SD, Hahm E-R, Warin R, Singh SV (2008) Withaferin A Causes FOXO3a- and BimDependent Apoptosis and Inhibits Growth of Human Breast Cancer Cells In Vivo. Cancer Res 68: 7661

240. Jayaprakasam B, Zhang Y, Seeram NP, Nair MG (2003) Growth Inhibition of Human Tumor Cell Lines by Withanolides from Withania somnifera Leaves. Life Sci 74: 125

241. Damasceno Rocha D, Gadelha Militão GC, Veras ML, Deusdênia Loiola Pessoa O, Rocha Silveira E, Negreiros Nunes Alves AP, Odorico de Moraes M, Pessoa C, Veras Costa-Lotufo L (2006) Selective Cytotoxicity of Withaphysalins in Myeloid Leukemia Cell Lines Versus Peripheral Blood Mononuclear Cells. Life Sci 79: 1692

242. Chen W-Y, Chang F-R, Huang Z-Y, Chen J-H, Wu Y-C, Wu C-C (2008) Tubocapsenolide A, a Novel Withanolide, Inhibits Proliferation and Induces Apoptosis in MDA-MB-231 Cells by Thiol Oxidation of Heat Shock Proteins. J Biol Chem 283: 17184

243. Chang H-C, Chang F-R, Wang Y-C, Pan M-R, Hung W-C, Wu Y-C (2007) A Bioactive Withanolide Tubocapsanolide A Inhibits Proliferation of Human Lung Cancer Cells Via Repressing Skp2 Expression. Mol Cancer Ther 6: 1572

244. Magalhães HIF, Veras ML, Pessoa ODL, Silveira ER, Moraes MO, Pessoa C, Costa-Lotufo LV (2006) Preliminary Investigation of Structure-Activity Relationship of Cytotoxic Physalins. Lett Drug Design Discovery 3: 9 
245. Magalhães HIF, Veras ML, Torres M, Rocha, Alves APNN, Pessoa ODL, Silveira ER, Costa-Lotufo LV, de Moraes MO, Pessoa C (2006) In-Vitro and in-Vivo Antitumour Activity of Physalins B and D from Physalis angulata. J Pharm Pharmacol 58: 235

246. Hosoya T, Arai MA, Koyano T, Kowithayakorn T, Ishibashi M (2008) Naturally Occurring Small-Molecule Inhibitors of Hedgehog/Gli-Mediated Transcription. ChemBioChem 9: 1082

247. Choi JK, Murillo G, Su B-N, Pezzuto JM, Kinghorn AD, Mehta RG (2006) Ixocarpalactone A Isolated from the Mexican Tomatillo Shows Potent Antiproliferative and Apoptotic Activity in Colon Cancer Cells. FEBS J 273: 5714

248. Uma Devi P (1996) Withania somnifera Dunal (Ashwagandha): Potential Plant Source of a Promising Drug for Cancer Chemotherapy and Radiosensitization. Indian J Exp Biol 34: 927

249. Sharada AC, Solomon FE, Devi PU, Udupa N, Srinivasan KK (1996) Antitumor and Radiosensitizing Effects of Withaferin A on Mouse Ehrlich Ascites Carcinoma in Vivo. Acta Oncol 35: 95

250. Uma Devi P, Kamath R (2003) Radiosensitizing Effect of Withaferin A Combined with Hyperthermia on Mouse Fibrosarcoma and Melanoma. J Radiat Res 44: 1

251. Kinghorn AD, Su BN, Lee D, Gu JQ, Pezzuto JM (2003) Cancer Chemopreventive Agents Discovered by Activity-Guided Fractionation: An Update. Curr Org Chem 7: 213

252. Kang Y-H, Pezzuto JM, Helmut S, Lester P (2004) Induction of Quinone Reductase as a Primary Screen for Natural Product Anticarcinogens: Methods Enzymol, vol. 382, p 380. Elsevier, Inc., San Diego.

253. Misico RI, Song LL, Veleiro AS, Cirigliano AM, Tettamanzi MC, Burton G, Bonetto GM, Nicotra VE, Silva GL, Gil RR, Oberti JC, Kinghorn AD, Pezzuto JM (2002) Induction of Quinone Reductase by Withanolides. J Nat Prod 65: 677

254. Panjamurthy K, Manoharan S, Menon VP, Nirmal MR, Senthil N (2008) Protective Role of Withaferin-A on 7,12-Dimethylbenz(a)Anthracene-Induced Genotoxicity in Bone Marrow of Syrian Golden Hamsters. J Biochem Mol Toxic 22: 251

255. Mohan R, Hammers H, Bargagna-Mohan P, Zhan X, Herbstritt C, Ruiz A, Zhang L, Hanson A, Conner B, Rougas J, Pribluda V (2004) Withaferin A Is a Potent Inhibitor of Angiogenesis. Angiogenesis 7: 115

256. Bargagna-Mohan P, Ravindranath Padma P, Mohan R (2006) Small Molecule Anti-Angiogenic Probes of the Ubiquitin Proteasome Pathway: Potential Application to Choroidal Neovascularization. Invest Ophthalmol Vis Sci 47: 4138

257. Vandenberghe I, Créancier L, Vispé S, Annereau J-P, Barret J-M, Pouny I, Samson A, Aussagues Y, Massiot G, Ausseil F, Bailly C, Kruczynski A (2008) Physalin B, a Novel Inhibitor of the Ubiquitin-Proteasome Pathway, Triggers NOXA-Associated Apoptosis. Biochem Pharmacol 76: 453

258. Tinley TL, Randall-Hlubek DA, Leal RM, Jackson EM, Cessac JW, Quada JC, Jr., Hemscheidt TK, Mooberry SL (2003) Taccalonolides E and A: Plant-Derived Steroids with Microtubule-Stabilizing Activity. Cancer Res 63: 3211

259. Risinger AL, Jackson EM, Polin LA, Helms GL, LeBoeuf DA, Joe PA, Hopper-Borge E, Luduena RF, Kruh GD, Mooberry SL (2008) The Taccalonolides: Microtubule Stabilizers That Circumvent Clinically Relevant Taxane Resistance Mechanisms. Cancer Res 68: 8881

260. Risinger AL, Mooberry SL (2010) Taccalonolides: Novel Microtubule Stabilizers with Clinical Potential. Cancer Lett 291: 14

261. Tohda C, Kuboyama T, Komatsu K (2005) Search for Natural Products Related to Regeneration of the Neuronal Network. NeuroSignals 14: 34

262. Kuboyama T, Tohda C, Zhao J, Nakamura N, Hattori M, Komatsu K (2002) Axon- or Dendrite-Predominant Outgrowth Induced by Constituents from Ashwagandha. NeuroReport 13: 1715

263. Kuboyama T, Tohda C, Komatsu K (2005) Neuritic Regeneration and Synaptic Reconstruction Induced by Withanolide A. Br J Pharmacol 144: 961 
264. Kuboyama T, Tohda C, Komatsu K (2006) Withanoside IV and Its Active Metabolite, Sominone, Attenuate A $\beta(25-35)-I n d u c e d$ Neurodegeneration. Eur J Neurosci 23: 1417

265. Choudhary MI, Nawaz SA, Zaheer-ur-Haq, Lodhi MA, Ghayur MN, Jalil S, Riaz N, Yousuf S, Malik A, Gilani AH, Atta-ur-Rahman (2005) Withanolides, a New Class of Natural Cholinesterase Inhibitors with Calcium Antagonistic Properties. Biochem Biophys Res Commun 334: 276

266. Jiao M, Luna-Cavazos M, Bye R (2002) Allozyme Variation in Mexican Species and Classification of Datura (Solanaceae). Plant Syst Evol 232: 155

267. Luna-Cavazos M, Bye R, Jiao M (2009) The Origin of Datura metel (Solanaceae): Genetic and Phylogenetic Evidence. Gen Resour Crop Evol 56: 263 